NUREG/CR-6299

BMI-2184

\title{
Effects of Toughness
}

Anisotropy and Combined

Tension, Torsion, and Bending

Loads on Fracture Behavior

of Ferritic Nuclear Pipe

Prepared by

R. Mohan, C. Marschall, P. Krishnaswamy, F. Brust,

N. Ghadiali, G. Wilkowski

Battelle

Prepared for

U.S. Nuclear Regulatory Commission 


\section{AVAILABILITY NOTICE}

Availability of Reference Materials Cited in NRC Publications

Most documents cited in NRC publications will be available from one of the following sources:

1. The NRC Public Document Room, 2120 L Street, NW., Lower Level, Washington, DC 20555-0001

2. The Superintendent of Documents, U.S. Government Printing Office, P. O. Box 37082, Washington, DC 20402-9328

3. The National Technical Information Service, Springfield, VA 22161-0002

Although the listing that follows represents the majority of documents cited in NRC publications, it is not intended to be exhaustive.

Referenced documents avallable for inspection and copying for a fee from the NRC Public Document Room Include NRC correspondence and internal NRC memoranda; NRC bulletins, circulars, information notices, inspection and investigation notices; llcensee event reports; vendor reports and correspondence; Commission papers; and applicant and licensee documents and correspondence.

The following documents in the NUREG series are available for purchase from the Government Printing Office: formal NRC staff and contractor reports, NRC-sponsored conference proceedings, international agreement reports, grantee reports, and NRC booklets and brochures. Also available are regulatory guides, NRC regulations In the Code of Federal Regulations, and Nuclear Regulatory Commission Issuances.

Documents available from the National Technical Information Service include NUREG-series reports and technical reports prepared by other Federal agencies and reports prepared by the Atomic Energy Commission. forerunner agency to the Nuclear Regulatory Commission.

Documents avallable from public and special technical libraries include all open literature items, such as books, journal articles, and transactions. Federal Register notices, Federal and State legislation, and congressional reports can usually be obtained from these libraries.

Documents such as theses, dissertations, foreign reports and translations, and non-NRC conference proceedings are available for purchase from the organization sponsoring the publication cited.

Single coples of NRC draft reports are available free, to the extent of supply, upon written request to the Office of Administration, Distribution and Mail Services Section, U.S. Nuclear Regulatory Commission, Washington, DC 20555-0001.

Coples of industry codes and standards used in a substantive manner in the NRC regulatory process are maintained at the NRC Library. Two White Flint North, 11545 Rockville Pike, Rockville, MD 20852-2738, for use by the public. Codes and standards are usually copyrighted and may be purchased from the originating organization or, if they are American National Standards, from the American National Standards Institute, 1430 Broadway, New York, NY 10018-3308.

\section{DISCLAIMER NOTICE}

This document was prepared with the support of the U.S. Nuclear Regulatory Commission (NRC) Grant Program. The purpose of the NRC Grant Program is to support basic, advanced, and developmental scientific research for a public purpose in areas relating to nuclear safety. The nature of NRC's Grant Program is such that the grantee bears prime responsibility for the conduct of the research and exercises judgement and original thought toward attaining the scientific goals. The opinions, findings, conclusions, and recommendations expressed herein are therefore those of the authors and do not necessarily reflect the views of the NRC. 


\section{DISCLAIMER}

Portions of this document may be illegible in electronic image products. Images are produced from the best available original document. 
NUREG/CR-6299

BMI-2184

\section{Effects of Toughness}

Anisotropy and Combined

Tension, Torsion, and Bending

Loads on Fracture Behavior

of Ferritic Nuclear Pipe

Manuscript Completed: January 1995

Date Published: April 1995

Prepared by

R. Mohan, C. Marschall, P. Krishnaswamy, F. Brust,

N. Ghadiali, G. Wilkowski

Battelle

505 King Avenue

Columbus, OH 43201-2693

Prepared for

Division of Engineering Technology

Office of Nuclear Regulatory Research

U.S. Nuclear Regulatory Commission

Washington, DC 20555-0001

NRC Job Code B5702 


$$
\text { - }
$$




\begin{abstract}
This topical report summarizes the work on angled crack growth and combined loading effects performed within the Nuclear Regulatory Commission's research program entitled "Short Cracks in Piping and Piping Welds". The major impetus for this work stemmed from the observation that initial circumferential cracks in carbon steel pipes exhibited angular crack growth. This failure mode was little understood, and the effect of angled crack growth from an initially circumferential crack raised questions of how pipes under combined loading with torsional stresses would behave.

There were three major conclusions from this work. The first was that virtually all ferritic nuclear pipes will have toughness anisotropy. The second was that the ratio of the normalized crack driving force (as a function of angle) to the normalized toughness (also as a function of the angle of crack growth) showed that there was an equal likelihood of cracks growing at any angle between 25 and 65 degrees. This agreed with the scatter of crack growth angles observed in pipe tests. Third, for combined loads with torsional stresses, an effective moment allows pure bending analyses to be used up to crack initiation. Crack opening area under combined loads could also be determined in this manner.
\end{abstract}


EXECUTIVE SUMMARY $\ldots \ldots \ldots \ldots \ldots \ldots \ldots \ldots \ldots \ldots \ldots \ldots \ldots \ldots \ldots \ldots$

ACKNOWLEDGMENTS $\ldots \ldots \ldots \ldots \ldots \ldots \ldots \ldots \ldots \ldots \ldots \ldots \ldots \ldots \ldots$

NOMENCLATURE $\ldots \ldots \ldots \ldots \ldots \ldots \ldots \ldots \ldots \ldots \ldots \ldots \ldots \ldots \ldots \ldots \ldots$

PREVIOUS REPORTS IN SERIES $\ldots \ldots \ldots \ldots \ldots \ldots \ldots \ldots \ldots \ldots \ldots \ldots \ldots \ldots$

1. INTRODUCTION $\ldots \ldots \ldots \ldots \ldots \ldots \ldots \ldots \ldots \ldots \ldots \ldots \ldots \ldots \ldots \ldots \ldots \ldots \ldots$

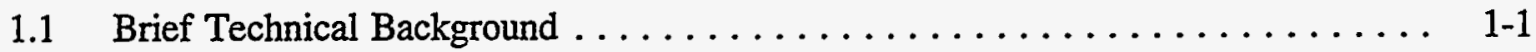

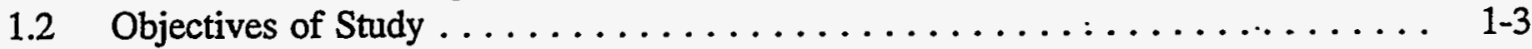

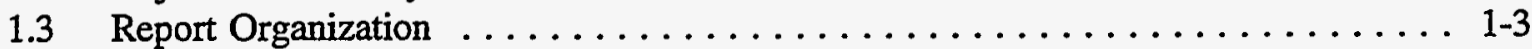

1.4 References ............................... 1-3

2. CAUSES AND MAGNITUDE OF ANISOTROPY EFFECTS . . . . . . . . . . 2-1

2.1 Findings from the Literature Review $\ldots \ldots \ldots \ldots \ldots \ldots \ldots \ldots \ldots \ldots \ldots \ldots$

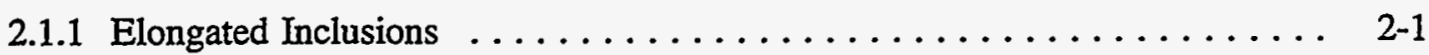

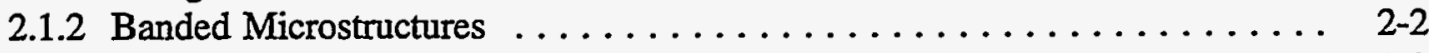

2.1.3 Crystallographic Texture or Preferred Orientation ............ 2-3

2.1.4 Summary of Literature Review $\ldots \ldots \ldots \ldots \ldots \ldots \ldots \ldots \ldots \ldots \ldots \ldots . \ldots \ldots$

2.2 Tensile and $\mathrm{C}(\mathrm{T})$ Test Results for Several Orientations $\ldots \ldots \ldots \ldots \ldots \ldots$

2.2.1 Tensile Tests . . . . . . . . . . . . . . . . . . . . . . $2-3$

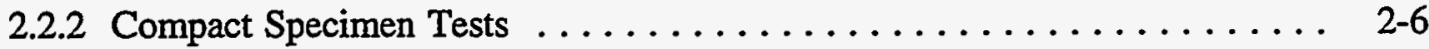

2.3 Dependence of Anisotropy on Inclusion Characteristics $\ldots \ldots \ldots \ldots \ldots$

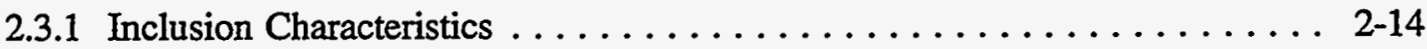

2.3.2 Charpy V-Notch Impact Tests . . . . . . . . . . . . . . 2-14

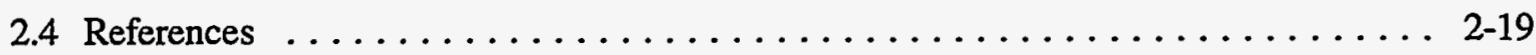

3. DEVELOPMENT OF A SCREENING CRITERION TO PREDICT

ANGLED CRACK GROWTH USING MATERIAL PROPERTY DATA . . . . . . . . . 3-1

3.1 Mapping of Fracture Paths in $\mathrm{C}(\mathrm{T})$ and Pipe Tests $\ldots \ldots \ldots \ldots \ldots \ldots \ldots$

3.2 Assessment of Usefulness of Screening Tests to Predict Angled Crack Growth in

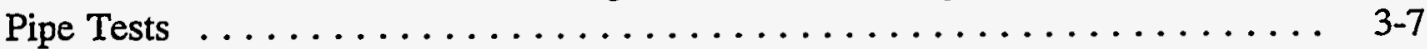

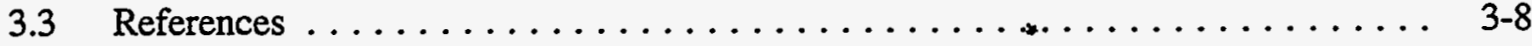




\section{CONTENTS}

\subsection{ANISOTROPY AND COMBINED LOADING EFFECTS ON}

FRACTURE OF THROUGH-WALL-CRACKED PIPES $\ldots \ldots \ldots \ldots \ldots \ldots \ldots \ldots$

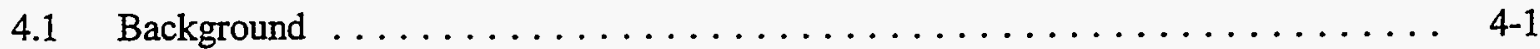

4.2 Survey of Typical Bending Moment-to-Torque Ratios for Plant Piping Systems . . . 4-2

4.2.1 Development of Engineering Approaches to Calculate Effective Moment for Piping Systems Experiencing Combined Loading $\ldots \ldots \ldots \ldots \ldots$ 4-5

4.3 Finite Element Modelling of Circumferential TWC Pipe $\ldots \ldots \ldots \ldots \ldots \ldots$

4.3.1 Pipe Geometry and Finite Element Meshes . . . . . . . . . . . . . 4-6

4.3.2 Boundary Conditions for the Loading Cases Considered . . . . . . . . . . . 4-9

4.3.3 Material Properties . . . . . . . . . . . . . . . . . . . . 4-13

4.3.4 Finite Element Analysis Code . . . . . . . . . . . . . . . . 4-13

4.3.5 Matrix of Calculations . . . . . . . . . . . . . . . . 43

4.4 The Use of $\mathrm{J}$ as a Fracture Parameter for Straight and Angled Cracks . . . . . . 4 4-15

4.5. Straight Circumferential TWC Analyses $\ldots \ldots \ldots \ldots \ldots \ldots \ldots \ldots \ldots$

4.5.1 Verification of J-Values Using Analytical Techniques . . . . . . . . . . 4-17

4.5.2 Variation of J Through the Thickness of Pipe . . . . . . . . . . 4-19

4.5 .3 Variation of $\mathrm{J}$ with Applied Loading . . . . . . . . . . . . . 4-20

4.5.4 Crack-Opening Displacements and Areas . . . . . . . . . . . . . 4-23

4.5.5 Crack-Tip Stress Fields for Pure and Combined Loadings . . . . . . . . . 4-26

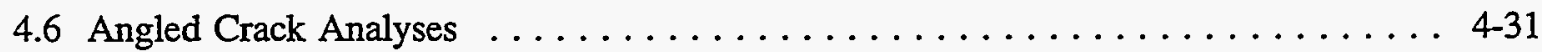

4.6.1 Elastic Analyses of Angled Cracks . . . . . . . . . . . . . 4-31

4.6.2 Elastic-Plastic Analyses: Pure Bending . . . . . . . . . . . . 4-31

4.6.4 Elastic-Plastic Analyses: Combined Loads . . . . . . . . . . . . . . 4-37

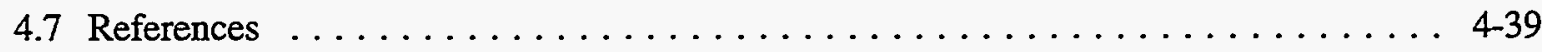

5. DISCUSSION AND CONCLUSIONS $\ldots \ldots \ldots \ldots \ldots \ldots \ldots \ldots \ldots \ldots \ldots \ldots \ldots \ldots \ldots \ldots$

5.1 Understanding Why Angled Crack Growth Occurs in Ferritic Pipes . . . . . . . 5 5-1

5.2 Analysis of Pipes Under Combined Tension, Bending and Torsion . . . . . . . . 5-3

Appendix A Illustrations of Fracture Paths in Carbon Steel Pipes Which Contained

Circumferential Flaws . . . . . . . . . . . . . . . . . 


\section{LIST OF FIGURES}

$\underline{\text { Figure }}$

$\underline{\text { Page }}$

1.1 Photograph of the fractured pipe from Experiment 4111-1 and a compact (tension)

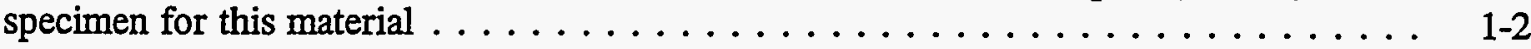

2.1 Orientation of skewed specimens machined from Pipe DP2-F11

(a) Tensile specimens, (b) $\mathrm{C}$ (T) specimens $\ldots \ldots \ldots \ldots \ldots \ldots \ldots \ldots$

2.2 Tensile properties as functions of specimen orientation for Pipe DP2-F11 (A333

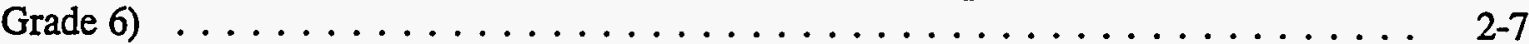

2.3 Engineering stress-strain curves for several different tensile specimen orientations in Pipe

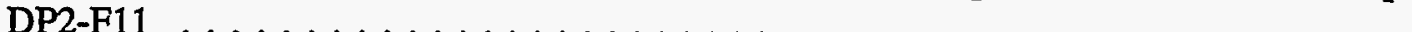

2.4 Load versus displacement curves for several different $C(T)$ specimen orientations in Pipe DP2-F11 . . . . . . . . . . . . . . . . . . . . . . . 2-9

2.5 J-resistance curves for several different $\mathrm{C}(\mathrm{T})$ specimen orientations in Pipe DP2-F11 . . 2-10

2.6 $\mathrm{J}_{\mathrm{i}}$ and $\mathrm{dJ} / \mathrm{da}$ as functions of $\mathrm{C}(\mathrm{T})$ specimen orientation in Pipe DP2-F11

(a) $\mathrm{J}_{\mathrm{i}}$, (b) dJ/da ............................... 2-11

2.7 Load versus displacement curves for two different $C(T)$ specimen orientations in Pipe

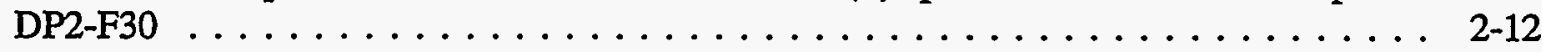

2.8 J-resistance curves for two different $\mathrm{C}(\mathrm{T})$ specimen orientations in Pipe DP2-F30 $\ldots \ldots$ 2-12

2.9 $\mathrm{J}_{\mathrm{i}}, \mathrm{J}$ at $\Delta \mathrm{a}=2 \mathrm{~mm}$, and $\mathrm{dJ} / \mathrm{da}$ as functions of $\mathrm{C}(\mathrm{T})$ specimen orientation in Pipe DP2F30

(a) $\mathrm{J}_{\mathrm{i}}$ and $\mathrm{J}$ at $2 \mathrm{~mm}$ crack extension and (b) $\mathrm{d} J / \mathrm{da} \ldots \ldots \ldots \ldots \ldots \ldots \ldots$

2.10 Photomicrographs of sulfide inclusions in carbon steel pipes

(a) Pipe DP2-F9 (A333 Grade 6), (b) Pipe DP2-F11 (A333 Grade 6),

(c) Pipe DP2-F26 (A515 Grade 60), (d) Pipe DP2-F29 (A106 Grade B),

and (e) Pipe DP2-F30 (A106 Grade B) . . . . . . . . . . . . . . . . . . . 2-16

2.11 Photographs and X-ray dot maps of selected inclusions in Pipe DP2-F9 (A333 Grade 6 carbon steel) to verify presence of manganese sulfides

(a) SEM photographs of inclusions, (b) X-ray dot map for manganese,

(c) X-ray dot map for sulfur, and (d) X-ray dot map for aluminum

2.12 Energy absorbed by Charpy V-notch specimens as a function of orientation (Note: All fractures were 100 percent ductile $) \ldots \ldots \ldots \ldots \ldots \ldots \ldots \ldots \ldots$

3.1 Examples of angled crack extension in tests on three different carbon steel pipes tested in four-point bending

(a) Experiment 4112-9, four-point bending, Pipe DP2-F13, A106 Grade B, 16-inch 


\section{LIST OF FIGURES}

Figure

Page

diameter, Schedule 40 (Ref. 3.1), (b) Experiment 4131-8, four-point bending, Pipe DP2-F9, A333 Grade 6, 10-inch diameter, Schedule 100 (Ref. 3.1), and

(c) Experiment 1.2-7, four-point bending, quasi-static monotonic, Pipe DP2-F30,

A106 Grade B, 6-inch diameter, Schedule 120 (Ref. 3.3) . . . . . . . . . . . .

3.2 Comparison of single-shear and double-shear fractures in carbon steel $\mathrm{C}(\mathrm{T})$ specimens

(a) Single-shear fracture and (b) Double-shear fracture $\ldots \ldots \ldots \ldots \ldots \ldots$

3.3 Crack-growth angle versus Anisotropy Index for circumferentially cracked carbon steel pipes tested at Battelle $(\mathrm{TWC}=$ through-wall crack, $\mathrm{SC}=$ surface crack, $\mathrm{IP}=$ internal

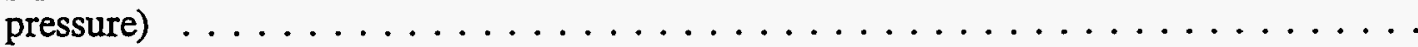

3.4 Crack-growth angle versus pipe diameter/thickness ratio for carbon steel pipes tested in four-point bending (TWC $=$ through-wall crack, $S C$ (int) $=$ internal surface crack) $\ldots$.

3.5 Crack-growth angle versus pipe diameter/thickness for carbon steel pipe tests (TWC = through-wall crack, $S C=$ surface crack, $I P=$ internal pressure) $\ldots \ldots \ldots$

4.1 Histogram of bending moment-to-torque ratios from Arizona Public Service Company

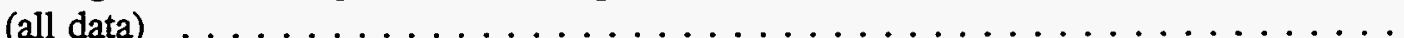

4.2 Histogram of bending moment-to-torque ratios from Arizona Public Service Company (bending moment-to-torque ratios between 0 and 20 ) $\ldots \ldots \ldots \ldots \ldots$

4.3 Histogram of bending moment-to-torque ratios from Arizona Public Service Company (bending moment-to-torque ratios between 0 and 3 ) $\ldots \ldots \ldots \ldots \ldots$

4.4 Illustration of an angled circumferential TWC in a pipe $\ldots \ldots \ldots \ldots \ldots \ldots$

4.5 Finite Element Mesh for straight circumferential TWC pipe

(a) Total model and (b) Close up . . . . . . . . . . . . . . . . . 4-7

4.6 Detailed view of Figure $4.5 \ldots \ldots \ldots \ldots \ldots \ldots \ldots \ldots \ldots \ldots \ldots \ldots$

4.7 Detail of the angled crack-tip region for the angled crack $\ldots \ldots \ldots \ldots$

4.8 Boundary conditions for combined tension, bending, and torsion of straight

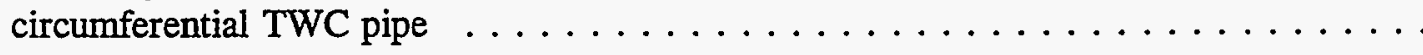

4.9 Boundary conditions for pure bending, pure tension, or combined bending plus tension of straight circumferential TWC pipe $\ldots \ldots \ldots \ldots \ldots \ldots \ldots \ldots$

4.10 Schematic illustration of in-plane displacement field at two material points with $|\mathrm{x}|=\mathrm{X}$ on the uncracked portion of the $\mathrm{z}=0$ plane for pure torsional loading

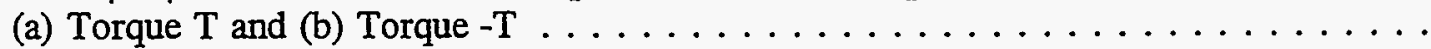




\section{LIST OF FIGURES}

Figure

Page

4.11 Boundary conditions for pure torsion of straight circumferential TWC pipe $\ldots \ldots$. . 4-12

4.12 Boundary conditions for angled cracks

(a) Pure bending or pure tension, (b) Pure torsion, and (c) Combined bending

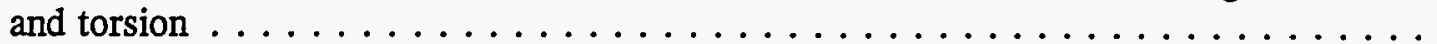

4.13 Ramberg-Osgood fit of the average engineering stress-engineering strain curve of Pipe

DP2-F11 material at $288 \mathrm{C}(550 \mathrm{~F})$ (Specimen F11-T3) . . . . . . . . . . . .

4.14 Integration path around the crack-tip for evaluation of $\mathrm{J} \ldots \ldots \ldots \ldots$

4.15 $\mathrm{J}$ normalized by $\mathrm{J}_{\mathrm{Ri}}$ (value of $\mathrm{J}$ at the inner pipe surface) versus distance, $\mathrm{d}_{\mathrm{r}}$, from inner surface normalized by the pipe wall thickness, $t$, for pure bending and combined bending

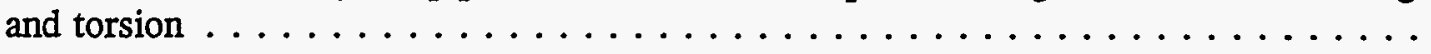

4.16 $\mathrm{J}$ normalized by $\mathrm{J}_{\mathrm{Ri}}$ (value of $\mathrm{J}$ at the inner pipe surface) versus distance, $\mathrm{d}_{\mathrm{I}}$, from inner surface normalized by the pipe wall thickness, $t$, for pure torsion $\ldots \ldots \ldots \ldots \ldots$

4.17 Effect of prior tension due to pressure on the variation of $\mathrm{J}$ at the mid-thickness with

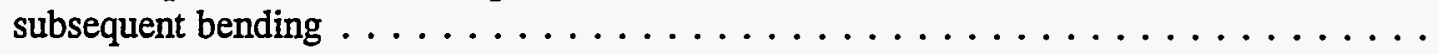

4.18 Effect of prior tension due to pressure on the variation of $J$ at the mid-thickness with

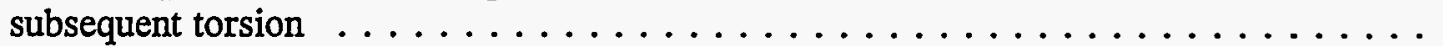

4.19 Effect of combined loading on the variation of $\mathrm{J}$ at the mid-thickness versus effective moment for various pure and combined loading cases

(a) Pure bending; pure torsion; combined bending and tension; and combined tension, bending, and torsion $\left(\mathrm{M}_{\mathrm{B}} / \mathrm{T}=3.0\right)$ and (b) Combined bending and tension; combined tension, bending, and torsion cases $\left(\mathrm{M}_{\mathrm{B}} / \mathrm{T}=3.0\right.$ and $\left.\mathrm{M}_{\mathrm{B}} / \mathrm{T}=1\right) \ldots \ldots \ldots \ldots$

4.20 Crack-opening profiles at various applied bending moments for tension plus bending ...

4.21 Crack-opening profiles at various effective moments (calculated using $c_{e}=\sqrt{3} / 2$ ) for combined tension, bending, and torsion

(a) $\mathrm{M}_{\mathrm{B}} / \mathrm{T}=3.0$ and (b) $\mathrm{M}_{\mathrm{B}} / \mathrm{T}=1.0$

4.22 Comparison of the variations of total crack-opening area with effective moment for the combined load cases of tension plus bending and tension plus bending plus torsion

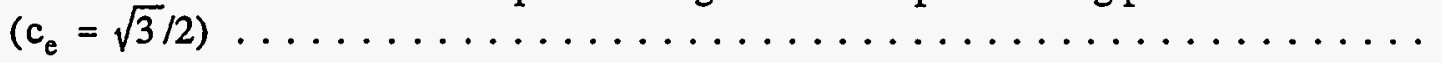

4.23 Variation of total crack-opening displacement with effective moment for the load cases of tension plus bending and combined tension, bending and torsion (The effective moment for the latter cases is calculated for several values of $c_{e}$ ) $\ldots \ldots \ldots \ldots \ldots$

4.24 Local crack-tip cylindrical coordinate system $\ldots \ldots \ldots \ldots \ldots \ldots \ldots$ 


\section{LIST OF FIGURES}

Figure

$\underline{\text { Page }}$

4.25 Angular variation of normalized stresses at a fixed radius $(0.2 \mathrm{~mm}$ [0.008 inch]) from

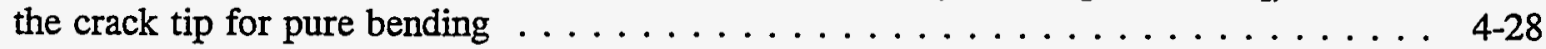

4.26 Angular variation of normalized stresses at a fixed radius $(0.2 \mathrm{~mm}$ [0.008 inch $])$ from the crack tip for pure torsion . . . . . . . . . . . . . . . . . . . 4-29

4.27 Angular variation of normalized stresses at a fixed radius $(0.2 \mathrm{~mm}$ [0.008 inch]) from the crack tip for combined bending plus tension . . . . . . . . . . . . . . . .

4.28 Angular variation of normalized stresses at a fixed radius $(0.2 \mathrm{~mm}$ [0.008 inch]) from the crack tip for combined tension, bending, and torsion $\left(\mathrm{M}_{\mathrm{B}} / \mathrm{T}=3.0\right) \ldots \ldots \ldots$. . . . .

4.29 Angular variation of normalized stresses at a fixed radius $(0.2 \mathrm{~mm}$ [0.008 inch] $)$ from the crack tip for combined tension, bending, and torsion $\left(\mathrm{M}_{\mathrm{B}} / \mathrm{T}=1.0\right) \ldots \ldots$. . . . 40

4.30 Variation of normalized angular driving force, $\mathrm{J}_{\Omega} / \mathrm{J}_{\Omega=0}$, versus crack-tip angle, $\Omega$, under pure bending, pure tension, plus pure torsion . . . . . . . . . . . . 4-32

4.31 Variation of $\mathrm{J}$ versus bending moment for straight as well as angled cracks for pure bending loading under elastic-plastic conditions $\ldots \ldots \ldots \ldots \ldots \ldots \ldots$

4.32 Normalized angular driving force, $\mathrm{J}_{\Omega} / \mathrm{J}_{\mathrm{\Omega}=0}$, as a function of bending moment (This figure illustrates the saturation obtained by these values) $\ldots \ldots \ldots \ldots \ldots$. . . . . . 43

4.33 The saturation values of $\mathrm{J}_{\Omega} / \mathrm{J}_{\Omega=0}$ as a function of crack-tip angle, $\Omega \ldots \ldots$ 4-34

4.34 The variation of $\mathrm{J}_{\text {applied }} / \mathrm{J}_{\mathrm{i}}$ (for Pipe DP2-F11) with crack-tip angle from the

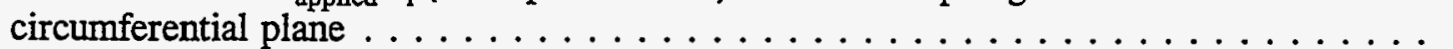

4.35 Center COD versus bending moment for straight as well as angled cracks subjected to pure bending

4.36 Bending moment versus end rotation for straight as well as angled cracks subjected to

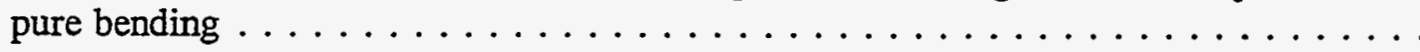

4.37 Variation of applied J with effective moment for straight and 45-degree cracks subjected to a bending moment-to-torque ratio of 1.0 (The effective moment is calculated for several values of $\left.c_{e}\right) \ldots \ldots \ldots \ldots \ldots \ldots \ldots \ldots \ldots \ldots \ldots$

4.38 Center COD versus effective moment for straight and 45-degree cracks subjected to a combined bending moment-to-torque ratio of $1.0 \ldots \ldots \ldots \ldots \ldots$

4.39 Effect of torsion on center COD for the 45-degree crack and straight crack $\ldots \ldots \ldots$ 4-38 


\section{LIST OF FIGURES}

Figure

Page

5.1 Variation of normalized angular crack growth parameter, $A$, with crack-tip angle, $\Omega$, from the circumferential plane (If this parameter assumes a value of unity or higher for a given angle, then the tendency for the crack to propagate along the circumferential plane is higher than its tendency to propagate at that angle) $\ldots \ldots \ldots \ldots \ldots$ 


\section{LIST OF TABLES}

$\underline{\text { Table }}$

2.1 Description of carbon steel pipes used in study of anisotropy $\ldots \ldots \ldots \ldots \ldots$

2.2 Chemical composition of carbon steel pipes used in study of anisotropy $\ldots \ldots \ldots$. . . .

2.3 Appearance of stringer-type inclusions in pipes used in study of anisotropy . . . . . . 2-15

2.4 Ratio of longitudinal to transverse toughness in Charpy V-notch impact specimens machined from carbon steel pipes . . . . . . . . . . . . . . . . . 2-19

3.1 Angled crack growth in circumferentially cracked carbon steel pipes tested at Battelle . . 3-5

4.1 Matrix of finite element analyses $\ldots \ldots \ldots \ldots \ldots \ldots \ldots \ldots \ldots$

4.2 Straight $\mathrm{TWC}$ pipe pure bending $\mathrm{J}$ values $\ldots \ldots \ldots \ldots \ldots \ldots$

4.3 Orientation dependent $\mathrm{J}$-initiation values measured from $\mathrm{C}(\mathrm{T})$ tests of specimens obtained from Pipe DP2-F11 ... . . . . . . . . . . . . . . . . . 4-34 


\section{EXECUTIVE SUMMARY}

This topical report summarizes work on angled through-wall-crack growth and combined loading effects on ferritic nuclear pipe performed as part of the Nuclear Regulatory Commission's research program entitled "Short Cracks in Piping and Piping Welds". The major impetus for this work stemmed from the observation that initially circumferentially oriented cracks in carbon steel pipes exhibited a high tendency to grow at a different angle when the cracked pipes were subjected to bending or bending plus pressure loads. This failure mode was little understood, and the effect of angled crack growth from an initially circumferential crack raised questions about how cracks in a piping system subjected to combined loading with torsional stresses would behave.

There were three major efforts undertaken in this study. The first involved a literature review to assess the causes of toughness anisotropy in ferritic pipes and to develop strength and toughness data as a function of angle from the circumferential plane. The second effort was an attempt to develop a screening criterion based on toughness anisotropy and to compare this screening criterion with experimental pipe fracture data. The third and more significant effort involved finite element analyses to examine why cracks grow at an angle and what is the effect of combined loads with torsional stresses on a circumferentially cracked pipe. These three efforts are summarized below.

\section{Literature Review of Toughness Anisotropy and Data Development}

The literature review of toughness anisotropy showed that there were three contributors to toughness anisotropy. By far, the largest contributor was the inclusion size and shape. Smaller contributions were thought to come from crystallographic texture and banding. An Anisotropy Index was developed which was the ratio of the maximum toughness (usually in the L-C orientation, i.e., the circumferential through-wall crack growth direction), to the minimum toughness (usually in the C-L orientation, i.e., the axial through-wall crack growth direction). Anisotropy Index values of approximately three are common for ferritic pipes, although for plates heavily rolled to increase the strength, the Anisotropy Index was found to be greater than six. Cross-rolling of plates can bring this ratio to one (isotropic toughness) which is possible with seam-welded pipes, but not with seamless pipes.

Also, in this effort, tensile and $C(T)$ data were developed at various angles for one particular A333 Grade 6 pipe used in the Degraded Piping Program Experiment 4111-1. This was a seamless pipe and had nonmetallic inclusions with large aspect ratios oriented at an angle of approximately 66 degrees to the circumferential plane. The tensile tests showed very little sensitivity to the orientation of the specimen. The $C(T)$ specimens were side grooved, to force them to grow at a predetermined angle. As was expected, cracks growing along the inclusion direction yielded the lowest fracture toughness values, while those growing normal to the inclusions yielded the highest values. The Anisotropy Index based on the initiation toughness values was 3.1 for this pipe steel. Additionally, Charpy tests at a temperature corresponding to the upper shelf were conducted on five other steels at various orientations. Metallographic examinations of the five pipes revealed that nonmetallic inclusions with large aspect ratios were aligned either at 66 degrees to the circumferential plane (in one pipe) or more commonly along the pipe axis. The Anisotropy Index number for each pipe was then determined from the Charpy values and ranged from 1.7 to 3.4. However, from 0 to 45 degrees, the slope of the Charpy energy versus angle data was very similar for each of the five steels. Beyond 45 degrees the data from one steel had a slope chạnge. 
Screening Criteria Based on Toughness Data

The angles of crack growth from numerous past carbon steel pipe tests from the Degraded Piping, IPIRG-1, and the Short Cracks in Piping and Piping Welds programs were documented. The Anisotropy Index was then plotted versus the angle of crack growth from the pipe experiments. No strong trends were found. A slightly better trend was found when looking at the crack angle versus the pipe diameter-to-thickness ratio, but this was also a weak trend. Indeed there were many cases of pipe experiments using pipe from the same heat of pipe where the crack angle varied from 20 to 65 degrees. Hence, a simple, accurate, angled crack growth criterion from just the Anisotropy Index number could not be determined, nor could the scatter in the data be explained.

\section{Finite Element Analyses}

There were two objectives in this effort. The first was to see if angled crack growth could be explained analytically, and the second was to investigate combined tenșion, bending, and torsion loading on pipes. To accomplish these objectives, Experiment 4111-1 on a 4-inch nominal diameter Schedule 80 A333 Grade 6 pipe from the Degraded Piping Program was analyzed. This pipe had a 37-percent long circumferential through-wall crack. These pipe and crack dimensions were used in numerous other finite element analyses. The finite element analyses had straight circumferential cracks or cracks with a short length of angled crack at the crack tip. Crack tip angles $(\Omega)$ of 25,45 , and 65 were analyzed. The angled crack tip invokes combined mode loading, i.e., Mode I (opening), Mode II (sliding shear) and Mode III (out-of-plane tearing). A review of combined-mode, elastic-plastic fracture parameters showed that although the analysis procedure is pushing the state-of-the-art, what was done was reasonable. Detailed descriptions of the finite element analyses and boundary conditions are given since under the various loading conditions, one cannot assume quarter symmetry, especially for the case of the angled crack tip or combined loading involving torsion. The analyses were done using the ABAQUSß computer code.

The results of the elastic-plastic analyses of straight and angled cracks indicated that the normalized angular crack driving force, $\mathrm{J}_{\Omega} / \mathrm{J}_{\Omega=0}$ [ratio of the $\mathrm{J}_{\text {applied }}$ value for an angled crack $\left(\mathrm{J}_{\Omega}\right)$ and the corresponding value for straight crack $\left(J_{\Omega=0}\right)$ ] had a constant value once plasticity occurred. A normalized angular crack growth parameter, $\mathcal{A}$, was developed, where

$$
\mathcal{A}=\frac{\text { normalized angular fracture resistance }}{\text { normalized angular crack driving force }}=\frac{\mathrm{J}_{\mathrm{i} \Omega} / \mathrm{J}_{\mathrm{i} \Omega=0}}{\mathrm{~J}_{\Omega} / \mathrm{J}_{\Omega=0}}
$$

and $\mathrm{J}_{\mathrm{i} \Omega}$ is the initiation toughness at an angle $\Omega$, and $\mathrm{J}_{\mathrm{i} \Omega=0}$ is the initiation toughness in the L-C orientation (circumferential crack growth direction). It is important to mention that this parameter is not a material parameter, but rather a combination of the directional sensitivity of both the fracture toughness and the crack-driving-force. This parameter was found to be useful in gaining an understanding of the angular crack growth phenomenon. When this parameter has a value of unity or higher for a given crack-tip angle, then the tendency for the crack to grow along the circumferential plane is higher than the tendency for it to propagate along that angle. Similarly, if the parameter is less than one at other than $\Omega=0$, then the crack should grow at that angle. The variation of this parameter with the crack tip angle from the circumferential plane for the analysis of Experiment 4111-1 showed that the crack would be more likely to grow at an angle, and the parameter $\mathcal{A}$ was essentially the same from 25 to 65 degrees. Hence, the crack could grow in any direction from 25 to 
65 degrees. This observation agrees with the experimental observation that the crack propagated at 37 and 59 degrees from the two crack tips in Experiment 4111-1.

Since the analyses reported pertain only to this pipe, strictly speaking the results obtained for the driving force for straight and angled cracks cannot be used to examine the experimental data obtained for the other pipes. This limitation is because the $\mathrm{J}_{\text {applied }}$ term used in $\mathrm{J}_{\Omega} / \mathrm{J}_{\Omega=0}$ may be sensitive to crack length, pipe diameter-to-thickness ratios, and stress-strain characteristics of the material. However, the normalized angular fracture resistance values from the Charpy tests on the other pipe materials evaluated were used with the results from the finite element analyses to see if pipes similar in geometry to Experiment $4111-1$, and made of these other ferritic steels, would exhibit angular crack growth. It was found that the range of angles over which the crack may propagate varied considerably from pipe to pipe, even though the slopes of the Charpy energy versus $\Omega$ graphs were only slightly different. Hence, it is believed that local variability in toughness anisotropy may significantly affect the direction of crack growth. The sensitivity of the $\mathrm{J}_{\Omega} / \mathrm{J}_{\Omega=0}$ term to crack length, pipe diameter-tothickness ratio, and stress-strain properties is not known. The development of the proposed $\mathcal{A}$ parameter appears promising in explaining angled crack growth in ferritic pipes, but it is not generally validated for other crack lengths and pipe sizes.

The other main objective of this work was to assess the fracture behavior of pipes subjected to torsional stresses in addition to bending stresses and tension stresses from internal pressure. Prior to starting this analysis, a survey of piping stress analyses results from various companies was undertaken. This survey showed that bending moment-to-torque ratios of 3.0 were common and occasionally this ratio was as low as 1.0. Analyses were then conducted using both of these ratios. It was found that an effective bending moment could be defined in at least four different ways to account for torsional and bending moments. By adopting the Von Mises relation to define the effective bending stress, $\sigma_{\mathrm{eff}}$, in terms of the applied bending stress, $\sigma_{\mathrm{B}}$, and the torsional stress, $\tau_{\mathrm{T}}$

$$
\sigma_{\text {eff }}=\left[\sigma_{B}^{2}+3 \tau_{T}^{2}\right]^{0.5}
$$

it was seen that the finite element solutions obtained for the crack-driving force and crack-opening displacement under bending conditions may be used in evaluating the corresponding quantities for cracked pipes subjected to combined bending and torsion. The finite element results demonstrated the validity of this approach for a straight circumferential through-wall crack as well as for an angled circumferential through-wall crack with a crack-tip angle of 45 degrees. This significant conclusion enables the use of simple engineering estimation schemes of through-wall-cracked pipes under bending to be used to determine fracture parameters when combined loading with torsion occurs. The limitation to this approach, however, is that the analyses conducted to date were restricted to very small amounts of angular crack growth. For large crack growth at an angle, there may be some deviations from the results obtained to date. For instance, the ratio of the J-R curves at different orientations do not seem to be constant with crack growth, and the ratio of the $J_{\text {applied }}$ values with crack-tip angle for a growing crack is unknown. Alșo we did not conduct crack growth analyses for the straight growing crack to examine the validity of the effective moment concept, but anticipate that this approach would work. Nevertheless, the conclusion of using this effective bending stress for combined loads involving torsion is valid for all leak-rate calculations of concern to LBB analyses and for determining loads up to crack initiation. Finally it should be noted that these results are for 


\section{Executive Summary}

circumferential through-wall-cracked pipe, and surface-cracked pipe may behave quite differently under combined loads. 


\section{ACKNOWLEDGMENTS}

This work is supported by the U. S. Nuclear Regulatory Commission through the Electrical, Materials and Mechanical Engineering Branch of the Office of Nuclear Regulatory Research under Contract No. NRC-04-90-069. Mr. Allen Hiser was the program monitor during most of this program. Mr. Michael Mayfield was the monitor during the last year.

We express our gratitude to Dr. M. L. Aggarwal of Ontario Hydro, Canada, and Dr. Sushil Daftuar of Arizona Public Service Company for providing us with data on loads on piping systems used in the survey in this report to determine typical torsion-to-bending ratios to guide the analyses. We also appreciate the helpful discussions we had with Prof. C. F. Shih, Brown University and Dr. R. Stonesifer, Computational Mechanics, Inc.

We would also like to thank others at Battelle who have helped in these efforts, including Mr. P. Held and Mr. P. Mincer for mechanical testing and Mr. G. Clark for metallographic examination of inclusions, and Mr. A. Krishna for assistance with computations. We thank Ms. Brenda Blanton, Mrs. V. Kreachbaum, and Ms. C. Pepper for typing various sections of this report and Mr. D. Hayes for drafting assistance. Finally, we thank Mr. P. Scott, Dr. A. Hopper, and Dr. D. K. Snediker for their help in reviewing the manuscript. 


\section{NOMENCLATURE}

\section{SYMBOLS}

$\mathcal{A}$

a

$b_{0}$

c

$c_{e}$

d

$d_{r}$

D

de

$\mathrm{D}_{\mathrm{m}}$

E

El

E-P

$\mathrm{F}_{\mathrm{k}}$

$\mathcal{G}$

G

$I_{n}$

$\mathrm{J}$

$\mathrm{J}_{\text {applied }}$

$\mathrm{J}_{\mathbf{i}}$

$\mathrm{J}_{\mathrm{i} \Omega}$
Normalized angular crack growth parameter

Crack length in $\mathrm{C}(\mathrm{T})$ specimens

$\mathrm{W}-\mathrm{a}_{\mathrm{o}}$ in $\mathrm{C}(\mathrm{T})$ specimens

Half the circumferential through-wall crack length

Effective moment parameter for combined bending and torsion

Surface crack depth

Distance along thickness direction, from inner surface of pipe

Nominal outside pipe diameter

Differential length of the integration path

Mean pipe diameter

Young's modulus

Elastic

Elastic-plastic

Line-integral of the energy-momentum tensor around a defect

Potential energy-release rate

Shear modulus

Integration constant used in elastic-plastic crack-tip fields

J-integral fracture parameter

Applied driving force

J-integral at crack initiation but not necessarily a valid $\mathrm{J}_{\mathrm{Ic}}$ by ASTM E813-81

J-integral at crack initiation for angled crack 
$\mathrm{J}_{\mathrm{Ri}}$

$\mathrm{J}_{\mathrm{Ro}}$

$\mathrm{J}_{\Omega}$

$\mathrm{J}_{\Omega} / \mathrm{J}_{\Omega=0}$

$\mathrm{J}_{\mathrm{i} \Omega} / \mathrm{J}_{\mathrm{i} \Omega=0}$

J-R

$\mathrm{K}_{\mathrm{I}}$

$\mathrm{K}_{\mathrm{II}}$

$\mathrm{K}_{\mathrm{III}}$

$\mathrm{M}_{\mathrm{B}}$

$\mathrm{M}_{\text {eff }}$

$M_{x}, M_{y}$

n

$\mathbf{n}_{\mathbf{k}}$

P

Q

r

$\mathrm{R}$

$\mathrm{R}_{\mathrm{f}}$

$\mathrm{R}_{\mathrm{i}}$

$\mathrm{R}_{\mathrm{o}}$

$\mathrm{t}$

$t_{i}$
$\mathrm{J}$ at the inner radius of circumferential TWC pipe

$\mathrm{J}$ at the outer radius of circumferential TWC pipe

$\mathrm{J}$ for angled crack with crack-tip angle, $\Omega$

Normalized angular driving force

Normalized angular fracture resistance

J-integral resistance (curve)

Mode I stress intensity factor

Mode II stress intensity factor

Mode III stress intensity factor

Bending moment

Effective moment

In-plane and out-of-plane bending moments, respectively

Ramberg-Osgood strain-hardening exponent

Unit outward normal component to integration path

Label for a material point

Label for a material point

Distance from crack-tip

Ratio of minimum-to-maximum stress in cyclic loading

Reaction force

Inside radius

Outside radius

Thickness of pipe wall

Traction component acting on the outer side of the integration path 
$\mathrm{U}_{\mathrm{i}, \mathrm{k}}$

$U_{0}$

$\mathrm{U}_{\mathrm{r}}$

$U_{r}^{P}, U_{r}^{Q}$

$\mathrm{U}_{\mathrm{x}}$

$\mathrm{U}_{\mathrm{y}}$

$\mathrm{U}_{\mathrm{z}}$

$\mathrm{U}_{\theta}$

W

$\mathrm{x}, \mathrm{y}, \mathrm{z}$

$x_{1}, x_{2}, x_{3}$

$\mathrm{X}, \mathrm{Y}, \mathrm{Z}$

$y^{\prime}$

$\alpha$

$\beta$

$\Gamma$

$\Delta \mathrm{a}$

$\delta_{t}$

$\eta_{\mathrm{u}}$

$\xi$

$\psi$
Torque

d-c electric potential

Component of the displacement gradient

Value of $U$ at crack initiation

Radial displacement

Radial displacement of material Points $\mathrm{P}$ and $\mathrm{Q}$

Displacement in x-direction

Displacement in y-direction

Displacement in z-direction

Circumferential displacement

Compact tension specimen width

Coordinate axes

Local Cartesian coordinate system centered at the crack tip

Coordinates of a material point

The half-spacing of the voltage probes used to measure the d-c electric potential in fracture tests

Ramberg-Osgood parameter

Factor used in relating $\mathrm{K}_{\mathrm{I}}$ and $\mathrm{J}$

Integration path

Increment of crack growth

Crack-tip-opening displacement

Factor used in relating $\mathrm{K}_{\mathrm{I}}$ and crack-tip-opening displacement

Angle measured from center of circumferential TWC

Coordinate axis for local cylindrical system centered at crack-tip 
Nomenclature

$v$

$\sigma_{\mathrm{B}}$

$\sigma_{\text {eff }}$

$\sigma_{\mathrm{h}}$

$\sigma_{0}$

$\sigma_{r}, \sigma_{\psi}, \sigma_{r \psi}$,

$\sigma_{r z}, \sigma_{\psi z}$

$\tau_{\mathrm{T}}$

$\Omega$

2.

ABAQUS ${ }^{\circledR}$

ASTM

C-L .

$\mathrm{COA}$

COD

$\mathrm{C}(\mathrm{T})$

CVN

d-c EP

DS

FEA

HRR

IP

I-DEAS®
Poisson's ratio

Bending stress

Effective stress

Hydrostatic stress

Reference stress

Stress components in local cylindrical coordinate system centered at the crack tip

Torsional stress caused by torque, $\mathrm{T}$

Angle of crack-tip with respect to circumferential plane of pipe

\section{ACRONYMS AND INITIALISMS}

Finite element computer code

American Society for Testing and Materials

Circumferential-longitudinal orientation (direction of through-wall crack growth along pipe axis)

Total crack-opening area

Crack-opening displacement

Compact (tension) specimen

Charpy V-notch; sometimes Charpy V-notch energy

Direct-current electric potential

Double-shear fracture

Finite element analysis

Hutchinson-Rice-Rosengren

Internal pressure

I-DEAS pre- and post-processing software 
LBB

L-C

LLD

NRC

OBE

PWR

SC

SS

SEM

Ten

TWC
Leak before break

Longitudinal-circumferential orientation (direction of through-wall crack growth around pipe circumference)

Load-line displacement

Nuclear Regulatory Commission (U.S.)

Operating basis earthquake

Pressurized water reactor

Surface crack

Single-shear fracture

Scanning electron microscope

Tension

Through-wall crack, through-wall-cracked 


\section{PREVIOUS REPORTS IN SERIES}

\section{Previous Reports from this Program}

"Short Cracks in Piping and Piping Welds," First Semiannual Report, NUREG/CR-4599, Vol. 1, No. 1, March 1991.

"Short Cracks in Piping and Piping Welds," Second Semiannual Report, NUREG/CR-4599, Vol. 1, No. 2, April 1992.

"Short Cracks in Piping and Piping Welds," Third Semiannual Report, NUREG/CR-4599, Vol. 2, No. 1, September 1992.

"Short Cracks in Piping and Piping Welds," Fourth Semiannual Report, NUREG/CR-4599, Vol. 2, No. 2, February 1993.

"Short Cracks in Piping and Piping Welds," Fifth Semiannual Report, NUREG/CR-4599, Vol. 3, No. 1, October 1993.

"Short Cracks in Piping and Piping Welds," Sixth Semiannual Report, NUREG/CR-4599, Vol. 3, No. 2, March 1994.

"Short Cracks in Piping and Piping Welds," Seventh Program Report, NUREG/CR-4599, BMI-2173, Vol. 4, No. 1, April 1995.

"Assessment of Short Through-Wall Circumferential Cracks in Pipes - Experiments and Analyses," NUREG/CR-6235, April 1995.

"Fracture Evaluations of Fusion-Line Cracks in Nuclear Pipe Bimetallic Welds," NUREG/CR-6297, April 1995.

"Effect of Dynamic Strain Aging on the Strength and Toughness of Nuclear Ferritic Piping at LWR Temperatures," NUREG/CR-6226, October 1994.

"Refinement and Evaluation of Crack-Opening Analyses for Short Circumferential Through-Wall Cracks in Pipes," NUREG/CR-6300, April 1995.

"Probabilistic Pipe Fracture Evaluations for Leak-Rate Detection Applications," NUREG/CR-6004, April 1995.

"Validity Limits in J-Resistance Curve Determination -- Volume 1: An Assessment of the $J_{M}$ Parameter," NUREG/CR-6264 Volume 1, February' 1995. 
Previous Reports in Series

"Validity Limits in J-Resistance Curve Determination -- Volume 2: A Computational Approach to Ductile Crack Growth Under Large-Scale Yielding Conditions," NUREG/CR-6264 Volume 2, February 1995.

“Stainless Steel Submerged Arc Weld Fusion Line Toughness,” NUREG/CR-6251, April 1995.

Previous Related Documents from NRC's Degraded Piping Program

“Degraded Piping Program - Phase II," Semiannual Report, NUREG/CR-4082, Vol. 1, Oct. 1984.

“Degraded Piping Program - Phase II," Semiannual Report, NUREG/CR-4082, Vol. 2, June 1985.

“Degraded Piping Program - Phase II," Semiannual Report, NUREG/CR-4082, Vol. 3, March 1986.

“Degraded Piping Program - Phase II," Semiannual Report, NUREG/CR-4082, Vol. 4, July 1986.

“Degraded Piping Program - Phase II," Semiannual Report, NUREG/CR-4082, Vol. 5, Dec. 1986.

“Degraded Piping Program - Phase II," Semiannual Report, NUREG/CR-4082, Vol. 6, April 1988.

“Degraded Piping Program - Phase II," Semiannual Report, NUREG/CR-4082, Vol. 7, March 1989.

“Degraded Piping Program - Phase II," Semiannual Report, NUREG/CR-4082, Vol. 8, March 1989.

"NRC Leak-Before-Break (LBB.NRC) Analysis Method for Circumferentially Through-Wall Cracked Pipes Under Axial Plus Bending Loads,” Topical Report, NUREG/CR-4572, March 1986.

"Elastic-Plastic Finite Element Analysis of Crack Growth in Large Compact Tension and Circumferentially Through-Wall-Cracked Pipe Specimen-Results of the First Battelle/NRC Analysis Round Robin," Topical Report, NUREG/CR-4573 September 1986.

"An Experimental and Analytical Assessment of Circumferential Through-Wall Cracked Pipes Under Pure Bending,” Topical Report, NUREG/CR-4574, June 1986.

"Predictions of J-R Curves With Large Crack Growth From Small Specimen Data," Topical Report, NUREG/CR-4575, August 1986.

"An Assessment of Circumferentially Complex-Cracked Pipe Subjected to Bending," Topical Report, NUREG/CR-4687, September 1986.

"Analysis of Cracks in Stainless Steel TIG Welds," Topical Report, NUREG/CR4806, November 1986.

"Approximate Methods for Fracture Analyses of Through-Wall Cracked Pipes," Topical Report, NUREG/CR-4853, January 1987.

"Assessment of Design Basis for Load-Carrying Capacity of Weld-Overlay Repair," Topical Report, NUREG/CR-4877, February 1987.

"Analysis of Experiments on Stainless Steel Flux Welds," Topical Report, NUREG/CR-4878, February 1987. 
"Experimental and Analytical Assessment of Circumferentially Surface-Cracked Pipes Under Bending," Topical Report, NUREG/CR-4872, April 1987.

Previous Related Documents from NRC's International Piping

Integrity Research Group (IPIRG) Program

"Evaluation and Refinement of Leak-Rate Estimation Models," NUREG/CR-5128, April 1991.

"Loading Rate Effects on Strength and Fracture Toughness of Pipe Steels Used in Task 1 of the IPIRG Program," Topical Report, NUREG/CR-6098, October 1993.

"Stability of Cracked Pipe Under Inertial Stresses--Subtask 1.1 Final Report," NUREG/CR-6233, Vol. 1, August 1994. 


\section{INTRODUCTION}

\subsection{Brief Technical Background}

In the Nuclear Regulatory Commission's (NRC) Degraded Piping Program, Battelle conducted numerous tests on circumferentially cracked carbon steel pipes at a typical nuclear-reactor operating temperature of $288 \mathrm{C}(550 \mathrm{~F})$. Nearly all of the tests employed four-point bending and some included internal pressure along with the bending; only one test was conducted with internal pressure alone.

It came as somewhat of a surprise when one of the first carbon steel pipes tested in bending fractured along a path which was at an angle from the expected circumferential path (Ref. 1.1). That pipe was ASTM A333 Grade 6, 4-inch nominal diameter Schedule 80 pipe, (Battelle identification Number DP2-F11). Figure 1.1 is a photograph of the fracture path in that pipe and in a compact specimen machined from that pipe. Metallographic examination of that seamless pipe revealed that it had been twisted during the extrusion process used in its manufacture, such that the majority of its nonmetallic, stringer-type inclusions were aligned at an angle of approximately 24 degrees to the pipe axis, or approximately 66 degrees to the pipe circumference. Since the direction of the stringer-type inclusions typically is the least fracture-resistant direction, it appeared that the crack in the pipe, which originally was circumferential, simply grew at an angle to the circumference to follow this path of least resistance.

Subsequent tests on other carbon steel pipes, whose nonmetallic inclusions were aligned with the pipe axis rather than twisted relative to the axis, revealed that they, too, exhibited angled crack growth relative to the original circumferential orientation of the crack (Refs. 1.2 and 1.3). However, since the crack did not follow the direction of the elongated inclusions (axial), it was hypothesized that the angled growth represented a compromise between circumferential crack extension, driven by the bending stresses, and axial crack growth, favored by the low toughness in that direction. By that reasoning, it could be argued that the greater the toughness anisotropy exhibited by the pipe, the greater would be the skewed angle of the crack extension. Further, the presence of internal pressure might also contribute to an increased skew angle.

From a pragmatic standpoint, the angled crack growth under applied bending loads is of little concern relative to current leak-before-break or ASME flaw evaluation procedures, because the maximum loads for angled crack growth tend to be greater than those predicted for straight cracks. However, concern does arise when internal pressure or torsional loads are present, because of the possibility that current flaw-evaluation procedures might underestimate the maximum load-carrying capacity under these reallife conditions.

The work described in this report was undertaken to gain a greater insight into the factors contributing to angled crack growth, and its possible significance under service conditions. 


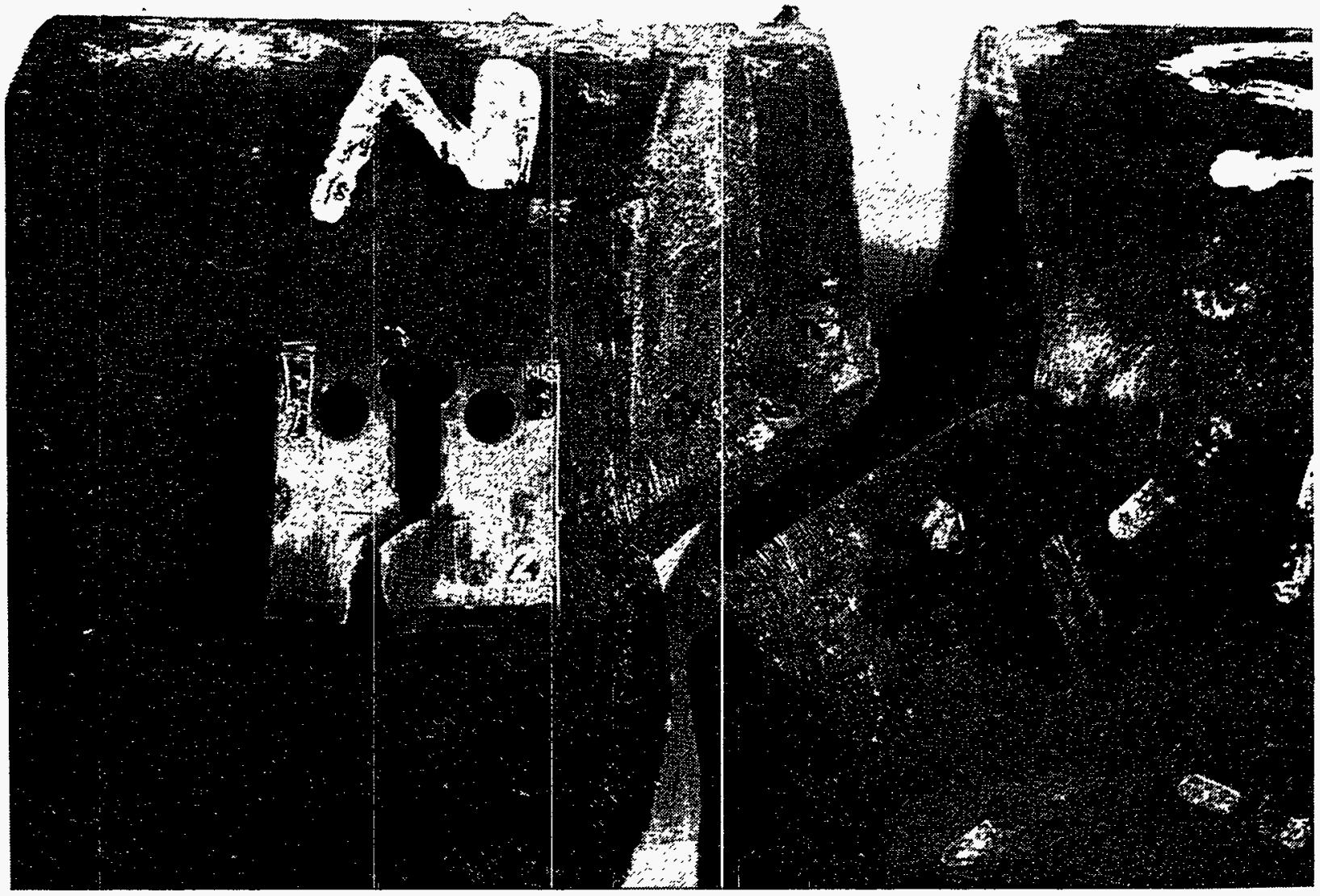

Figure 1.1 Photograph of the fractured pipe from Experiment 4111-1 and a compact (tension) specimen for this material 


\subsection{Objectives of Study}

This study had three principal objectives: (1) to assess the magnitude of anisotropy effects on strength and fracture toughness of carbon steels, (2) to develop a screening criterion for predicting angled crack growth in circumferentially cracked pipes, and (3) to assess the ramifications of toughness anisotropy and angled crack growth on the behavior of circumferentially cracked pipe under a broad range of service loading conditions.

\subsection{Report Organization}

In Section 2, past work on anisotropy effects has been reviewed and the material property tests conducted to characterize the magnitude of anisotropy are described. In Section 3, an attempt to predict angled crack growth with a proposed screening criterion based on material property data alone is described. Section 4 describes the analysis work on determining the crack driving force for straight and angled cracks under combined loads. An engineering approach to evaluate the effects of combined bending and torsion on TWC pipes is also presented. The validity of this approach is examined in some detail for straight as well as angled cracks. In the Discussion and Conclusions section (Section 5), a parameter is introduced which offers some promise in explaining angular crack growth in carbon steel pipes.

\subsection{References}

1.1 Wilkowski, G. M., "Anisotropic Fracture Toughness Effects on Failure Modes of Piping," ASME Journal of Pressure Vessel Technology, Vol. 113, pp 154-158, May 1991.

1.2 Wilkowski, G. M., and others, "Degraded Piping Program - Phase II," Summary of Technical Results and Their Significance to Leak-Before-Break and In-Service Flaw Acceptance Criteria, March 1984 - January 1989, NUREG/CR-4082, Vol. 8, March 1989.

1.3 Scott, P. and Brust, F., "An Experimental and Analytical Assessment of Circumferential Through-Wall-Cracked Pipes under Pure Bending," NUREG/CR-4574, September 1986. 


\section{CAUSES AND MAGNITUDE OF ANISOTROPY EFFECTS}

\subsection{Findings from the Literature Review}

A review of the literature revealed three main contributors to toughness anisotropy in carbon steels: (1) elongated inclusions, (2) banded microstructures, and (3) crystallographic texture. The importance of each contributor and methods for minimizing the adverse effects of each on toughness anisotropy are discussed separately.

\subsubsection{Elongated Inclusions}

By far the most important contributor to toughness anisotropy in carbon steels is elongated nonmetallic inclusions, predominantly manganese sulfides, which become elongated during the metalworking operations by virtue of their high ductility. When highly elongated sulfide inclusions are present, the ratio of toughness in the maximum-toughness direction to that in the minimum-toughness direction, hereafter referred to as the Anisotropy Index, can reach values as high as 3 or 4 (Refs. 2.1 through 2.7), although values as high as 6 were reported in Reference 2.4 .

Several methods have been advanced for minimizing or overcoming the toughness anisotropy due to the manganese sulfide inclusions. An obvious method would be to reduce the sulfur content of the steel. However, according to Matrosov and Polyakov (Ref. 2.8), significant reductions in toughness anisotropy occur only when the sulfur content is below approximately 0.01 percent. Reducing the sulfur from 0.04 to 0.02 percent has relatively little effect. Sharp improvements can be realized when the sulfur level is maintained at 0.004 percent or below. Nonetheless, two of the references examined (Refs. 2.6 and 2.9), in which steels containing 0.005 percent sulfur were tested, indicated that even low-sulfur steels can exhibit significant toughness anisotropy. For example, in Reference 2.6, the Anisotropy Index was 2.0 as determined from Charpy tests on a heat treated, low-alloy steel plate containing 0.005 percent sulfur, while in Reference 2.9, the Anisotropy Index for an A533, Grade B, Class 1 steel plate containing 0.005 -percent sulfur was 1.35 to 1.59 , as determined from compactspecimen tests. Although at one time the attainment of low sulfur levels was difficult and expensive, economical industrial methods are currently available for accomplishing this result.

Similarly, anisotropy due to manganese sulfide inclusions could be minimized by reducing the manganese content. However, because of its many useful alloying characteristics in carbon steels, elimination of manganese is not recommended (Ref. 2.8).

A second way to minimize anisotropy due to manganese sulfide inclusions is to employ cross rolling in the fabrication of plate and sheet. Hodge, Frazier, and Boulger (Ref. 2.6) demonstrated that planar anisotropy could be eliminated, i.e., the Anisotropy Index was 1.0, in a steel that contained as much as 0.06 percent sulfur, after cross rolling it 46 percent. 'However, cross rolling is not always practical and, in any event, can not be employed in the manufacture of seamless pipes.

A third method for minimizing toughness anisotropy is to reduce the ductility of the sulfur-bearing inclusions and, therefore, their ability to form highly elongated stringers during metalworking 
operations. As pointed out by Matrosov and Polyakov (Ref. 2.8), the most effective way to form lowplasticity sulfides is to add titanium, zirconium, or rare-earth metals, especially cerium. Each of these elements has a higher affinity for sulfur than does manganese. Those authors cited an investigation in which the Anisotropy Index was approximately 2.5 when the cerium/sulfur ratio in the steel was zero. However, when cerium was added to bring the cerium/sulfur ratio to 1.5 to 2.0, the Anisotropy Index was lowered to a value of approximately 1.18. Such means for achieving sulfide-shape control have been adequately investigated and developed for use in tonnage production of weldable structural steels.

Matrosov and Polyakov (Ref. 2.8) also discussed the role of oxygen in controlling the shape of sulfurbearing inclusions. Although the role of oxygen is relatively modest, the authors state that, in balanced or rimmed steels, the sulfides contain significant amounts of oxygen which considerably reduces their plasticity and their ability to form stringers. Therefore, rimmed steels are likely to show less toughness anisotropy than fully killed steels, in which most of the oxygen is present in the form of oxide inclusions and the sulfides are nearly pure manganese sulfide.

\subsubsection{Banded Microstructures}

A second contributor to toughness anisotropy is banded microstructures resulting from chemical inhomogeneities. For example, in a steel made up of ferrite and pearlite, a banded microstructure would appear in the microscope as alternating bands of ferrite (light etching) and pearlite (dark etching), aligned in the principal working direction. According to Matrosov and Polyakov (Ref. 2.8), banding alone can produce an Anisotropy Index as high as approximately 1.25. Several references were reviewed in which elevated-temperature homogenization treatments were employed to reduce the degree of banding. In Reference 2.9, hot-rolled carbon-manganese steel plates containing approximately 0.02 percent sulfur were homogenized at unspecified temperatures for unspecified times. For a steel that had been rare-earth treated to control sulfide shape, homogenization decreased the Anisotropy Index from 1.49 to 1.18. The effect of homogenization was much less pronounced for a steel without rare earth additions; the Anisotropy Index decreased only from 1.85 to 1.72 . In past work at Battelle, a ferritic steel plate of unspecified type and unspecified sulfur content showed a decrease in Anisotropy Index from 2.86 to 2.22 after a homogenization treatment. However, in Reference 2.6, relatively little effect on the Anisotropy Index was noted, regardless of sulfur content from 0.005 to 0.179 percent, from a homogenization treatment of 10 hours at $1,290 \mathrm{C}(2,350 \mathrm{~F})$. However, the Charpy values were increased in this treatment.

The degree of banding can also be reduced by decreasing the carbon content of the steel (Ref. 2.8). In order for the effect of lower carbon to be significant in reducing anisotropy due to banding, it is necessary to go to reduced-pearlite steels (carbon contents no greater than 0.08 percent) or even to pearlite-free steels (carbon contents no greater than 0.03 percent). Of course, reducing the carbon to those levels causes a substantial loss of strength which can be overcome by microalloying with elements such as niobium, vanadium, and titanium. The authors of Reference 2.8 point out that, even at the time of preparation of their paper (1976), the beneficial effect of a reduction in carbon was being widely utilized in the development of a group' of reduced-pearlite and pearlite-free precipitation hardening steels. 


\subsubsection{Crystallographic Texture or Preferred Orientation}

A third contributor to toughness anisotropy is known as crystallographic texture or preferred orientation. This condition exists in a plate or a pipe when the individual grains (crystals) are not randomly oriented but have a preferred orientation dictated by the details of the thermomechanical treatments to which the component has been subjected. Little information is available on the quantitative effect of crystallographic texture on toughness anisotropy. Fegredo, Faucher, and Shehata (Ref. 2.10) investigated the effect of texture by rolling low-carbon steels containing two levels of sulfur ( 0.007 and 0.02 percent) at a number of different temperatures, ranging from 680 to $1200 \mathrm{C}$ $(1,255$ to $2,190 \mathrm{~F})$. However, they did not make any toughness measurements in the orientations of highest toughness. Hence, it is not possible to determine anisotropy indexes from their data. In spite of the lack of data regarding texture effects on toughness anisotropy, it. is believed that the magnitude of the texture effect is comparable with that of banding and of much less importance than the sulfide inclusion shape.

\subsubsection{Summary of Literature Review}

In summary, the major contributor to toughness anisotropy is highly elongated, stringer-type, sulfurbearing inclusions. When they are present, anisotropy indexes as high as 3 to 4 are commonly observed, and on occasions have been reported to be as high as 6 (Ref. 2.4). Reducing sulfur levels below approximately 0.005 percent and achieving sulfide shape control by addition of elements that reduce the plasticity of the inclusions are effective in achieving greatly lowered anisotropy indexes. Nonetheless, significant anisotropy may remain even after those procedures are adopted. The most certain way to achieve an Anisotropy Index of 1.0 is to employ cross rolling. Unfortunately, that procedure is not always practical nor can it be employed in the manufacture of seamless pipe. Much less is known about two other sources of toughness anisotropy -- banded microstructures and crystallographic texture -- but each is believed to be much less important than inclusion shape. Some researchers report that modest reductions in anisotropy due to banding can be achieved by thermal homogenization treatments. The literature review yielded no information on angled crack growth in carbon-steel pipes containing circumferential flaws, or on an explanation for the angled growth.

\subsection{Tensile and C(T) Test Results for Several Orientations}

Experiments were conducted to provide tensile stress-strain curves and J-resistance curves at $288 \mathrm{C}$ $(550 \mathrm{~F})$ at several different specimen orientations for a 4-inch nominal diameter seamless carbon steel pipe, DP2-F11 (A333 Grade 6). This pipe was shown previously to have stringer-type inclusions that are at an angle of approximately 24 degrees to the pipe axis (Ref. 2.11). A description of Pipe DP2F11 appears in Table 2.1 and the chemical composition in Table 2.2.

\subsubsection{Tensile Tests}

Tensile tests were conducted at $288 \mathrm{C}(550 \mathrm{~F})$ on round-bar threaded-end tensile specimens machined from Pipe DP2-F11 in four different orientations. The fracture plane, i.e., the plane normal to the specimen axis, in those four orientations was at $0,45,66$, and 90 degrees to the circumferential direction, as is illustrated schematically in Figure 2.1a. Note that the 66-degree specimen 
Table 2.1 Description of carbon steel pipes used in study of anisotropy

\begin{tabular}{|c|c|c|c|c|}
\hline \multirow{2}{*}{$\begin{array}{l}\text { Pipe Ident. } \\
\text { No. }\end{array}$} & \multirow[b]{2}{*}{ Material Type } & \multirow[b]{2}{*}{ Schedule } & \multicolumn{2}{|c|}{ Pipe Dimensions, mm (inch) } \\
\hline & & & Nominal Diameter & Wall Thickness \\
\hline DP2-F9 & ASTM A333 Grade 6 & 100 & $254(10)$ & $18.3(0.719)$ \\
\hline DP2-F11 & ASTM A333 Grade 6 & 80 & $102(4)$ & $8.60(0.337)$ \\
\hline DP2-F26 & ASTM A515 Grade 60 & 60 & $711(28)$ & $22.2(0.875)$ \\
\hline DP2-F29 & ASTM A106 Grade B & 100 & $406(16)$ & $26.2(1.031)$ \\
\hline DP2-F30 & ASTM A106 Grade B & 120 & $152(6)$ & $14.3(0.562)$ \\
\hline DP2-F32 & API-5LX65 & N.A. & $1067(42)$ & $15.9(0.625)$ \\
\hline
\end{tabular}

N.A. $=$ Not applicable

Table 2.2 Chemical composition of carbon steel pipes used in study of anisotropy

\begin{tabular}{cllllll}
\hline & \multicolumn{5}{c}{ Weight Percentage for Indicated Pipe } \\
\cline { 2 - 7 } Element & $\begin{array}{c}\text { Pipe } \\
\text { DP2-F9 }\end{array}$ & $\begin{array}{c}\text { Pipe } \\
\text { DP2-F11 }\end{array}$ & $\begin{array}{c}\text { Pipe } \\
\text { DP2-F26 }\end{array}$ & $\begin{array}{c}\text { Pipe } \\
\text { DP2-F29 }\end{array}$ & $\begin{array}{c}\text { Pipe } \\
\text { DP2-F30 }\end{array}$ & $\begin{array}{c}\text { Pipe } \\
\text { DP2-F32 }\end{array}$ \\
\hline $\mathrm{C}$ & 0.14 & 0.21 & 0.13 & 0.28 & 0.15 & 0.12 \\
$\mathrm{Mn}$ & 0.99 & 0.84 & 0.80 & 0.82 & 0.65 & 1.39 \\
$\mathrm{P}$ & 0.008 & 0.010 & 0.009 & 0.010 & 0.012 & 0.009 \\
$\mathrm{~S}$ & 0.024 & 0.015 & 0.027 & 0.023 & 0.014 & 0.012 \\
$\mathrm{Si}$ & 0.20 & 0.19 & 0.25 & 0.18 & 0.20 & 0.19 \\
$\mathrm{Cu}$ & 0.076 & 0.035 & 0.12 & 0.088 & 0.28 & 0.032 \\
$\mathrm{Sn}$ & 0.014 & 0.001 & 0.007 & 0.011 & 0.018 & 0.001 \\
$\mathrm{Ni}$ & 0.12 & 0.006 & 0.13 & 0.11 & 0.14 & 0.013 \\
$\mathrm{Cr}$ & 0.12 & 0.027 & 0.13 & 0.14 & 0.18 & 0.010 \\
$\mathrm{Mo}$ & 0.042 & 0.012 & 0.040 & 0.041 & 0.055 & 0.009 \\
& & & & & & \\
$\mathrm{Al}$ & 0.018 & 0.030 & 0.003 & 0.000 & 0.010 & 0.011 \\
$\mathrm{~V}$ & 0.000 & 0.000 & 0.000 & 0.001 & 0.001 & 0.057 \\
$\mathrm{Cb}$ & 0.000 & 0.000 & 0.000 & 0.000 & 0.000 & 0.046 \\
$\mathrm{Zr}$ & 0.000 & 0.000 & 0.000 & 0.000 & 0.000 & 0.000 \\
$\mathrm{Ti}$ & 0.000 & 0.000 & 0.000 & 0.000 & 0.000 & 0.001 \\
$\mathrm{~B}$ & 0.0001 & 0.0000 & 0.0001 & 0.0001 & 0.0000 & 0.0001 \\
$\mathrm{Co}$ & 0.006 & 0.000 & 0.006 & 0.005 & 0.008 & 0.012 \\
$\mathrm{~W}$ & 0.00 & 0.00 & 0.00 & 0.00 & 0.00 & N.D. \\
$\mathrm{Pb}$ & 0.00 & 0.00 & 0.00 & 0.00 & 0.00 & 0.00 \\
$\mathrm{Ca}$ & $\mathrm{N} . \mathrm{D}$. & $\mathrm{N} . \mathrm{D}$. & N.D. & N.D. & N.D. & 0.0000 \\
\hline
\end{tabular}

N.D. $=$ Not determined 


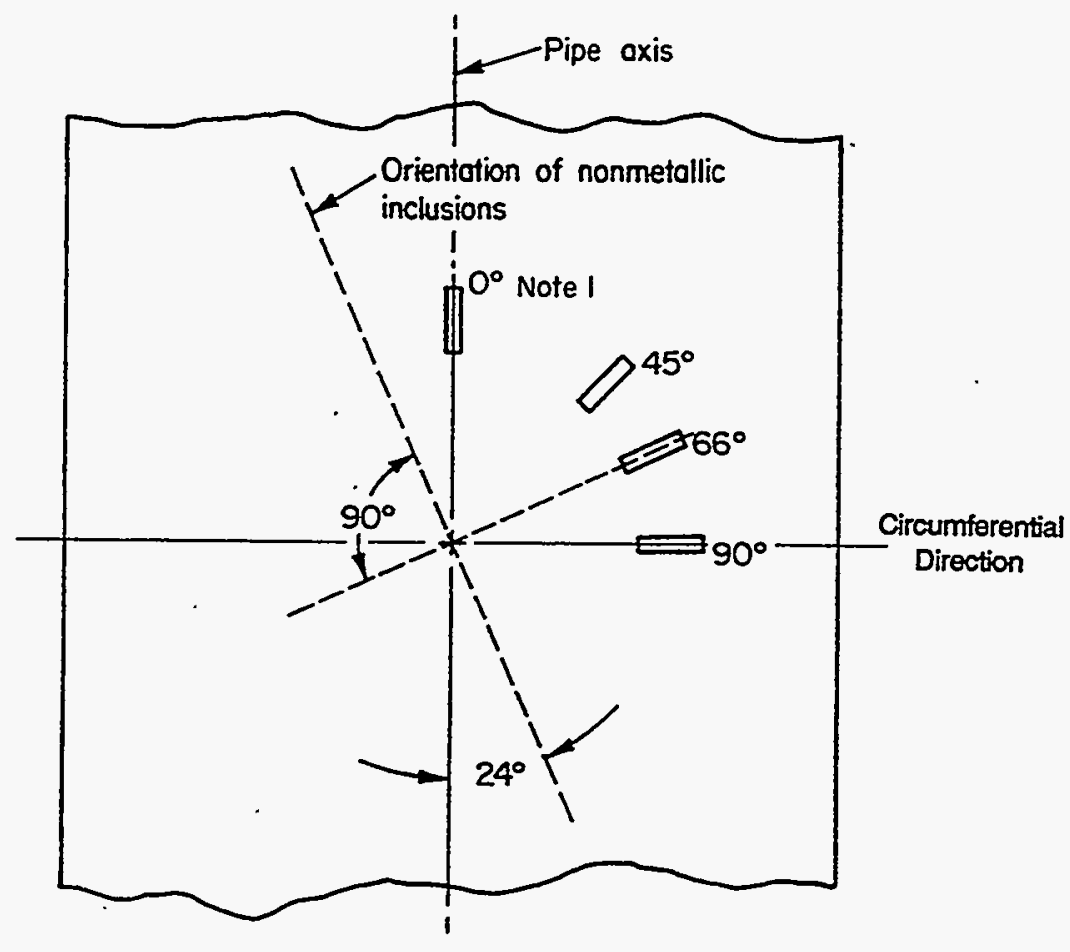

(a) Tensile specimens

Note 1:

Number adjacent to tensile specimen indicates the angle between the crack plane and the circumferential direction of pipe.

Note 2:

Number adjacant to $C(T)$ specimen indicates the angle between the specimen crack direction and the circumferential direction of pipe.

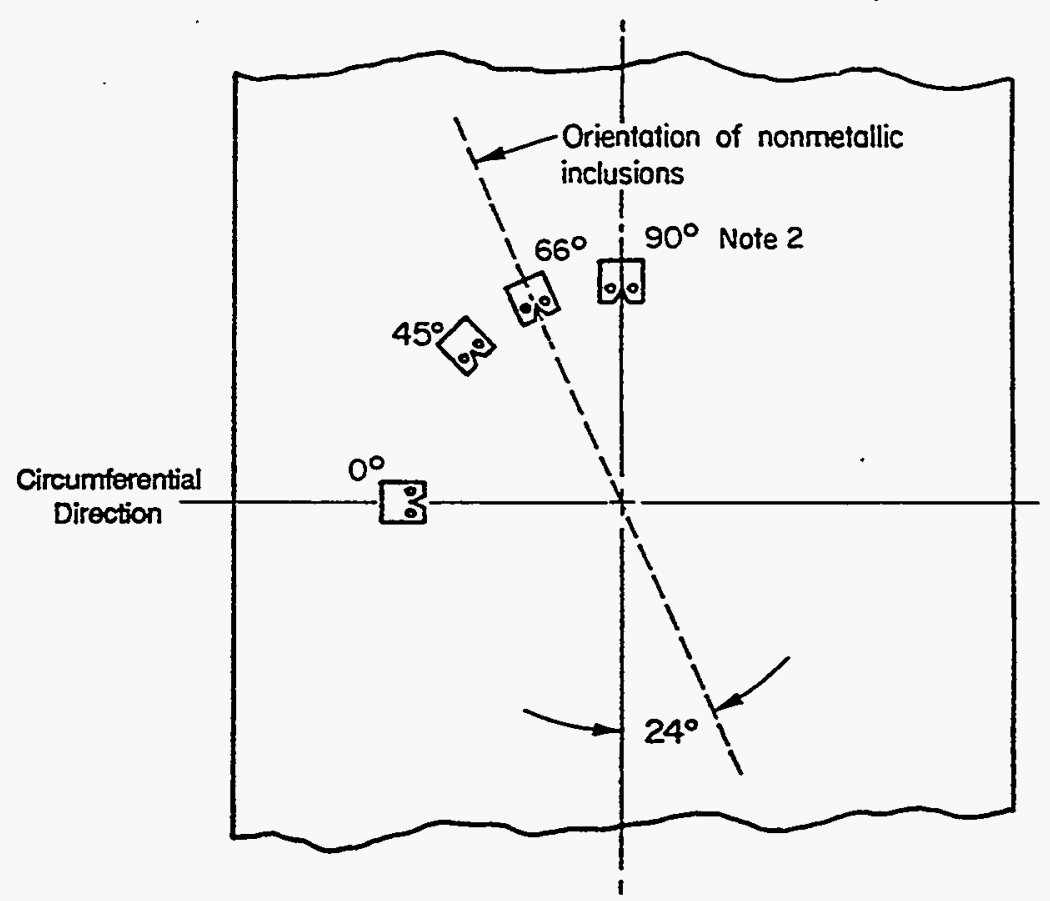

(b) $\mathrm{C}(\mathrm{T})$ specimens

Figure 2.1 Orientation of skewed specimens machined from Pipe DP2-F11 
had its fracture plane parallel with the long axis of the stringer-type inclusions. Tensile tests were conducted at a strain rate of approximately $3 \times 10^{-4} \mathrm{~s}^{-1}$ in a servohydraulic test machine. The data were analyzed to obtain 0.2-percent offset yield strength, ultimate tensile strength, elongation, and reduction of area. In addition, complete stress-strain curves were obtained from each test.

The results of tensile tests at four different orientations are presented in Figures 2.2 and 2.3. Figure 2.2 shows yield strength, ultimate tensile strength, elongation, and reduction of area as functions of specimen angle relative to the pipe axis. Figure 2.3 shows engineering stress-strain curves for the various orientations.

The most noteworthy feature of the tensile results is the relatively high yield strength and low fracture elongation of the specimen whose crack plane was parallel with the axis of the inclusions, that is, the 66-degree specimen.

\subsubsection{Compact Specimen Tests}

Compact specimens were prepared to assess the crack growth resistance in four different orientations $(0,45,66$, and 90 degrees, as is illustrated schematically in Figure 2.1b). Note in the figure that the 66-degree specimen had the crack extending along the major axis of the stringer-type inclusions. The compact specimens were $0.4 \mathrm{~T}$ planform size by $5.1 \mathrm{~mm}(0.2$ inch) thick.

An additional piece of information pertaining to specimen-orientation effects on crack growth resistance was obtained for another pipe, DP2-F30 (6-inch nominal diameter A106 Grade B; see Tables 2.1 and 2.2). One of the $C(T)$ specimens machined for another study was machined in the C-L orientation, that is, the crack grew in the direction of the pipe axis rather than in the circumferential direction. Metallographic examination of Pipe DP2-F30 showed that the stringer-type inclusions were aligned with the pipe axis.

The compact specimens were tested in crosshead control in a screw-driven Instron machine at $288 \mathrm{C}$ $(550 \mathrm{~F})$. The crosshead speed was selected to cause crack initiation in approximately 5 to 10 minutes. Data obtained during each test included load, load-line displacement, and direct-current electric potential, the latter to indicate the point of crack initiation and the amount of crack extension. To estimate the point of crack initiation, graphs of electric potential (U) versus load-line displacement (LLD) and load versus $U$ were examined for points of slope change prior to maximum load. Engineering judgment was then applied to estimate $U_{o}$, the value of $U$ at crack initiation. Crack growth beyond initiation was calculated from the ratio $\mathrm{U} / \mathrm{U}_{\mathrm{o}}$ using the Johnson expression (Ref. 2.12). Note that the term for the spacing of the voltage probes $\left(2 y^{\prime}\right)$ in the Johnson expression was allowed to increase in proportion to the LLD as the test progressed, because experience has shown that this procedure provides a more accurate estimate of the crack growth (Ref. 2.13).

The procedures used to calculate $J$ values and J-resistance curves from each compact-specimen test were those specified in ASTM E1152-87, Standard Test Method for Determining J-R Curves. The value of $\mathrm{J}$ at crack initiation, $\mathrm{J}_{\mathrm{i}}$, as used in this report, refers to the onset of crack extension rather than to a finite amount of crack extension. The slope of the J-R curve, $\mathrm{dJ} / \mathrm{da}$, was calculated for crack extensions in the range of 0.15 to $1.5 \mathrm{~mm}$ ( 0.006 to 0.060 inch). 

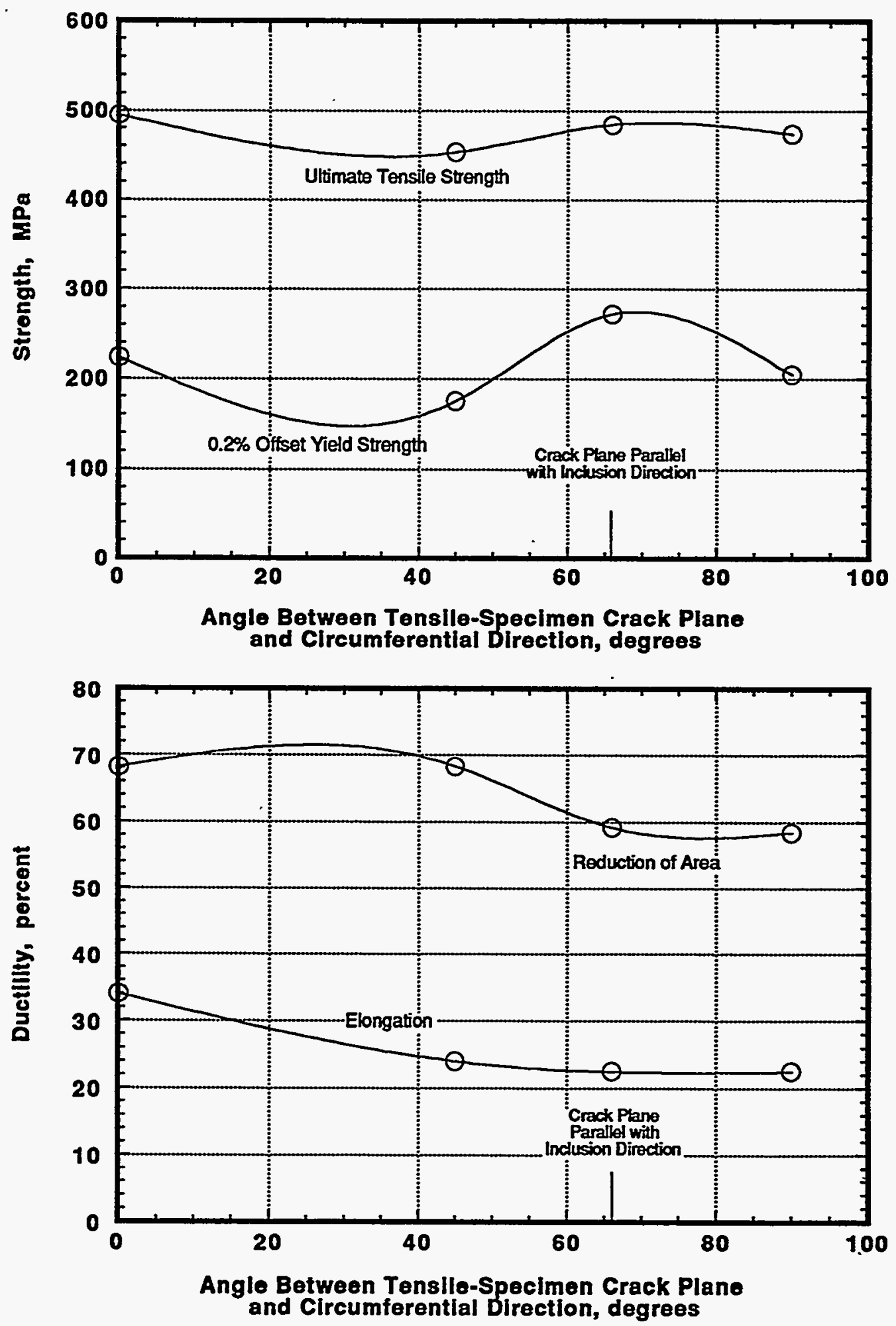

Figure 2.2 Tensile properties as functions of specimen orientation for Pipe DP2-F11 (A333 Grade 6) 


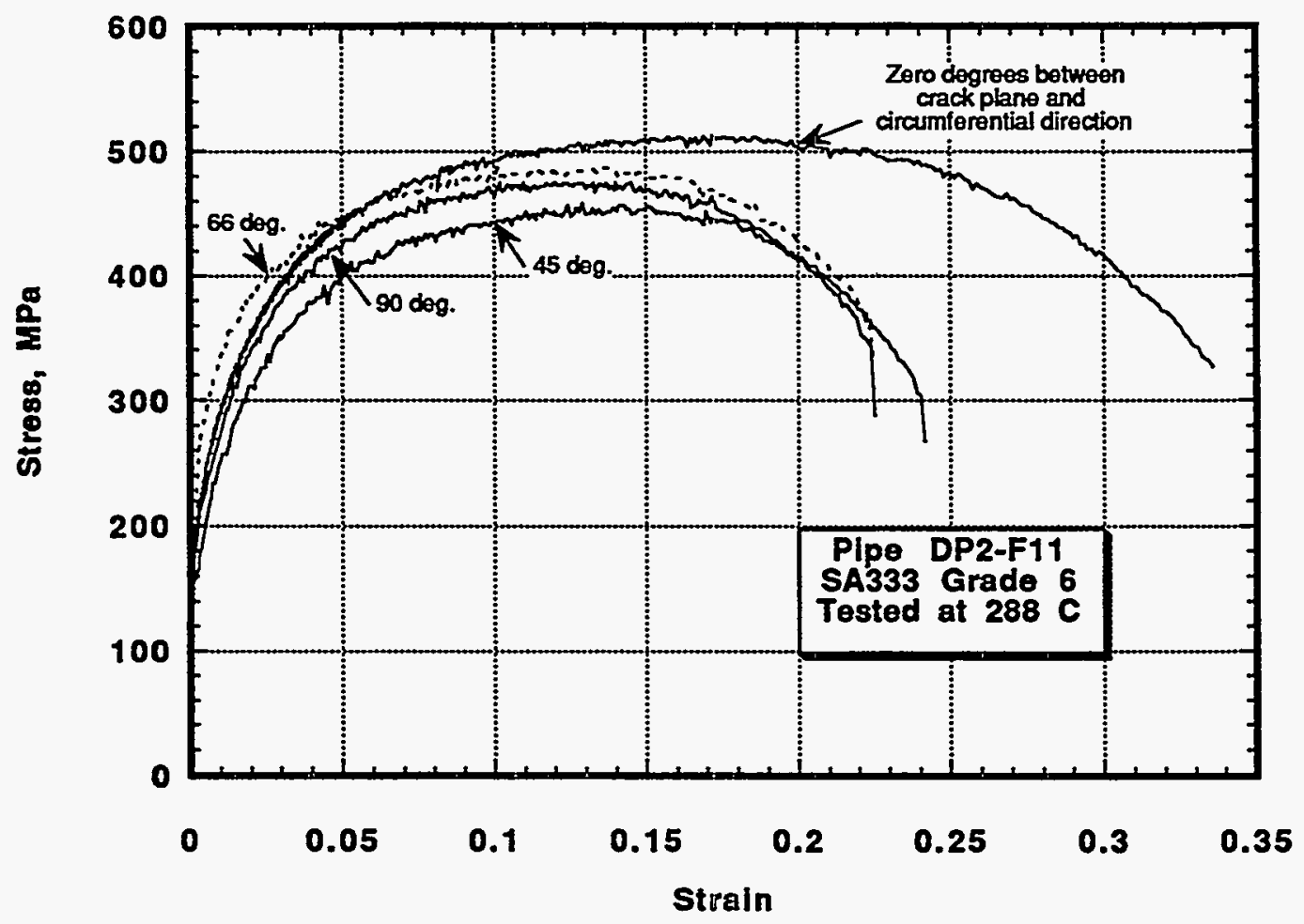

Figure 2.3 Engineering stress-strain curves for several different tensile specimen orientations in Pipe DP2-F11 
The results of compact specimen tests at $288 \mathrm{C}(550 \mathrm{~F})$ for various orientations for Pipe DP2-F11 are presented in Figures 2.4 through 2.6. Figure 2.4 shows load-displacement curves, Figure 2.5 shows Jresistance curves, and Figure 2.6 shows $\mathrm{J}_{\mathrm{i}}$ and $\mathrm{d} J / \mathrm{da}$ values as a function of the angle of the crack relative to the circumferential direction. Each of the three figures shows, as expected, that the specimen in which the crack was aligned with the stringer-type inclusions exhibited the lowest crack growth resistance, both in terms of $\mathrm{J}_{\mathfrak{i}}$ and $\mathrm{d} / \mathrm{da}$.

Results for Pipe DP2-F30, tested at two different orientations, are presented in Figures 2.7 through 2.9. Figure 2.7 shows load-displacement curves, Figure 2.8 shows J-resistance curves, and Figure 2.9 shows $\mathrm{J}_{\mathrm{i}}, \mathrm{J}$ at $2 \mathrm{~mm}(0.08 \mathrm{inch})$ of crack extension, and $\mathrm{dJ} / \mathrm{da}$ values at the two different orientations. As was expected, the resistance to crack extension was lower in the C-L orientation than in the L-C orientation.

\subsection{Dependence of Anisotropy on Inclusion Characteristics}

Four carbon steel pipes were subjected to metallographic examination to establish the types of inclusions present and their size, shape, and orientation. The same pipes were subjected to Charpy Vnotch impact testing of specimens that were machined from the pipe in four different orientations. A fifth pipe (Pipe DP2-F11) had been subjected to metallographic examination in the Degraded Piping

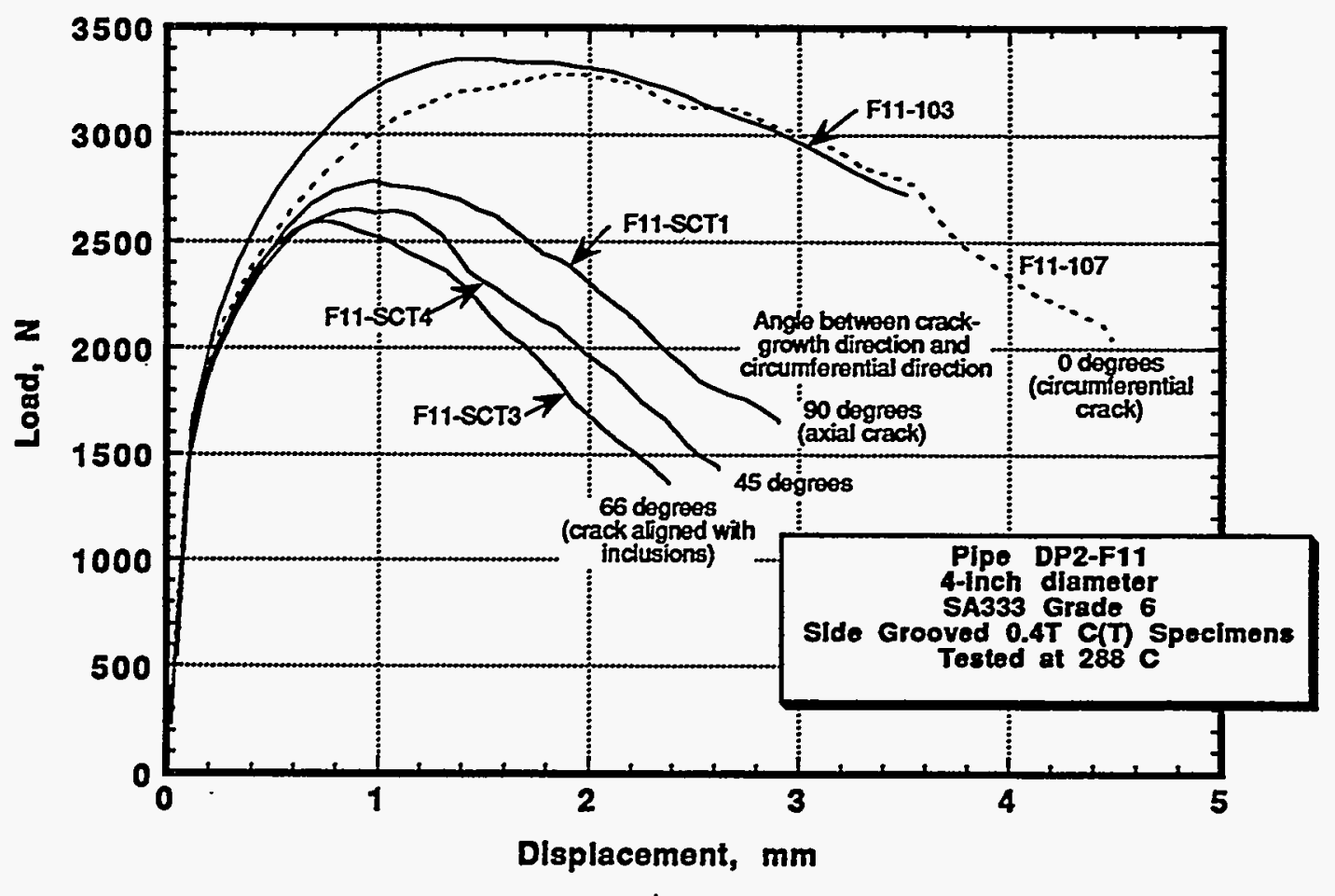

Figure 2.4 Load versus displacement curves for several different C(T) specimen orientations in Pipe DP2-F11 


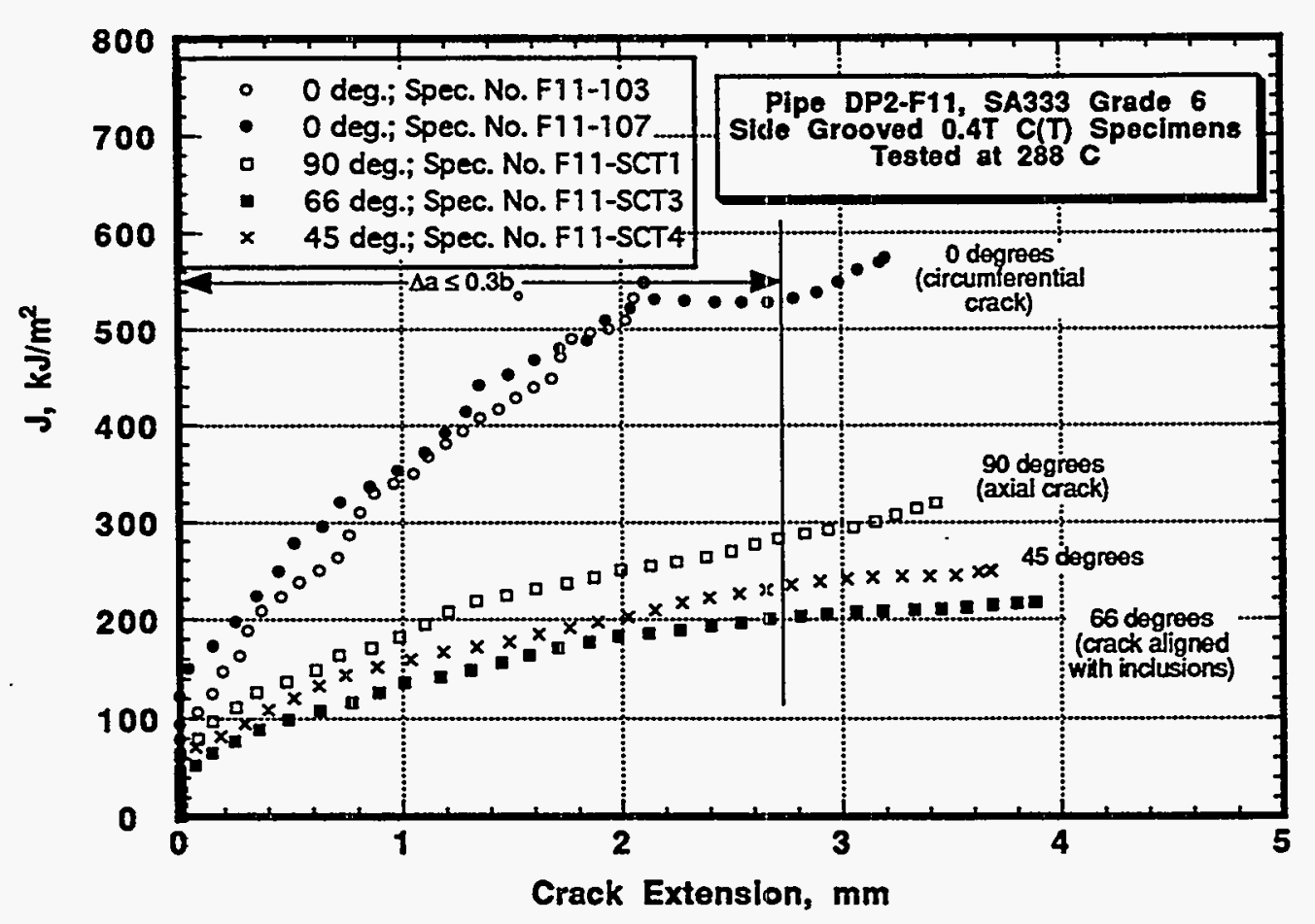

Figure 2.5 J-resistance curves for several different $\mathrm{C}(\mathrm{T})$ specimen orientations in Pipe DP2-F11 


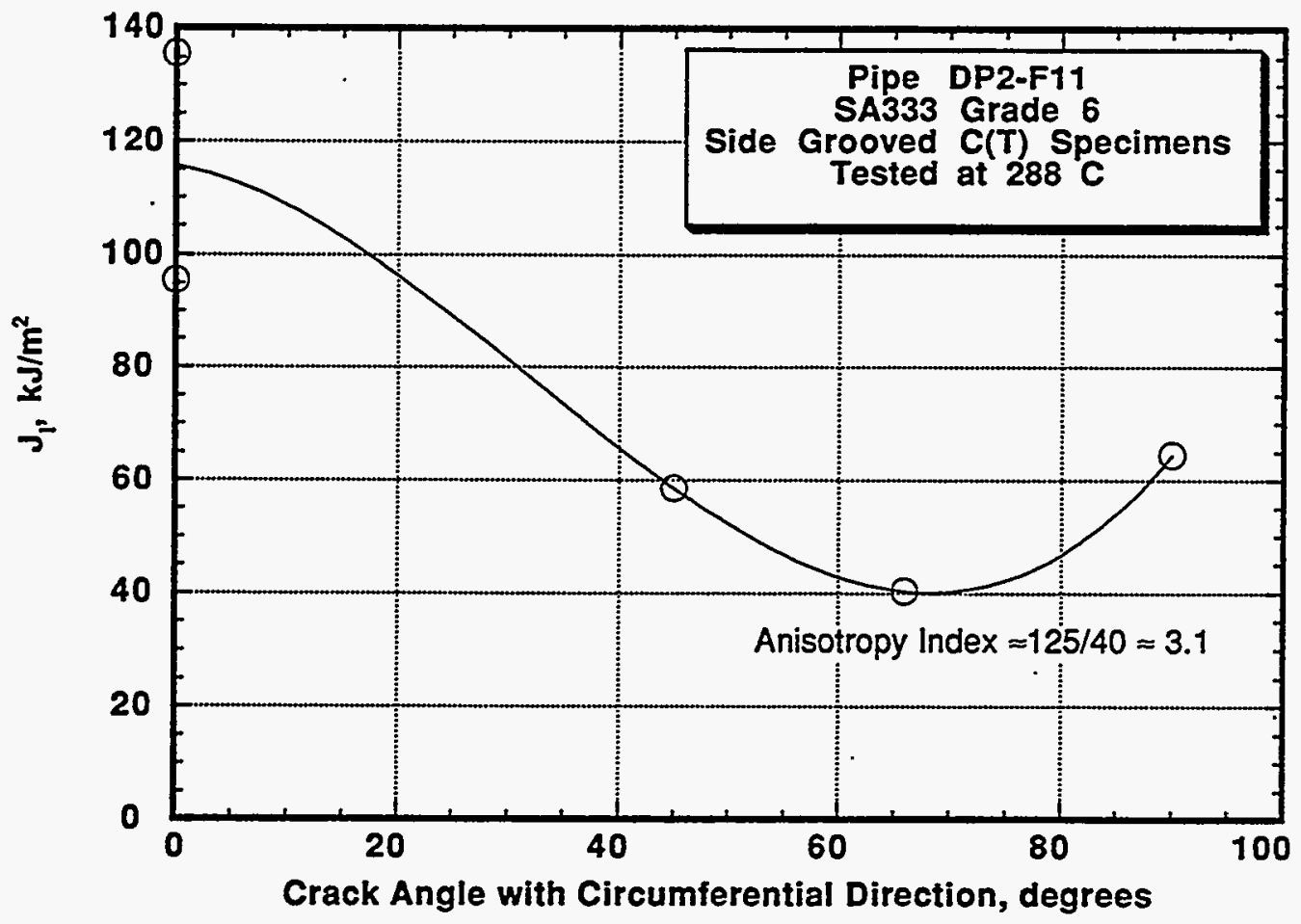

(A) $\mathbf{J}_{\mathbf{i}}$

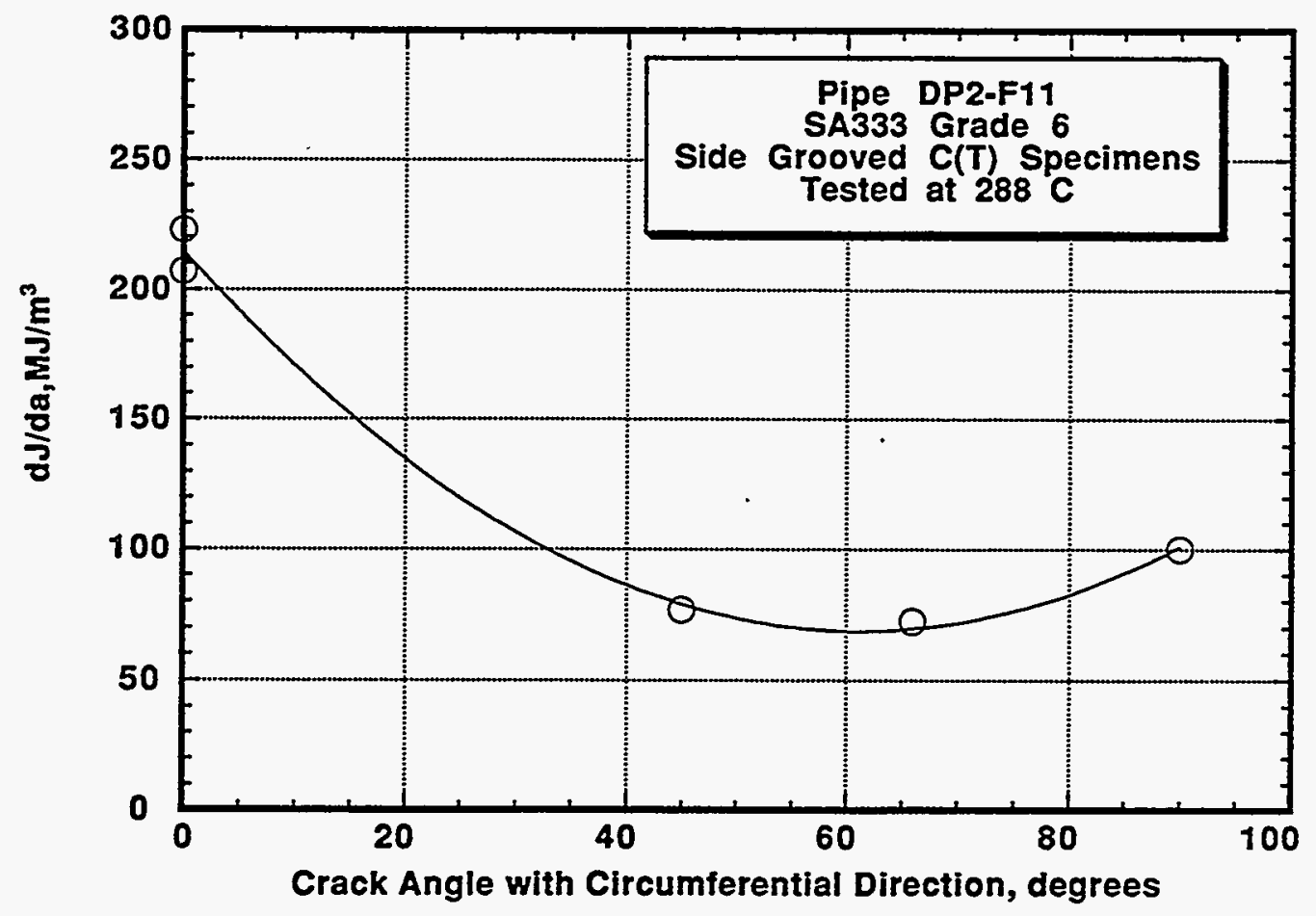

(b) $\mathbf{d J} / \mathrm{da}$

Figure 2.6 $J_{i}$ and $d J / d a$ as functions of $C(T)$ specimen orientation in Pipe DP2-F11 


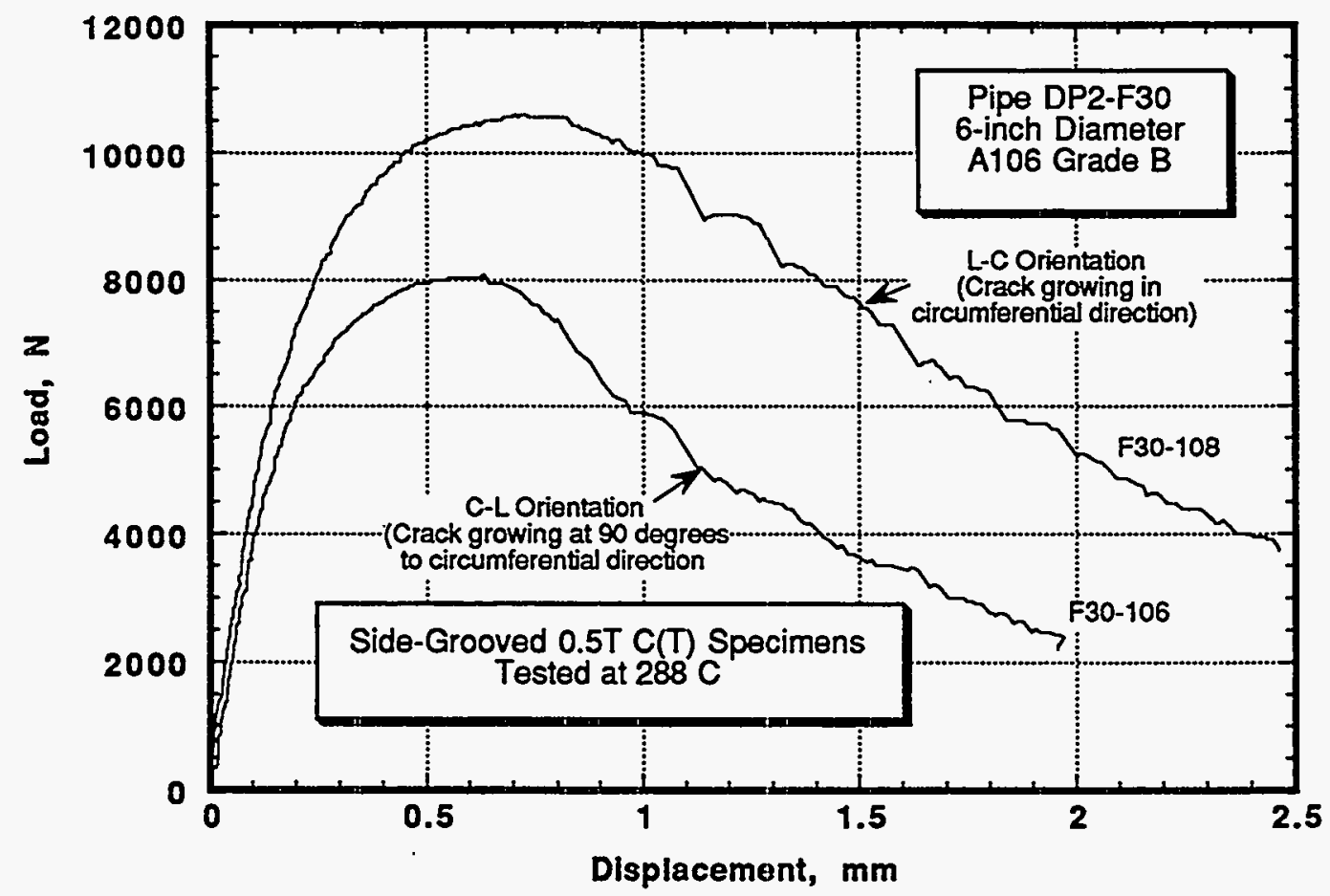

Figure 2.7 Load versus displacement curves for two different C(T) specimen orientations in Pipe DP2-F30

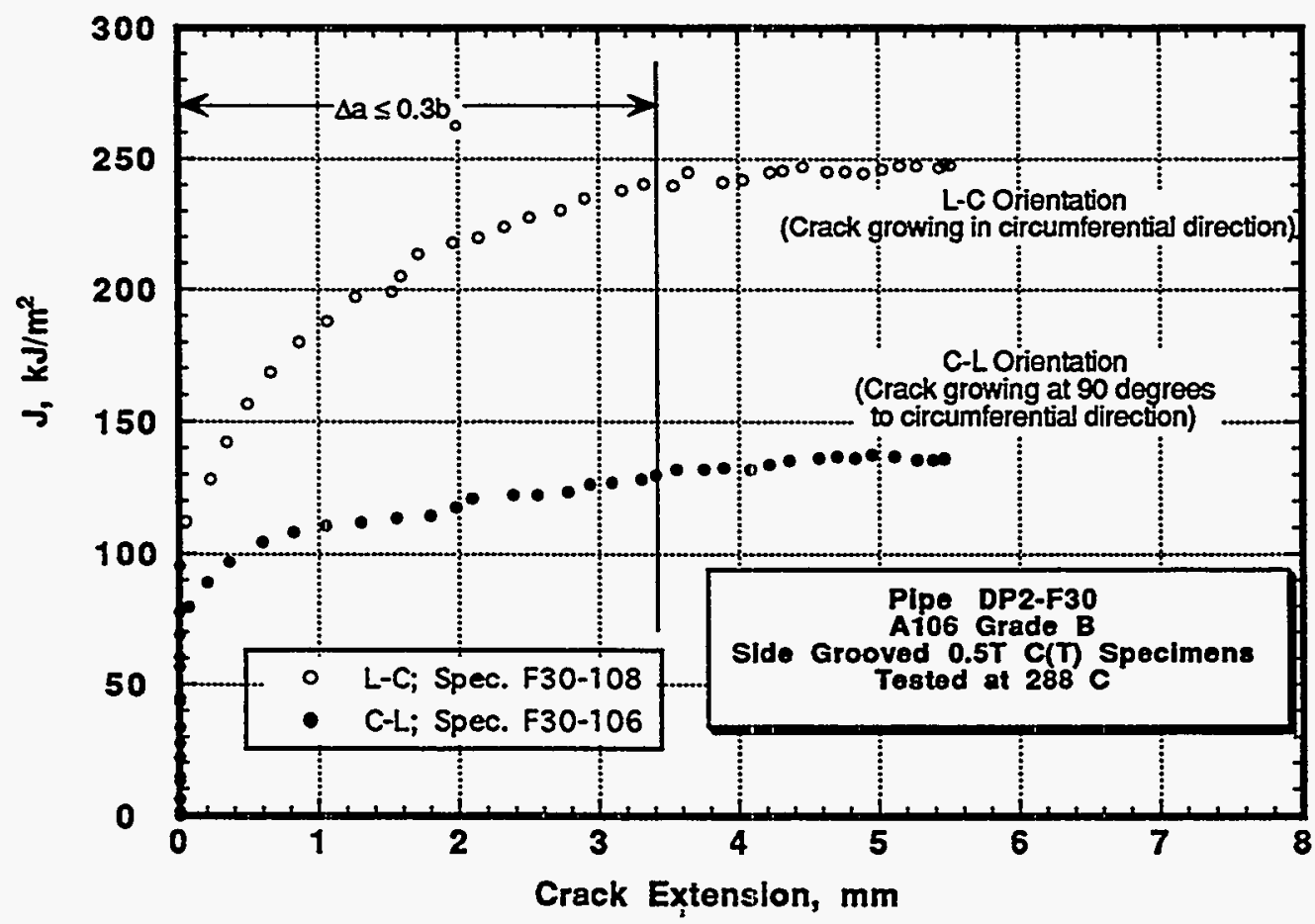

Figure 2.8 J-resistance curves for two different $\mathrm{C}(\mathrm{T})$ specimen orientations in Pipe DP2-F30 


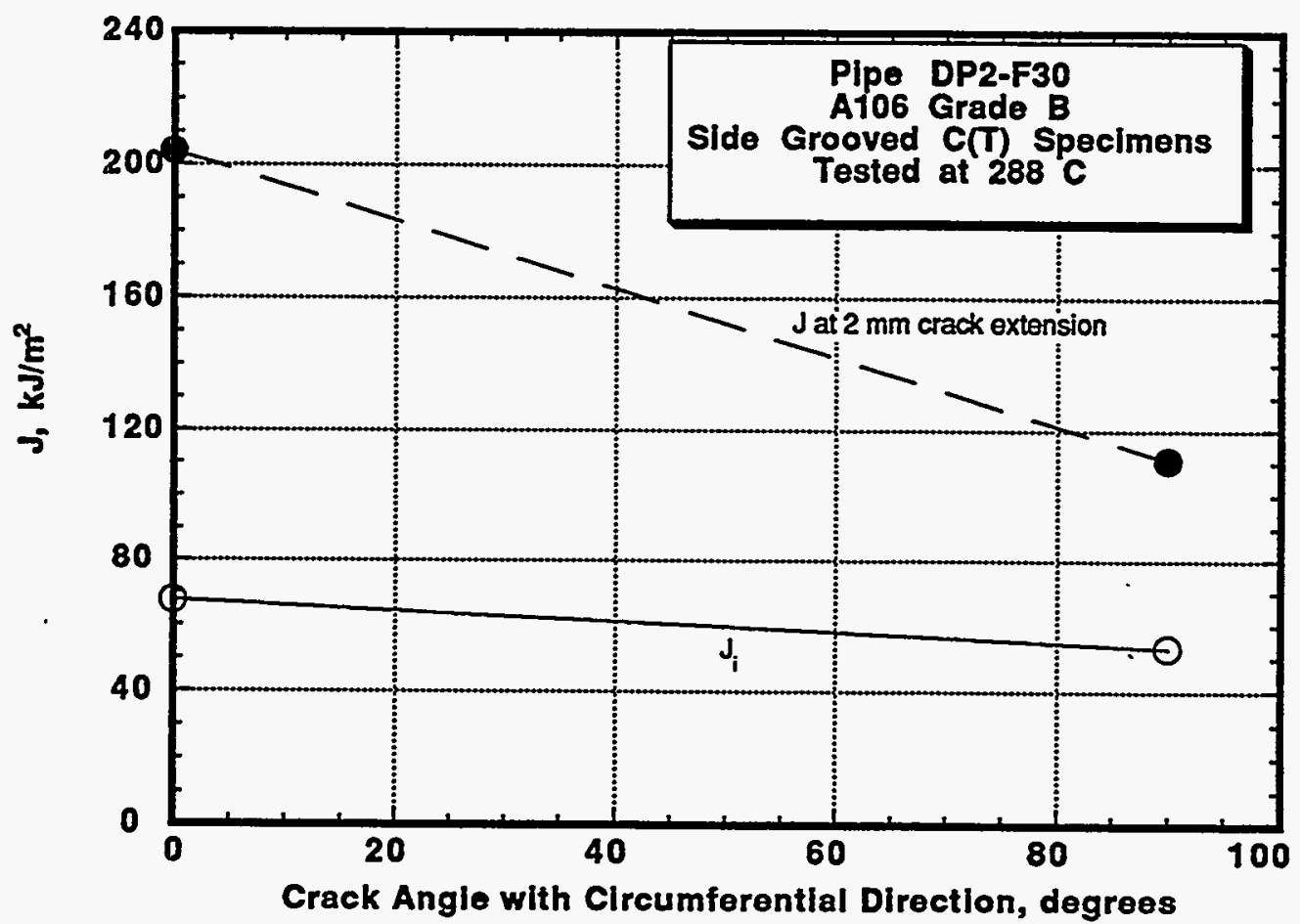

(a) $J_{i}$ and $J$ at $2 \mathrm{~mm}$ crack extension

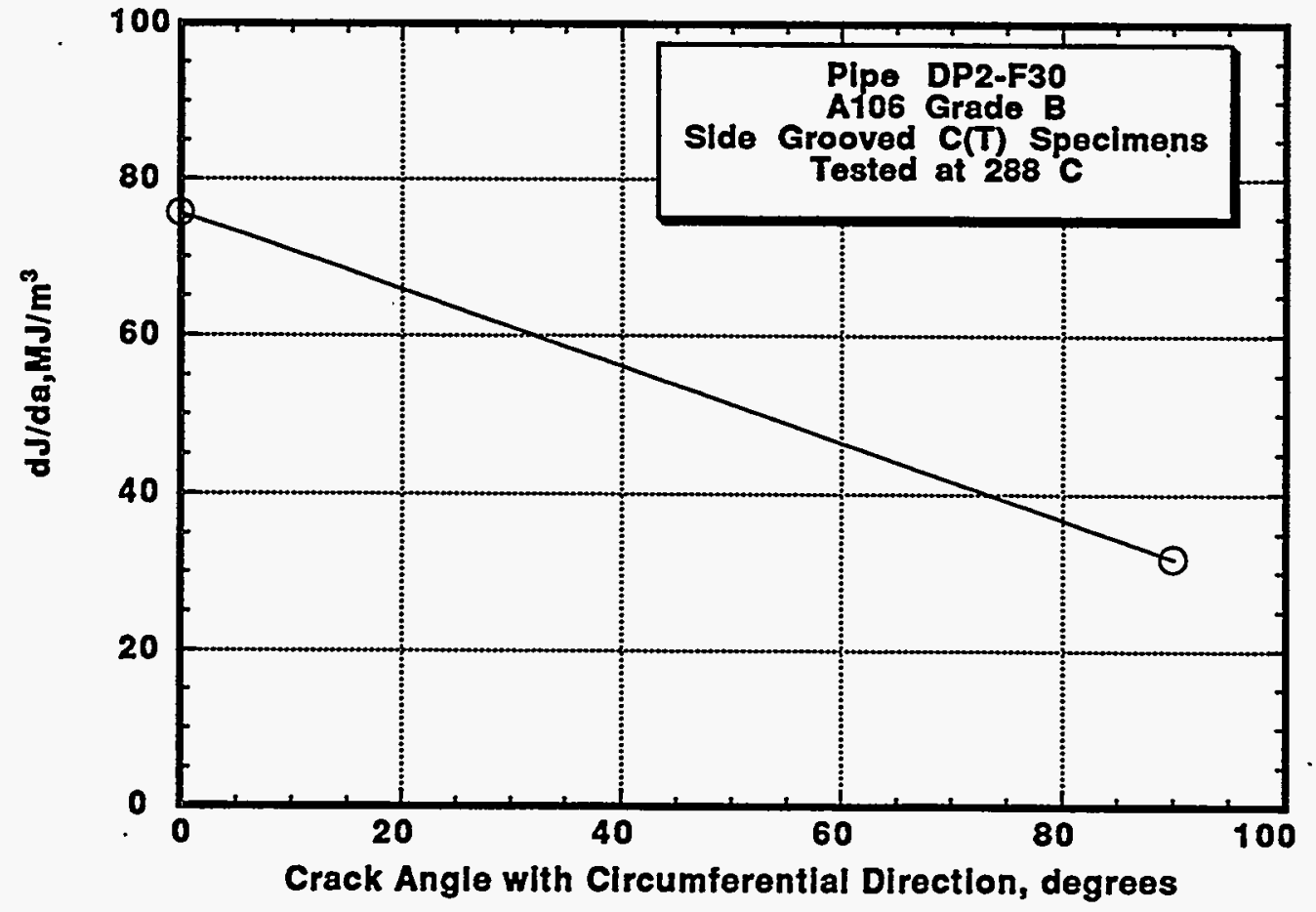

(b) $\mathbf{d J} / \mathbf{d a}$

Figure $2.9 J_{i}, J$ at $\Delta a=2 \mathrm{~mm}$, and $\mathrm{dJ} / \mathrm{da}$ as functions of $\mathrm{C}(\mathrm{T})$ specimen orientation in Pipe DP2-F30 
Program (Ref. 2.11) but not to Charpy testing because of that pipe's relatively small size. A sixth pipe (Pipe DP2-F32) was subjected to Charpy testing in two orientations but not to metallographic examination. The six carbon steel pipes are described in Table 2.1 and their chemical compositions are given in Table 2.2 .

\subsubsection{Inclusion Characteristics}

Specimens that measured approximately 38 by $25 \mathrm{~mm}$ (1-1/2 by 1 inch) were cut from four carbon steel pipes (DP2-F9, -F26, -F29, and -F30) such that the longer dimension was parallel with the pipe axis. The outside surface of each specimen was ground flat and that surface was then prepared metallographically. The unetched polished surface was examined in an optical microscope to determine the nature of the nonmetallic inclusions. Photomicrographs at $100 \mathrm{X}$ and $500 \mathrm{X}$ magnification were taken of at least three areas selected at random on each specimen. Subsequent to the examination in the optical microscope, the specimens were subjected to imaging and X-ray mapping in a JEOL $840 \mathrm{~A}$ scanning electron microscope to determine the chemical makeup of selected inclusions, using energy dispersive $\mathrm{X}$-ray spectrometry.

Of the five carbon steel pipes examined metallographically (four in this study and one in the Degraded Piping Program), only one was found to have inclusions that were at a significant angle to the pipe axis. That pipe was DP2-F11, a nominal 4-inch diameter A333 Grade 6 pipe, which was also subjected to tensile and $\mathrm{C}(\mathrm{T})$ tests to determine the effect of specimen orientation on strength and crack growth resistance. The results of those tests were described previously in Section 2.2 and indicated that the minimum toughness was associated with a crack growing parallel with the inclusions, which were inclined at an angle of approximately 24 degrees to the pipe axis. In each of the other pipes examined, the inclusions were nominally aligned with the pipe axis.

As is indicated in Table 2.3, the general shapes of the inclusions varied among the five pipes examined. The two in which the stringer-type inclusions were the most elongated were DP2-F11 and -F30. Pipe DP2-F9 contained a mixture of short, medium, and long stringers, Pipe DP2-F29 had short to medium stringers, and Pipe DP2-F26 showed little evidence of stringer-type inclusions. Examples of inclusions in each of the five steels at a magnification of 500X are shown in Figure 2.10.

Examination of the metallographically prepared specimens in the scanning electron microscope using energy dispersive $\mathrm{X}$-ray spectrometry indicated the inclusions to be mainly manganese sulfides, along with some aluminum oxides, and occasional silicates. An example of manganese sulfide inclusions in Pipe DP2-F9 is shown in Figure 2.11a at 1540X magnification. The X-ray dot maps in Figures 2.11b, $\mathrm{c}$, and $\mathrm{d}$, in which the bright dots indicate the presence of manganese, sulfur, and aluminum, respectively, confirm that the inclusions shown in Figure 2.11a are, indeed, manganese sulfides.

\subsubsection{Charpy V-Notch Impact Tests}

Charpy V-notch impact specimens were machined from four different carbon steel pipes so that the crack would grow at an angle of $0,30,60$, or 90 degrees to the circumferential direction of the pipe. Duplicate specimens were tested at a temperature which produced 100 percent shear fracture; for Pipes 
Table 2.3 Appearance of stringer-type inclusions in pipes used in study of anisotropy

\begin{tabular}{|c|c|c|}
\hline $\begin{array}{l}\text { Pipe Ident. } \\
\text { No. }\end{array}$ & Material Type & $\begin{array}{c}\text { General Shapes of Stringer-Type } \\
\text { Inclusions }\end{array}$ \\
\hline DP2-F9 & A333 Grade 6 & $\begin{array}{l}\text { Mixture of short, medium, and long stringers } \\
\text { aligned with pipe axis }\end{array}$ \\
\hline DP2-F11 & A333 Grade 6 & $\begin{array}{l}\text { Numerous long stringers at an angle of }-24 \\
\text { degrees to the pipe axis }\end{array}$ \\
\hline DP2-F26 & A515 Grade 60 & Short stringers only, aligned with pipe axis \\
\hline DP2-F29 & A106 Grade B & $\begin{array}{l}\text { Mixture of short and medium stringers, aligned } \\
\text { with pipe axis }\end{array}$ \\
\hline DP2-F30 & A106 Grade B & Numerous long stringers aligned with pipe axis \\
\hline
\end{tabular}




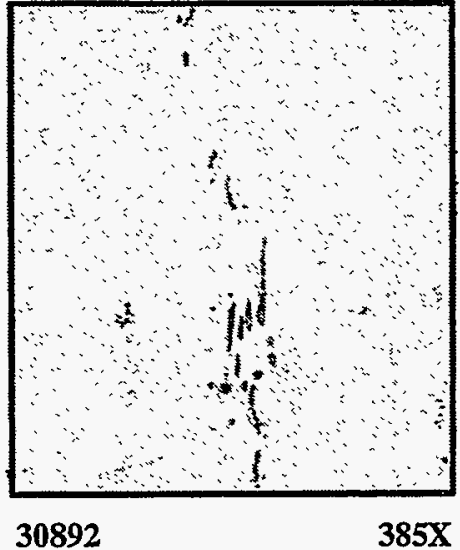

(a) Pipe DP2-F9 (A333 Grade 6)

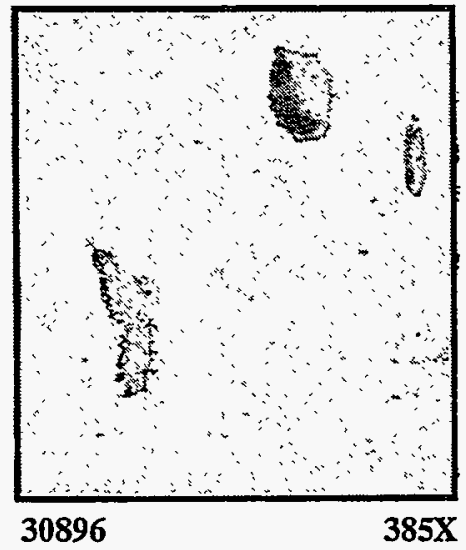

(c) Pipe DP2-F26 (A515 Grade 60)

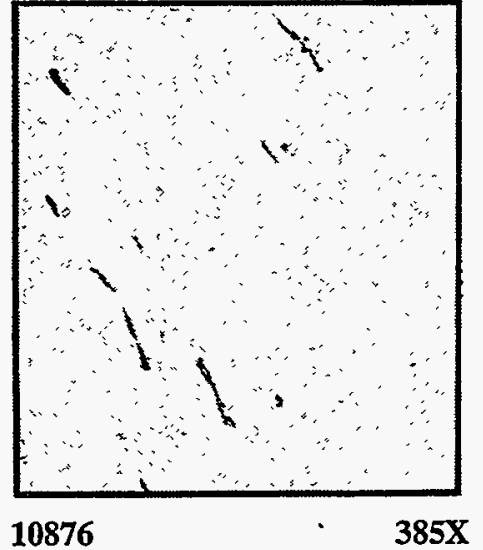

(b) Pipe DP2-F11 (A333 Grade 6)

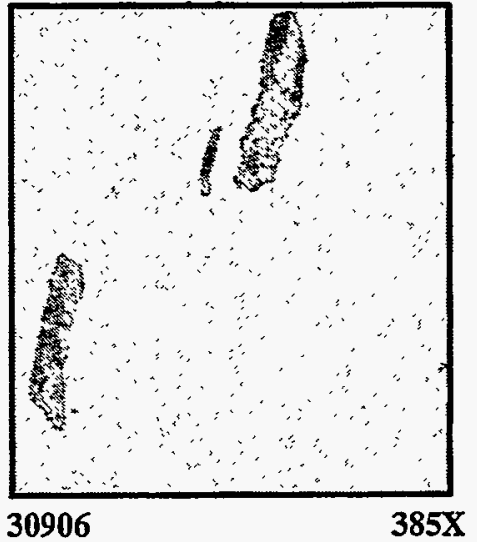

(d) Pipe DP2-F29 (A106 Grade B)
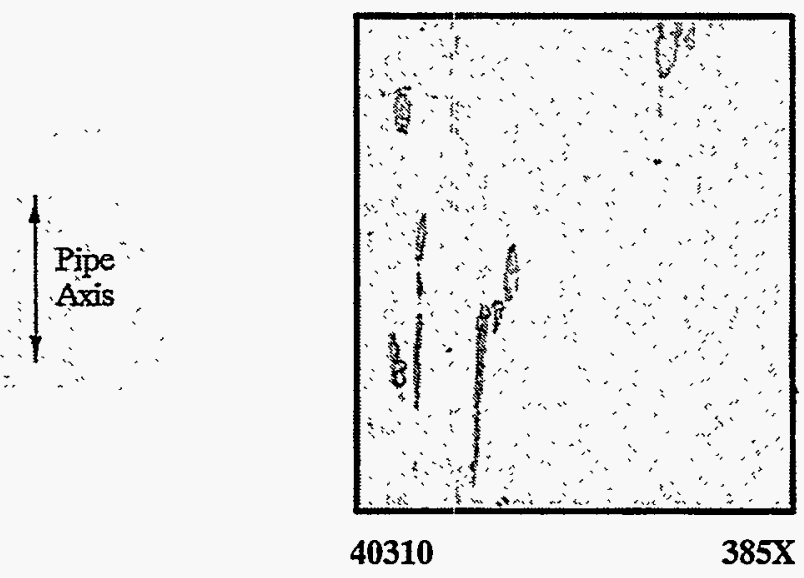

(e) Pipe DP2-F30 (A106 Grade B)

Figure 2.10 Photomicrographs of sulfide inclusions in carbon steel pipes 


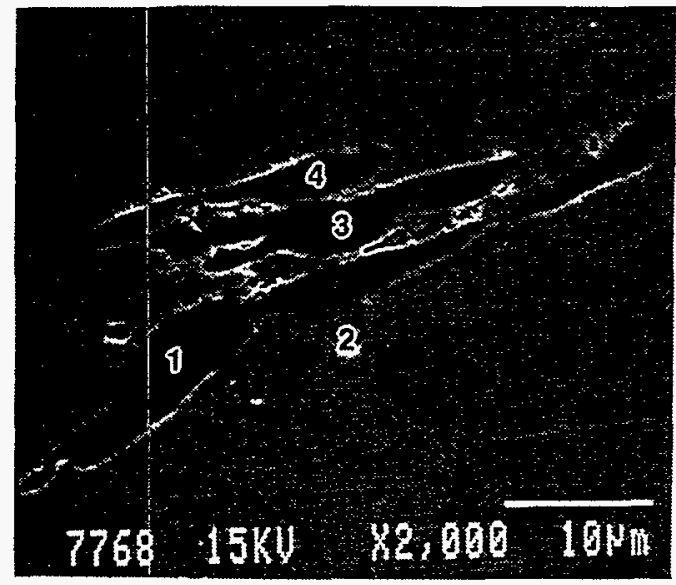

J7768

(a) SEM photographs of inclusions

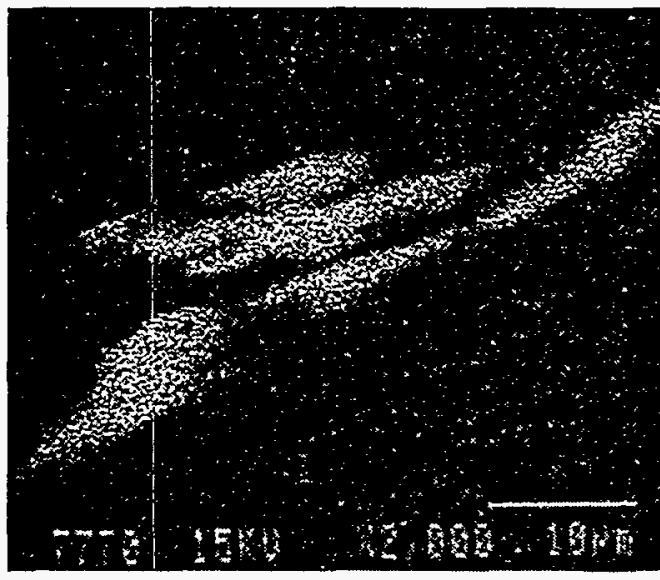

$\mathbf{J 7 7 7 0}$ $1540 \mathrm{X}$

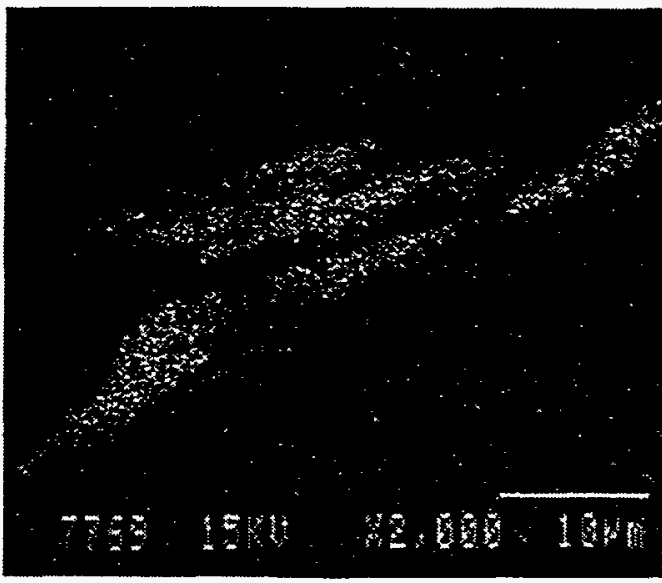

J7769

$1540 \mathrm{X}$

(b) X-ray dot map for manganese

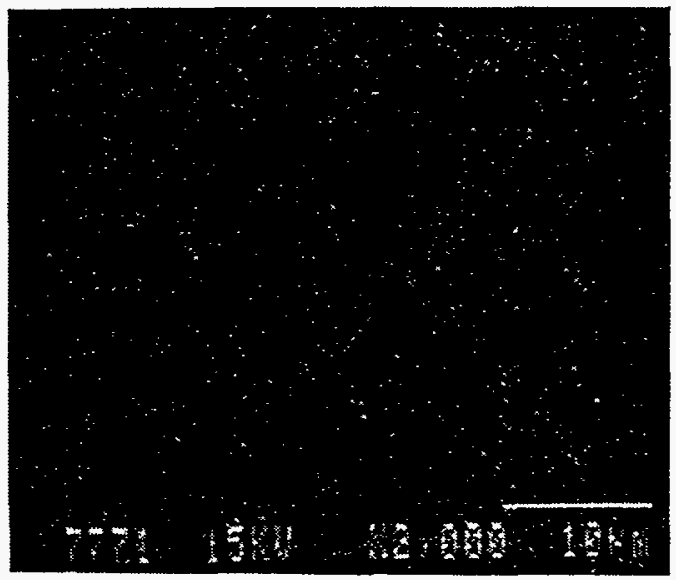

J7771

$1540 \mathrm{X}$

(d) X-ray dot map for aluminum

(c) X-ray dot map for sulfur 
DP2-F9, -F26, and -F29, that temperature was $38 \mathrm{C}(100 \mathrm{~F})$, whereas for Pipe DP2-F30, that temperature was $204 \mathrm{C}(400 \mathrm{~F})$. Data recorded included absorbed energy, fracture appearance, and lateral expansion.

The results of Charpy V-notch impact tests are shown in Figure 2.12. A strong effect of specimen orientation is evident; the toughness for a crack growing axially (transverse toughness, 90 degrees in Figure 2.12) ranged from approximately 30 to 55 percent of that for a crack growing circumferentially (longitudinal toughness, zero degrees). Those toughness ratios yielded Anisotropy Index values of approximately 1.8 to 3.3 , which are similar to those found for rolled steel plate in the literature review.

From the summary of results shown in Table 2.4, no clear picture emerges as to the effect of sulfur content on toughness anisotropy. The greatest value of Anisotropy Index, expressed as the ratio of longitudinal toughness to transverse toughness, was exhibited by Pipe DP2-F30, and the smallest value of the Anisotropy Index occurred in Pipe DP2-F29, despite the fact that Pipe DP2-F30 contains less sulfur. Inclusion shape, on the other hand, appears to have a predictable effect on toughness anisotropy. Pipe DP2-F30, which contains numerous, long, stringer-type inclusions, exhibited the greatest toughness anisotropy. Pipes DP2-F26 and -F29, on the other hand, which contain few, if any, long stringer-type inclusions, exhibited the least toughness anisotropy. Even in those less anisotropic pipes, however, the longitudinal toughness was nearly twice the transverse toughness.

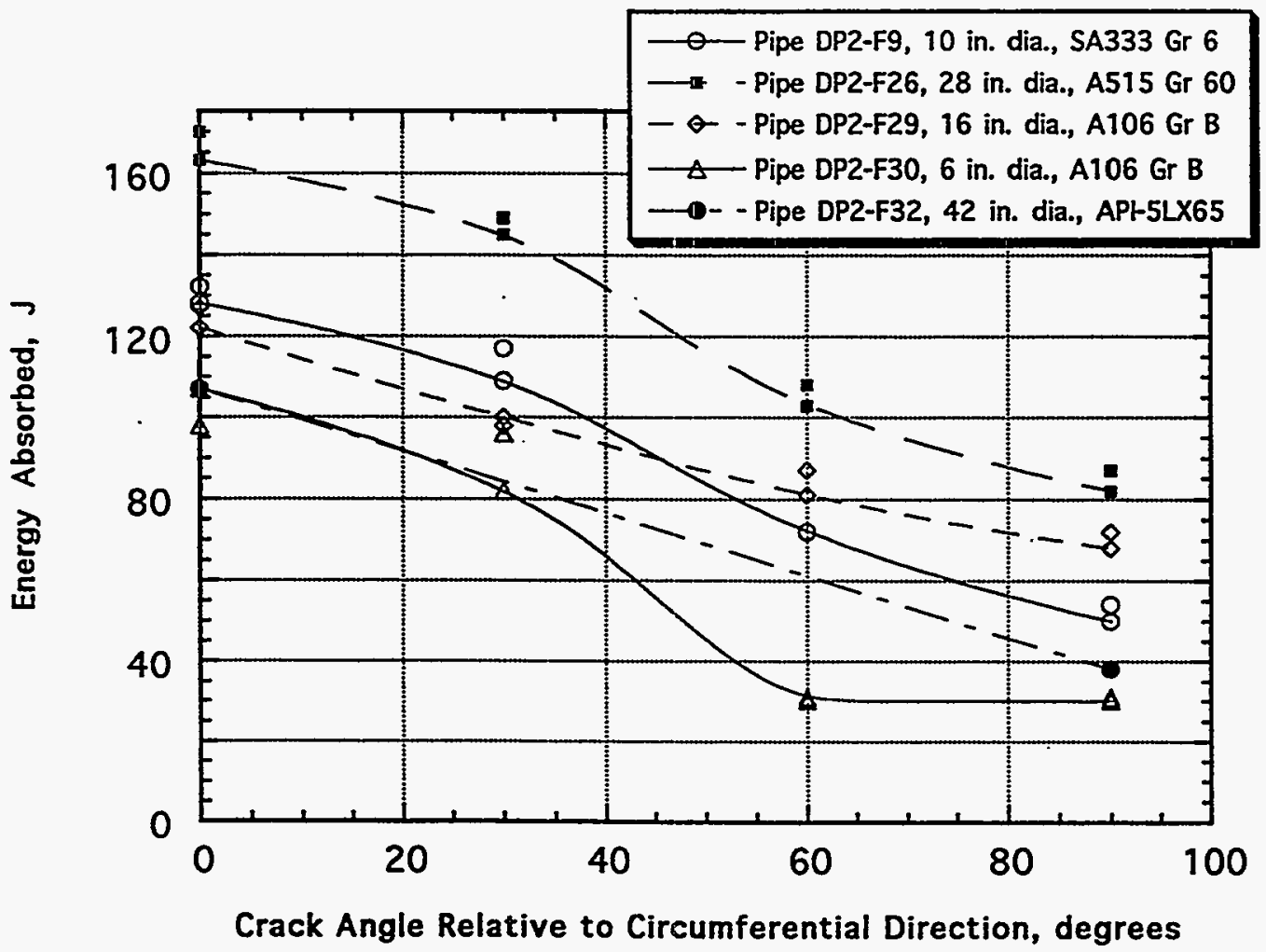

Figure 2.12 Energy absorbed by Charpy V-notch specimens as a function of orientation (Note: All fractures were $\mathbf{1 0 0}$ percent ductile) 
Table 2.4 Ratio of Iongitudinal to transverse toughness in Charpy V-notch impact specimens machined from carbon steel pipes

\begin{tabular}{ccccc}
\hline Pipe Ident. No. & Material Type & $\begin{array}{c}\text { Sulfur } \\
\text { Content }\end{array}$ & Stringer Type & $\begin{array}{c}\text { Anisotropy Index, } \\
\text { CVN }_{\text {long. }} \text { /CVN }\end{array}$ trans. \\
DP2-F9 & A333 Grade 6 & 0.024 & $\begin{array}{c}\text { Mixture of short, } \\
\text { medium, long length }\end{array}$ & 2.50 \\
DP2-F26 & A515 Grade 60 & 0.027 & Short & 1.96 \\
DP2-F29 & A106 Grade B & 0.023 & $\begin{array}{c}\text { Mixture of short and } \\
\text { medium length }\end{array}$ & 1.82 \\
DP2-F30 & A106 Grade B & 0.014 & Long & 3.40 \\
DP2-F32 & API-5LX65 & 0.012 & Not determined & 2.86 \\
\hline
\end{tabular}

\subsection{References}

2.1 Wilkowski, G. M. and others, "Short Cracks in Piping and Piping Welds," Battelle, NUREG/CR-4599, BMI-2173, Vol. 1, No. 2, December 1991.

2.2 Burnos, V. A., Vaschilo, T. P., and Balandina, L. E., "Evaluation of the Quality of the Metal of Pipes According to Impact Toughness with Anisotropy Taken into Account," Industrial Laboratory (USSR); English Translation of Zavodskaya Laboratoriya, Vol. 54, No. 5, pp 548550, May 1988.

2.3 Harada, S., Endo, T., and Kaseda, M., "Effects of Forging Ratio and Specimen Orientation on Elastic-Plastic Fracture Toughness of Thick Forged Steel Plates," Role of Fracture Mechanics in Modern Technology, G. C. Sih, H. Nisitani, and T. Ishihara, Eds., Elsevier Science Publishers, pp 485-496, 1987.

2.4 Kramer, G. S., Wilkowski, G. M., and Maxey, W. A., "Flaw Tolerance of Spiral-Welded Line Pipe," Battelle Report to American Gas Association, A.G.A. Catalogue No. L51514, January 1987.

2.5 Williams, D. N., "Metallurgical Factors," in 6th Symposium on Line Pipe Research, American Gas Association Catalog No. L30175, October 29, 1979.

2.6 Hodge, J. M., Frazier, R. H., and Boulger, F. W., "The Effect of Sulfur on the Notch Toughness of Heat-Treated Steels," Transactions of the Metallurgical Society of AIME, Volume 215, pp 745-753, October 1959. 
2.7 Tomita, Y., "Effect of Decreased Hot-Rolling Reduction Treatment on Fracture Toughness of Low-Alloy Structural Steels," Metallurgical Transactions A, Vol. 21A, pp 2555-2563, September 1990.

2.8 Matrosov, Yu, I. and Polyakov, I. E., "Improving Toughness and Ductility and Reducing Property Anisotropy in Low Alloy Steels," BISI Translation 14384, Stal' (2), pp 162-167, 1976.

2.9 Garwood, S. J., "The Effect of Temperature, Orientation, and Constraint on the Toughness of A533 Class 1 Steel," Application of Fracture Mechanics to Materials and Structures, Martinus Nijhoff Publishers, pp 939-950, 1984.

2.10 Fegredo, D. M., Faucher, B., and Shehata, M. T., "Influence of Inclusion Content, Texture and Microstructure on the Toughness Anisotropy of Low Carbon Steels," Strength of Metals and Alloys, Vol. 2, Pergamon Press, Ltd., Oxford, pp 1127-1132, 1985.

2.11 Scott, P. and Brust, F., "An Experimental and Analytical Assessment of Circumferential Through-Wall-Cracked Pipes under Pure Bending," NUREG-4574, September 1986.

2.12 Schwalbe, K. H. and Hellmann, D., "Application of the Electric Potential Method to Crack Length Measurements Using Johnson's Formula," Journal of Testing and Evaluation, Vol. 9, No. 3, pp 218-221, 1981.

2.13 Marschall, C. W., Held, P. R., Landow, M. P., and Mincer, P. N., "Use of the Direct-Current Electric Potential Method to Monitor Large Amounts of Crack Growth in Highly Ductile Metals," Fracture Mechanics: Twenty-First Symposium, ASTM STP 1074, J. P. Gudas, J. A. Joyce, and E. M. Hackett, Eds., American Society for Testing and Materials, Philadelphia, pp 581-593, 1990. 


\section{DEVELOPMENT OF A SCREENING CRITERION TO PREDICT ANGLED CRACK GROWTH USING MATERIAL PROPERTY DATA}

In Section 2, it was shown from a review of the technical literature that toughness anisotropy in carbon steels arises principally from the presence of highly elongated, stringer-type, manganese sulfide inclusions in the microstructure. If angled crack growth in pipe fracture experiments is due to this toughness anisotropy, it would be useful if the phenomenon could be predicted from some easily measured characteristic of the steel, such as its sulfur content or the shape of the microscopic inclusions. These tests, which require only minute samples of material, would be essentially nondestructive. Should they prove to be insufficient, destructive tests, such as the relatively simple Charpy V-notch impact tests, might be beneficial.

However, from material presented in Sections 2.1.1 and 2.3.2, it is already known that the sulfur content by itself is not a good predictor of a steel's toughness anisotropy. Furthermore, the shape of the sulfide inclusions, while indicative of the degree of anisotropy, is not highly useful because, even in pipes with few stringer-type inclusions, longitudinal toughness is still approximately twice the transverse toughness. What remains to be seen is whether ratios of longitudinal-to-transverse Charpy V-notch impact-test values can accurately predict angled crack growth. To assess this hypothesis, measurements were made of the actual crack growth angles in pipe experiments conducted at Battelle (Refs 3.1-3.3).

\subsection{Mapping of Fracture Paths in $\mathrm{C}(\mathrm{T})$ and Pipe Tests}

As was discussed in Section 1.1, crack extension in circumferentially cracked carbon steel pipes tested at Battelle nearly always took place at an angle to the expected circumferential direction: Similarly, in nonside-grooved $\mathrm{C}(\mathrm{T})$ specimens machined from the pipes such that the initial crack was in the circumferential direction, crack growth sometimes was at an angle to the circumferential direction.

To quantify angled crack-growth and attempt to relate it to other characteristics of the pipe, detailed maps were prepared of fracture paths, both in pipe experiments and in $\mathrm{C}(\mathrm{T})$ specimens. Fracture paths were examined and documented in a total of 23 circumferentially cracked-pipe fracture experiments representing 10 different carbon steel pipes tested at Battelle. Examples of the pipe-fracture maps are shown in Figure 3.1 for three different carbon steel pipes tested in four-point bending. The view is from the outside of the pipe, as if the pipe had been flattened. Notice the three significantly different crack growth patterns pictured in Figure 3.1. In Figure 3.1a, the crack path changed direction several times, such that its average direction was circumferential. In Figure 3.1b, the crack at each end of the starting flaw grew upward, whereas in Figure 3.1c, the crack grew upward at one end and downward at the other end. A complete set of fracture-path skétches can be found in Appendix A.

Examples of the $C(T)$ specimen sketches are shown in Figure 3.2. Figure 3.2a shows a single-shear crack that grew in the intended direction, while Figure $3.2 \mathrm{~b}$ shows a double-shear crack that veered sharply from the intended (circumferential) direction. Probably the most striking difference observed 


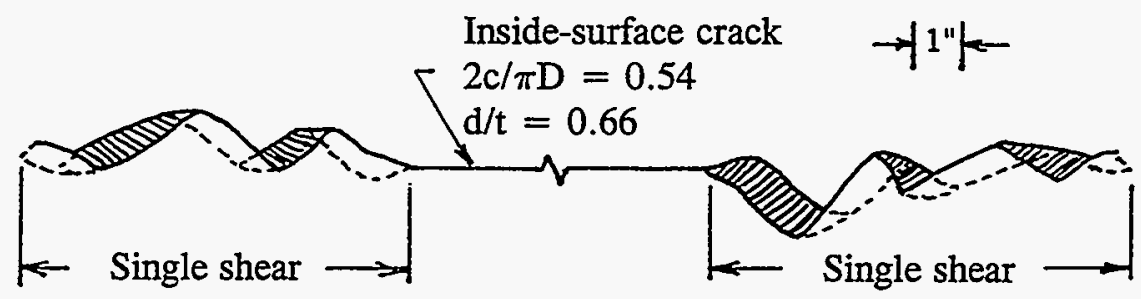

(a) Experiment 4112-9, four-point bending

Pipe DP2-F13, A106 Grade B, 16-inch diameter, Schedule 40 (Ref. 3.1)

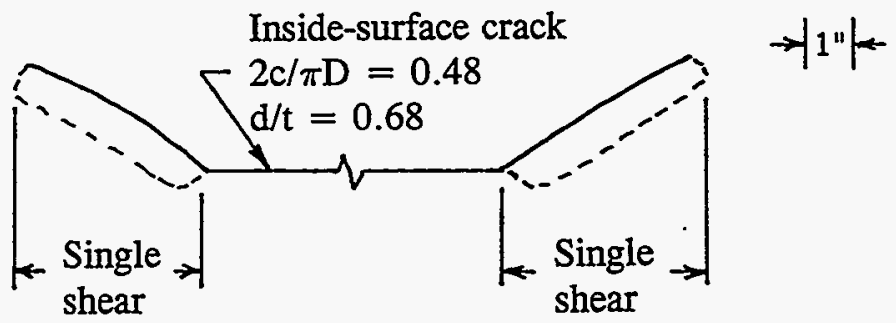

(b) Experiment 4131-8, four-point bending

Pipe DP2-F9, A333 Grade 6, 10-inch diameter, Schedule 100 (Ref. 3.1)

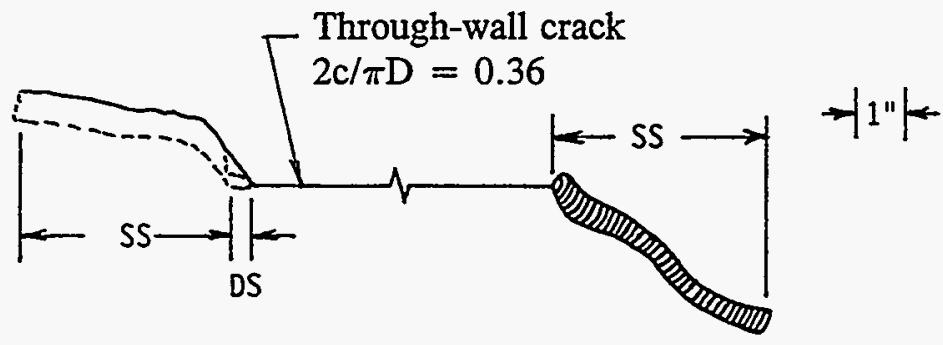

(c) Experiment 1.2-7, four-point bending, quasi-static monotonic

Pipe DP2-F30, A106 Grade B, 6-inch diameter, Schedule 120 (Ref. 3.3)

Figure 3.1 Examples of angled crack extension in tests on three different carbon steel pipes tested in four-point bending 

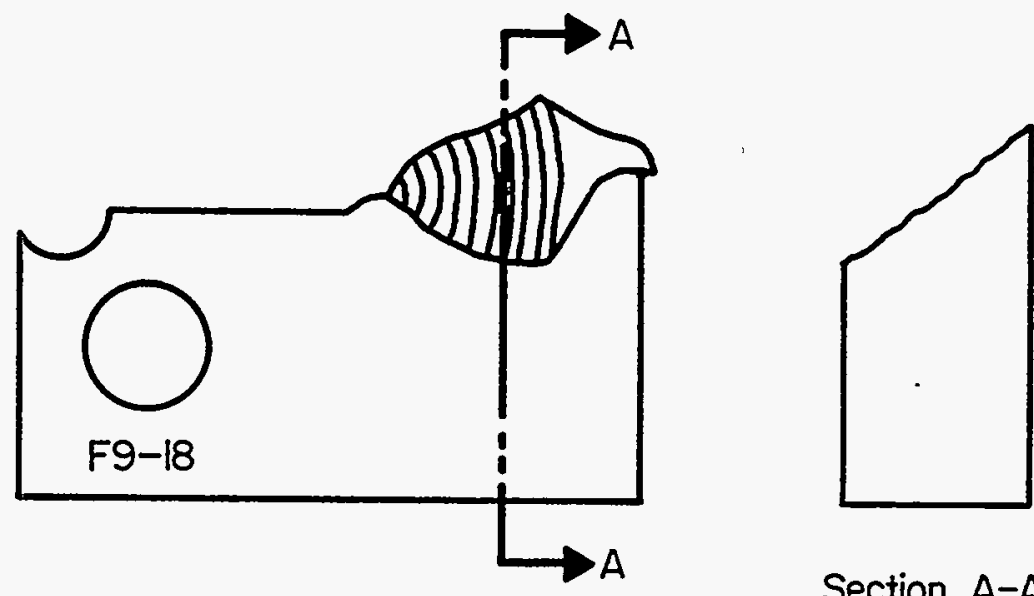

\section{Section A-A}

(a) Single-shear fracture
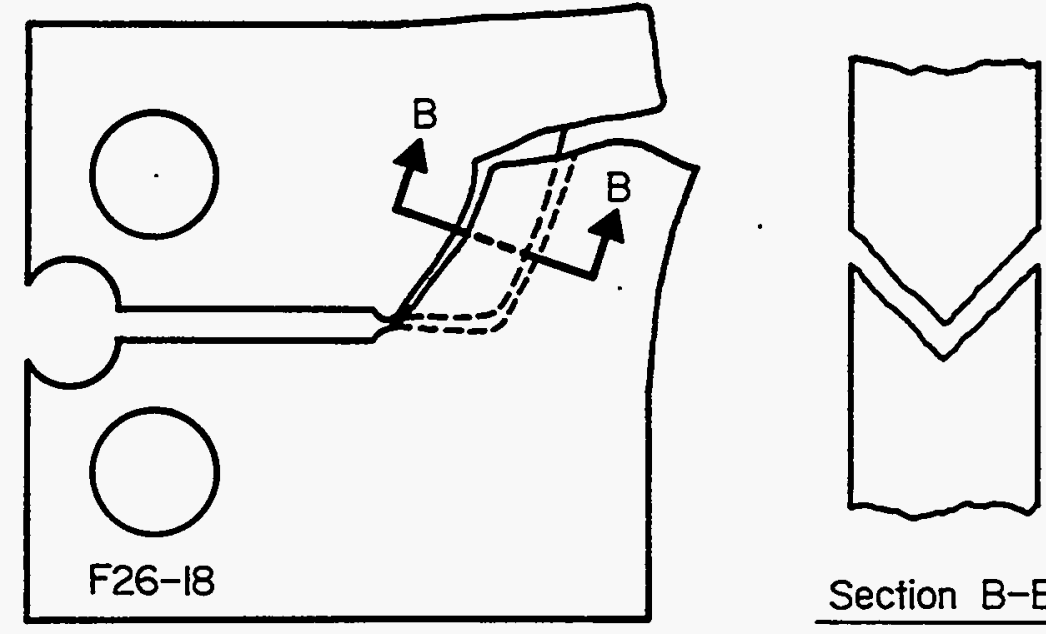

Section B-B

(b) Double-shear fracture

Figure 3.2 Comparison of single-shear and double-shear fractures in carbon steel $\mathbf{C}(\mathbf{T})$ specimens 
between $\mathrm{C}(\mathrm{T})$ tests and pipe tests was in the contribution of double-shear fracture to angled crack growth. In $\mathrm{C}(\mathrm{T})$ specimens, if the growing crack developed as a double-shear crack, it veered off from the circumferential direction at a very steep angle. If, on the other hand, it developed as a single-shear crack, which appeared to be about equally likely, the crack extended circumferentially, although the fracture surface was tilted through the thickness. In 23 pipe specimens examined, doubleshear fractures were almost nonexistent and yet the cracks in nearly every case grew at an angle from the circumferential plane.

These results suggest that a $C(T)$ specimen test in which the crack extends in double shear and veers sharply from the circumferential direction probably has little relevance to pipe fracture tests, for two reasons: (1) double-shear fractures rarely occur in pipe tests, and (2) the J-R curve data obtained from a $C(T)$ test in which the crack grows in double shear are unreliable beyond crack initiation, due to the unusually flat load-displacement curve beyond maximum load and the uncertainty in the length of the growing crack. Hence, where side grooving is not an acceptable means to achieve straight crack growth in $\mathrm{C}(\mathrm{T})$ specimens, it is recommended that only results from non-side-grooved specimens in which the crack extends in single shear be used to develop J-R curves for correlation with pipe tests.

Crack growth angles were determined for the 23 pipe fracture experiments from the sketches shown in Appendix A. The measured angles along with values of the Anisotropy Index are presented in Table 3.1. For each pipe experiment, at least two values of crack-growth angle are included in Table 3.1, one for each tip of the crack. Where more than two values are listed, the crack changed direction one or more times during the test.

Figure 3.3 is a graph of crack-growth angle versus the Anisotropy Index of the pipe, in which the data have been differentiated according to the type of crack and type of loading. The data shown represent a total of seventeen pipe tests on five different pipes for which Anisotropy Index values were available. The important features of Figure 3.3 are: (1) the crack-growth-angle data are highly scattered, even for multiple tests on the same lot of pipe, and (2) if a least-squares-fit trend line were to be drawn and extrapolated to lower values of the Anisotropy Index (indicative of a lesser degree of toughness anisotropy), say to 1.2 to 1.4 , it would predict that the crack would still grow at an angle of 25 to 30 degrees, on average, if the pipe were subjected to bending.

In addition to the unexpected lack of correlation between the crack-growth angle and the Anisotropy Index in Figure 3.3, two other puzzling features are evident. First, the addition of internal pressure loading to the four-point bend loading, depicted by filled circles and filled squares in Figure 3.3, did not significantly change the crack-growth angle at a given value of Anisotropy Index. An increase in angle might have been anticipated because internal pressure loading by itself tends to favor axial crack growth by increasing the hoop stresses. Second, the lone test in which loading was accomplished entirely by internal pressure (no bending), and in which it might have been expected that an unusually large crack-growth angle would occur, exhibited circumferential crack growth. Similar behavior was observed in a pressure-to-failure test on $762-\mathrm{mm}$ (30-inch) diameter by 8.33 - $\mathrm{mm}(0.328$-inch) thick X60 gas pipeline tested by Kiefner (Ref. 3.4). This'pipe was longitudinally seam welded from rolled plate that probably had an Anisotropy Index of at least three; however, the actual Anisotropy Index number is not known. 
Table 3.1 Angled crack growth in circumferentially cracked carbon steel pipes tested at Battelle

\begin{tabular}{|c|c|c|c|c|c|c|c|}
\hline $\begin{array}{c}\text { Pipe Ident. } \\
\text { No. }\end{array}$ & Steel Type & Pipe Test No. ${ }^{\text {(a) }}$ & $\begin{array}{l}\text { Type of } \\
\text { Crack }^{(b)}\end{array}$ & $\begin{array}{l}\text { Type of } \\
\text { Loading }\end{array}$ & $\begin{array}{l}\text { Diameter/ } \\
\text { Thickness }\end{array}$ & $\begin{array}{l}\text { Approx. Crack } \\
\text { Growth Angle } \\
\text { Relative to } \\
\text { Circ. Dir., } \\
\text { degree }^{(d)}\end{array}$ & $\begin{array}{c}\text { Anisotropy } \\
\text { Index }^{(\mathrm{e})}\end{array}$ \\
\hline$\overline{D P 2-F 1}$ & A106 Gr. B & $4112-5$ & SC (int) & 4 pt. bend & 21.4 & $17 ; 24$ & N.D. ${ }^{(t)}$ \\
\hline DP2-F2 & A106 Gr. B & $4112-7$ & SC (int) & 4 pt. bend & 6.9 & 47,$72 ; 48,48$ & N.D. \\
\hline \multirow[t]{6}{*}{ DP2-F9 } & A333 Gr. 6 & $4115-1$ & $S C$ (int) & 4 pt. bend & 13.9 & $52 ; 35$ & 2.55 \\
\hline & & $4121-6$ & SC (ext) & IP onily & 13.9 & $0 ; 0$ & 2.55 \\
\hline & & $4131-3$ & TWC & 4 pt. bend + IP & 13.9 & $45 ; 19$ & 2.55 \\
\hline & & $4131-4$ & SC (int) & 4 pt. bend + IP & 13.9 & $28 ; 35$ & 2.55 \\
\hline & . & $4131-7$ & TWC & 4 pt. bend & 13.9 & $18 ; 25$ & 2.55 \\
\hline & & $4131-8$ & $S C$ (int) & 4 pt. bend & 13.9 & $31 ; 32$ & 2.55 \\
\hline DP2-F11 & A333 Gr. 6 & $4111-1$ & TWC & 4 pt. bend & 11.9 & $59 ; 37$ & $3.1^{(g)}$ \\
\hline DP2-F13 & A106 Gr. B & $4112-9$ & SC (int) & 4 pt. bend & 32.0 & $\begin{array}{l}25,31,39,25,25 \\
40,48,36,27,18 \\
27\end{array}$ & N.D. \\
\hline DP2-F26 & A515 Gr. 60 & $4111-2$ & TWC & 4 pt. bend & 32.0 & 15,$34 ; 27,32$ & $1.96^{(\mathrm{h})}$ \\
\hline DP2-F29 & A106 Gr. B & $4112-8$ & SC (int) & 4 pt. bend & 15.5 & $29 ; 38$ & $1.78^{(b)}$ \\
\hline DP2-F29W & $\begin{array}{l}\text { SAW in } \\
\text { A106 Gr. B }\end{array}$ & $4141-9$ & TWC & 4 pt. bend + IP & 15.5 & 30,$13 ; 52^{(1)}$ & 1.78 \\
\hline \multirow[t]{9}{*}{ DP2-F30 } & A106 Gr. B & $4112-6$ & $S C$ (int) & 4 pt. bend & 10.7 & $30 ; 42$ & $3.40^{(\mathrm{h})}$ \\
\hline & & IPIRG-1 1.2-2 & TWC & 4 pt. bend $(1)$ & 10.7 & $63 ; 63$ & $3.40^{(\mathrm{h})}$ \\
\hline & & IPIRG-1 $1.2-4$ & TWC & 4 pt. bend $(k)$ & 10.7 & $57 ; 56$ & $3.40^{(h)}$ \\
\hline & & IPIRG-1 $1.2-6$ & TWC & 4 pt. bend ${ }^{(\mathfrak{l})}$ & 10.7 & $27 ; 29$ & $3.40^{(\mathrm{h})}$ \\
\hline & & IPIRG-1 1.2-12 & TWC & 4 pt. bend ${ }^{(m)}$ & 10.7 & $36 ; 38$ & $3.40^{(\mathrm{b})}$ \\
\hline & & IPIRG-1 $1.2-7$ & TWC & 4 pt. bend & 10.7 & $51 ; 34$ & $3.40^{(b)}$ \\
\hline & & IPIRG-1 $1.2: 8$ & TWC & 4 pt. bend ${ }^{(m)}$ & 10.7 & $12 ; 32$ & $3.40^{(\mathrm{b})}$ \\
\hline & & IPIRG-1 $1.2-10$ & TWC & 4 pt. bend ${ }^{(n)}$ & 10.7 & $27 ; 28$ & $3.40^{(\mathrm{b})}$ \\
\hline & & IPIRG-1 1.2-11 & TWC & 4 pt. bend ${ }^{(m)}$ & 10.7 & $29 ; 30$ & $3.40^{(h)}$ \\
\hline DP2-F32 & API-X65 & $4111-4$ & TWC & 4 pt. bend & 67.2 & $0 ; 0$ & $3.40^{(h)}$ \\
\hline
\end{tabular}

(a) IPIRG-1 tests from Refs. 3.2 and 3.3, all other tests from Degraded Piping Program

(b) $\mathrm{SC}($ int) $=$ internal surface crack. $S C$ (ext) $=$ external surface crack.

(c) $\quad \mathbb{P}=$ internal pressure.

(d) Where more than two angles are listed, the crack changed direction; sometimes the new growth angle returned the crack toward the plane of the original circumferential crack. For SC pipe, the angle is after the crack grows beyond the initial notch.

(c) Ratio of maximum to minimum toughness.

(f) Not determined.

(g) Determined from compact-specimen tests in several directions. Note that the minimum-toughness direction was at angle of approximately 66 degrees to the circumferential direction in this seamless pipe.

(h) Determined from Charpy V-notch impact tests in two, or more, directions.

(i) Cracks grew out of weld metal into base metal.

() Cyclic loading; $R$ ratio (i.e., $\mathrm{min}$. load $/ \max$. load) $=0$.

(k) Cyclic loading; $R=-1$.

(l) Cyclic loading at high rate; $R=-1$.

(m) Monotonic loading at high loading rate.

(n) Cyclic loading at high loading rate; $R=0$. 


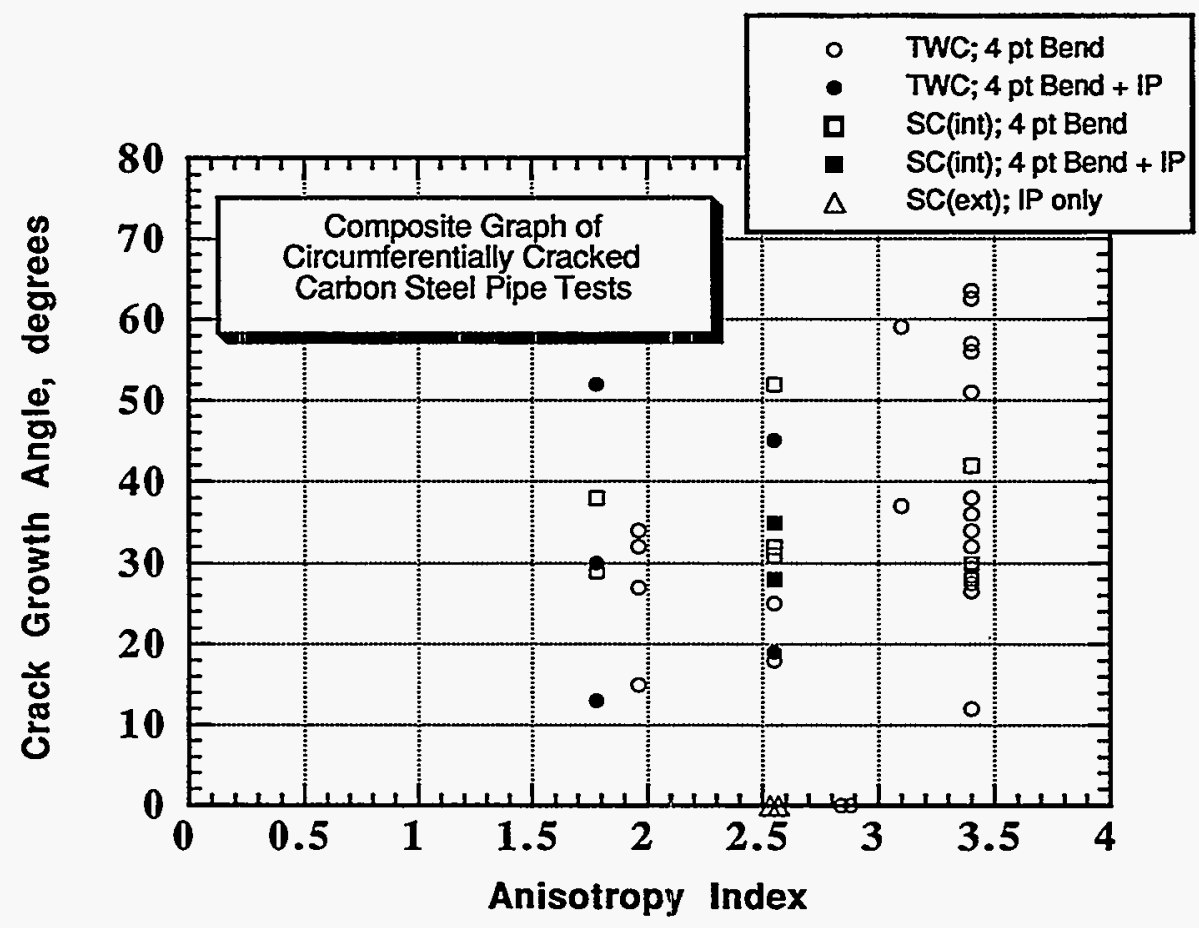

Figure 3.3 Crack-growth angle versus Anisotropy Index for circumferentially cracked carbon steel pipes tested at Battelle (TWC $=$ through-wall crack, $\mathrm{SC}=$ surface crack, $\mathrm{IP}=$ internal pressure)

The data included in Table 3.1 for Pipe DP2-F32, which exhibited only circumferential crack growth (zero degrees), suggest that the pipe dimensions might be a greater contributor to angled crack growth than is the toughness anisotropy. The ratio of pipe diameter to pipe thickness (D/t) for Pipe DP2-F32 is 67, whereas for all the other carbon steel pipes tested in the Battelle programs the $D / t$ ratio ranged from approximately 7 to 32 . Figure 3.4 is a graph of crack angle versus $D / t$ for a variety of carbon steel pipes having either through-wall cracks or internal surface cracks, tested in four-point bending. Notice that, despite a high degree of scatter, the D/t ratio of the pipe appears to have a strong effect on the crack-growth angle. This result suggests that pipe dimensions may have more to do with angled crack growth than does the Anisotropy Index.

Figure 3.5 is a plot similar to Figure 3.4, except that data have been added for pipe tests in which internal pressure was employed (filled circles and squares), usually in conjunction with four-point bending. Inasmuch as internal pressure tends to favor axial crack growth over circumferential crack growth, it was anticipated that the tests which included internal pressure would exhibit greater crackgrowth angles than those which did not include pressure. Figure 3.5 reveals that such was not the case; the data for four-point bending plus internal pressure appear to lie within the data band for fourpoint bending alone. Especially puzzling are the data points for the single test conducted under internal pressure alone. In that test, the crack grew circumferentially at both ends (crack growth angle equal to zero degrees), even though it might have been expected that, in the absence of bending, axial crack growth would have occurred. 


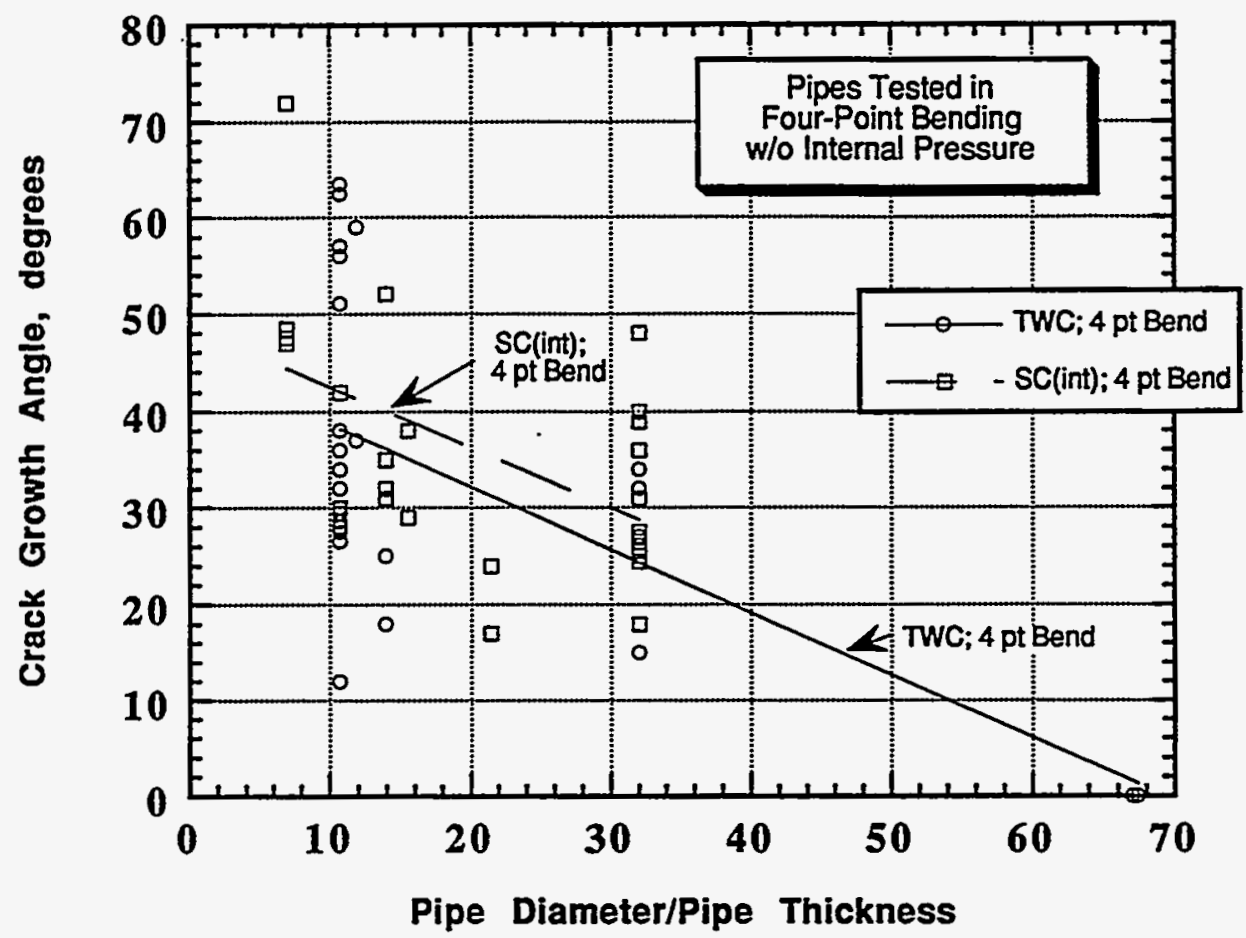

Figure 3.4 Crack-growth angle versus pipe diameter/thickness ratio for carbon steel pipes tested in four-point bending (TWC = through-wall crack, SC(int) = internal surface crack)

\subsection{Assessment of Usefulness of Screening Tests to Predict Angled Crack Growth in Pipe Tests}

Attempts were made to develop a simple screening criterion involving chemical analysis, microstructural examination, and Charpy testing in several directions to predict the tendency for angled crack growth in pipe tests on carbon steels.

Chemical analysis for sulfur proved not to be a reliable predictor because most pipe steels contain more than enough sulfur to create the sulfide inclusions mainly responsible for toughness anisotropy; only when sulfur levels drop below 0.01 percent by weight are appreciable toughness improvements noted and, even then, significant toughness anisotropy persists. Likewise, microstructural examination to determine the shape of the sulfide inclusions was found to be of only limited value; while elliptical shaped sulfides produced less anisotropy than did stringer-type sulfides, the Anisotropy Index for elliptical sulfides still had a value near 2.0. Finally, the Anisotropy Index, determined from Charpy tests in different orientations and initially thought to offer the best possibility for predicting angled crack growth, proved to yield highly scattered results. Further, the toughness index determined from Charpy tests suggested that cracks in pipes might grow at a significant angle to the circumferential direction even if that index were to approach a value of 1.0. 


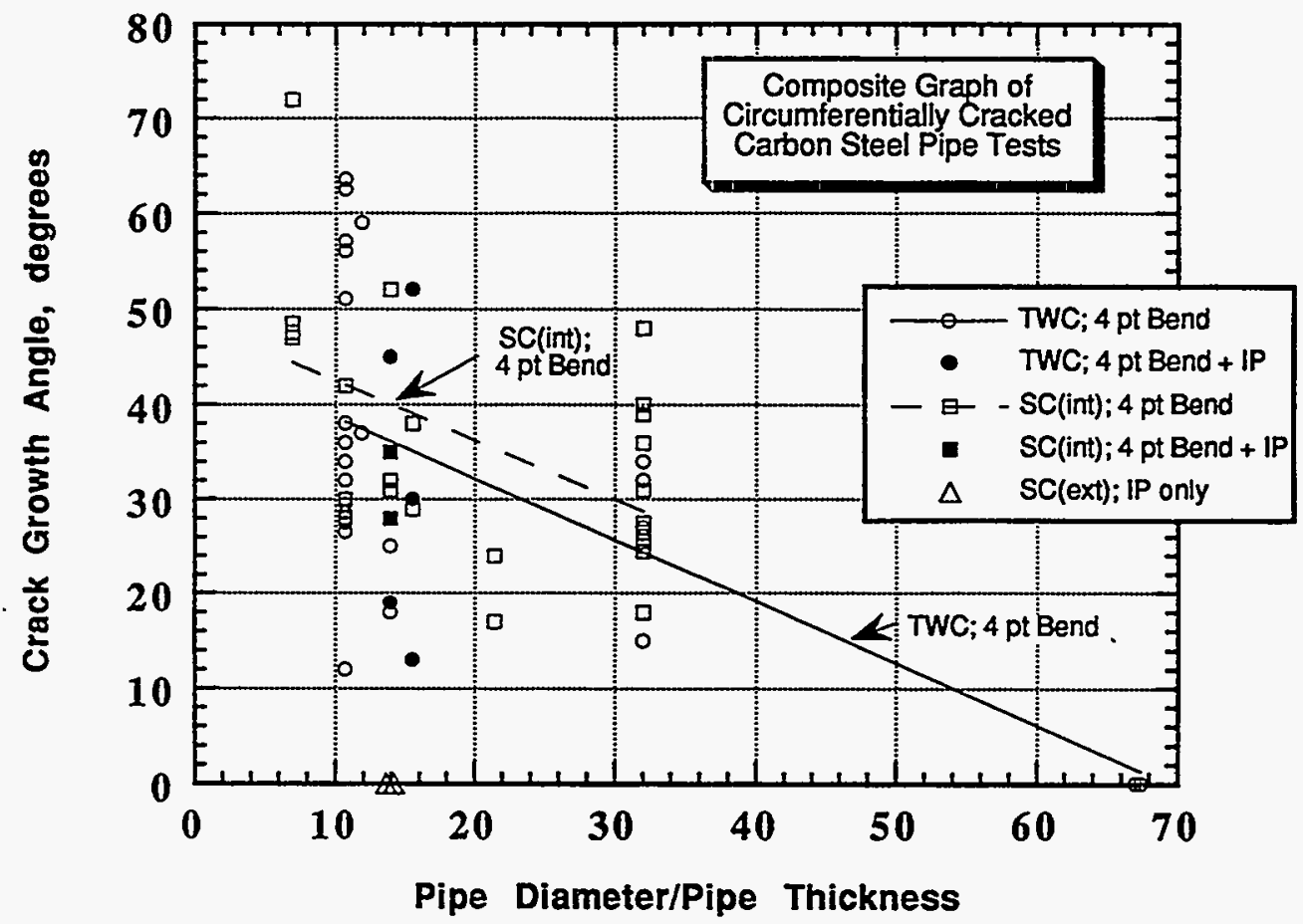

Figure 3.5 Crack-growth angle versus pipe diameter/thickness for carbon steel pipe tests ( $T W C=$ through-wall crack, $S C=$ surface crack, $I P=$ internal pressure)

A possibly more useful indicator of the tendency for angled crack growth in carbon steel pipe tests is the ratio of the pipe diameter, $D$, to the pipe thickness, $t$. Limited data suggest that the greater the value of $\mathrm{D} / \mathrm{t}$, the more likely it is that the crack will grow circumferentially (zero degrees) in fourpoint bend tests, with or without internal pressure. However, additional testing at large values of $D / t$ in pipes having significant toughness anisotropy is required to verify this hypothesis. The test data from Kiefner (Ref. 3.4) tends to support this, although we can only guess that the pipe tested should have had an Anisotropy Index of at least three.

\subsection{References}

3.1 Wilkowski, G. M. and others, "Degraded Piping Program - Phase II," Summary of Technical Results and Their Significance to Leak-Before-Break and In-Service Flaw Acceptance Criteria, March 1984-January 1989, by Battelle Columbus Division, NUREG/CR-4082, Vol. 8, March 1989.

3.2 Schmidt, R. A., Wilkowski, G. M., and Mayfield, M., "The International Piping Integrity Research Group (IPIRG) Program--An Overview," SMiRT-11 Proceedings, Paper G23/1, August 1991. 
3.3 Scott, P., Kramer, G., Vieth, P., Francini, R., and Wilkowski, G., "The Effect of Dynamic and Cyclic Loading During Ductile Tearing on Circumferentially Cracked Pipe -- Experimental Results," ASME PVP Vol. 280, pp 207-220, June 1994.

3.4 Kiefner, J. F., "Fracture Initiation," in 4th Symposium on Line Pipe Research, published by American Gas Association, A.G.A. Catalogue No. L30075, November 1969. 


\subsection{ANISOTROPY AND COMBINED LOADING EFFECTS ON FRACTURE OF THROUGH-WALL-CRACKED PIPES}

\subsection{Background}

From the experimental section of this report, it was seen that angled crack growth was observed in the vast majority of the circumferential through-wall-cracked (TWC) carbon steel pipes subjected to bending. Angled crack growth here meant that the crack grew at a significant angle to the circumferential direction. Although it was thought initially that the angled crack growth was associated with stringer-like nonmetallic inclusions oriented at a similar angle to the pipe circumference, subsequent metallographic examinations of five pipes having angled crack growth revealed that in only one case were the inclusions not perpendicular to the circumferential plane of the pipe.

Charpy V-notch impact tests and compact-specimen fracture toughness tests performed with cracks aligned at different angles with respect to the inclusion direction revealed that both the total absorbed energy to fracture and the energy release rate for crack initiation exhibited directional dependence; in each pipe investigated, the smallest energy values were associated with cracks running in the direction of the elongated inclusions. However, tensile tests performed on the specimens cut from the pipe at several angles to the pipe axis showed little or no effect of material anisotropy. This result is not entirely surprising since the triaxiality in a tensile test is not as significant as that which occurs at the tip of a crack. The triaxial stress state is important in the nucleation and growth of voids at or near the nonmetallic inclusions. Since the microstructural effects of void nucleation and growth at or near the nonmetallic inclusions are highly localized, they may play a dominant role in the process of crack initiation and growth.

Another important mechanism of crack extension that may operate in materials with such inclusions is shear-induced crack growth (Ref. 4.1). Microscopically, shear-induced crack growth appears to involve decohesion of the inclusion-matrix interface. In a tensile test where global behavior is measured, these localized effects are smeared out. Thus, based on the experimental results there appears to be no need to adopt an anisotropic plasticity constitutive model. It should also be mentioned that for austenitic stainless steel pipes subjected to bending, circumferential TWC growth occurred in the circumferential plane and showed no evidence of angled crack growth. This is not surprising since stainless steel does not show significant directional dependence or anisotropy of fracture toughness.

For TWC pipes subjected to simple bending, angled crack growth is of little practical concern because the maximum loads for angled crack growth are greater than those for straight cracks. The fracture anisotropy exhibited by carbon steels would be of more importance under combined bending and torsional loadings. In real piping systems, pipes are.subjected to both bending and torsional moments. Thus, it is important to evaluate the effects of combined loading and develop a suitable methodology to assess the effects of combined loading on cracked ferritic pipes. 
The main objectives of this study were:

- To understand the significance of angled crack growth in ferritic steel pipes through finite element analysis of a past Battelle TWC pipe test (Experiment Number 4111-1, Pipe Number DP2-F11),

- To determine if the results of the analyses could indicate why an initially straight crack should grow at an angle,

- To develop suitable methodology to assess the effect of combined loading on a circumferential through-wall-cracked ferritic pipe, and

- To develop a defensible approach, using engineering judgement, for assessing the effect of combined loading in piping systems.

Toward achieving this end, the following tasks were performed:

- $\quad$ Survey of torsion-bending ratios in nuclear plant piping,

- $\quad$ Finite-element analyses for one straight TWC pipe geometry (Experiment Number 4111-1, on Pipe Number DP2-F11) subjected to pure bending, pure torsion, and combined loading conditions,

- Finite-element analyses for the same pipe subjected to pure bending, where the tip of the crack is aligned at several angles with respect to the circumferential plane,

- Compare anisotropic toughness data to crack driving force as a function of crack-tip angle for predicting the resulting crack angle in the pipe test, and

- Assess the effects of combined loading of the straight TWC pipe using the developed methodology.

\subsection{Survey of Typical Bending Moment-to-Torque Ratios for Plant Piping Systems}

In order to guide the analysis, a survey of typical bending-to-torsion ratios was undertaken as part of this effort to ensure the torsion values used were of pragmatic value. This was not meant as an exhaustive survey, but rather to get a sampling of typical plant piping stresses to guide the input for the analysis. Members of the ASME Section XI Working Group on Pipe Flaw Evaluation were polled and generally it was believed that PWR primary piping would have very low torsional stresses, i.e., probably a bending moment-to-torque ratio of 10 or more. However, no specific stress data were supplied. Other members supplied data on secondary piping stress analyses. Stresses at normal operating and/or normal plus operating basis earthquake (OBE) design were supplied for various piping systems. The moment was taken as 


$$
M_{B}=\sqrt{M_{x}^{2}+M_{y}^{2}}
$$

The following ratios of bending moments $\left(\mathrm{M}_{\mathrm{B}}\right)$ to torque $\left(\mathrm{T}_{\mathrm{xy}}\right)$ have been obtained from the information supplied from the respective companies:

- Ontario-Hydro: 1.2 to 1.9

- $\quad$ Stone \& Webster: 3.0 to 4.0

- $\quad$ Arizona Public Service Company: 0.4 to 150 .

Since the ratios obtained from Arizona Public Service company show wide variation, histograms of the ratios were plotted. Figures 4.1 through 4.3 show the frequency of the occurrence versus ratios for the Arizona Public Service Company data over three different ranges of the data. It can be seen that ratios of bending moment-to-torque in the neighborhood of 1.0 are not infrequent. Based on all the information obtained from all three companies, it was decided to conduct combined bending plus torsion analyses for ratios of 3.0 and 1.0.

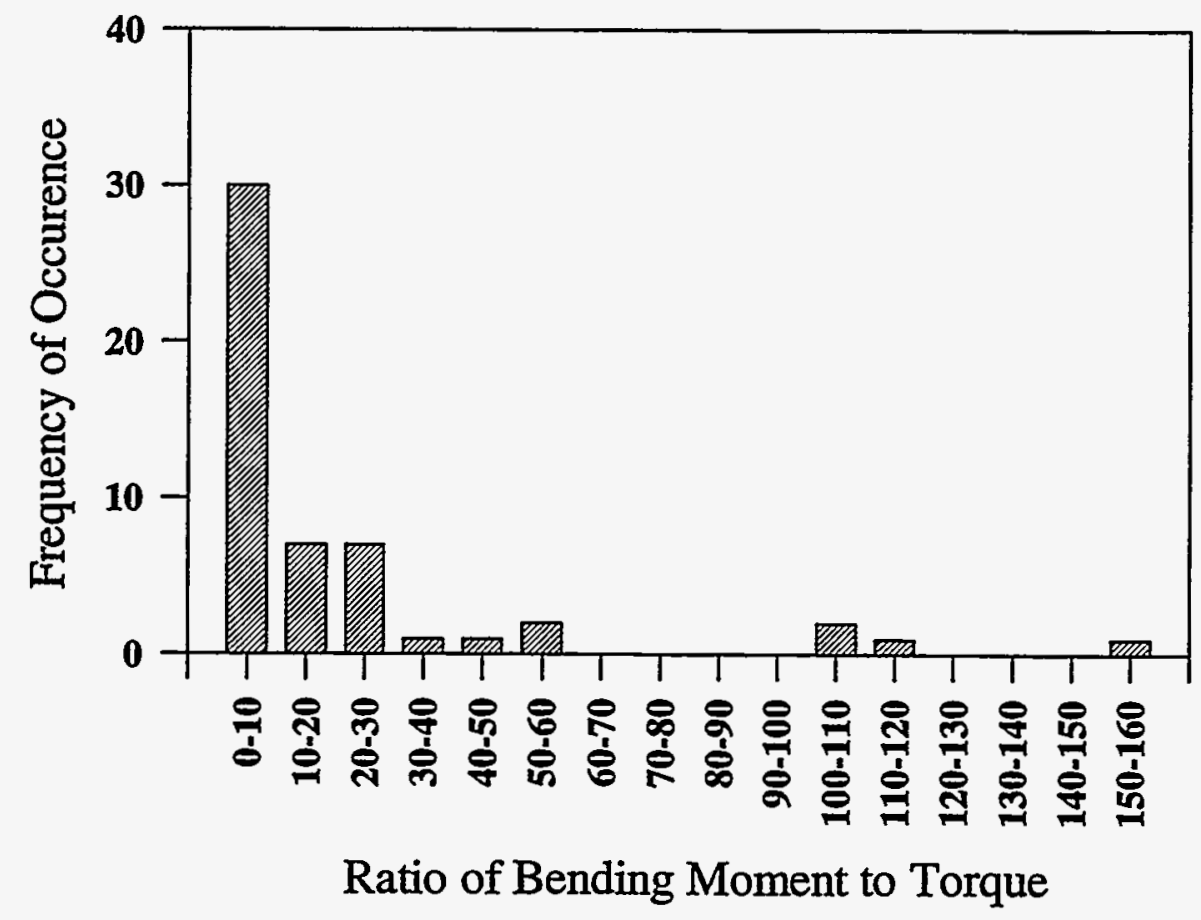

Figure 4.1 Histogram of bending moment-to-torque ratios from Arizona Public Service Company (all data) 


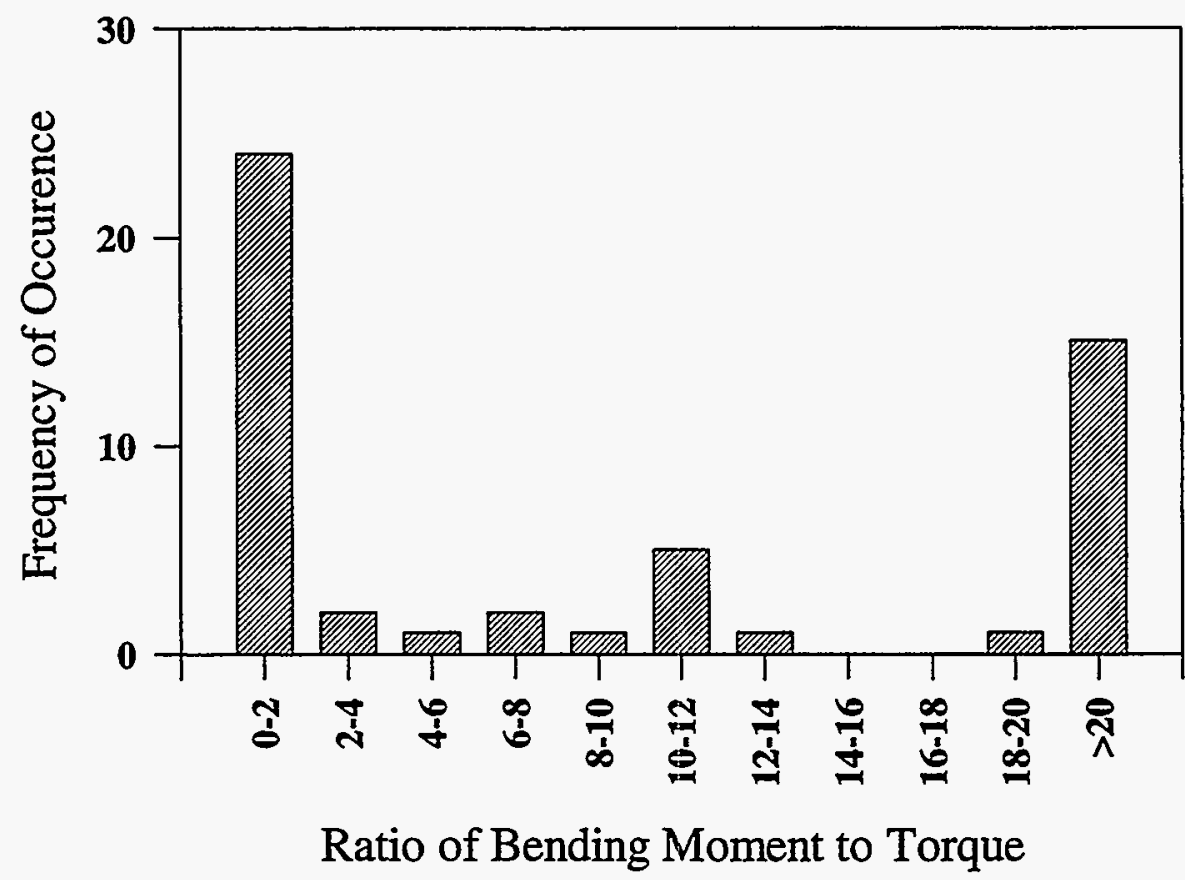

Figure 4.2 Histogram of bending moment-to-torque ratios from Arizona Public Service Company (bending moment-to-torque ratios between 0 and 20)

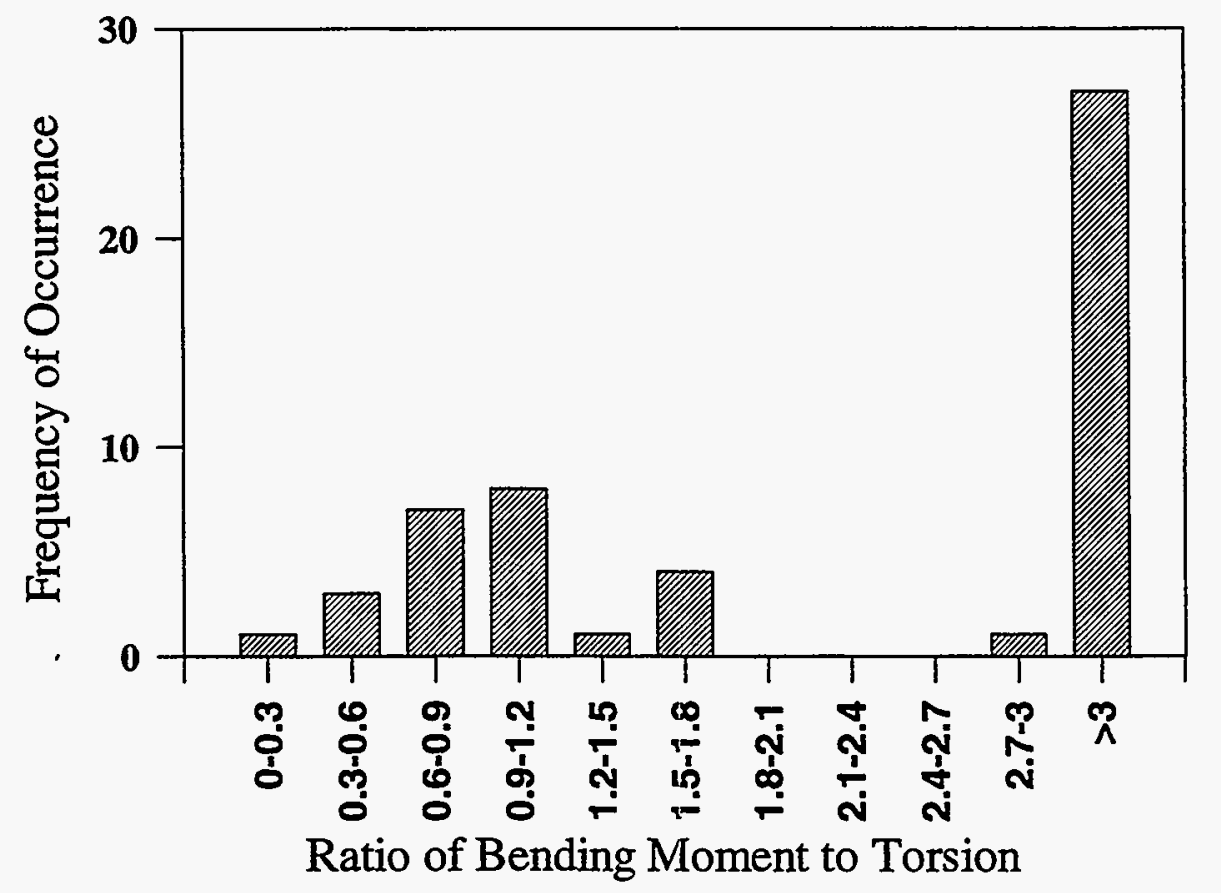

Figure 4.3 Histogram of bending moment-to-torque ratios from Arizona Public Service Company (bending moment-to-torque ratios between 0 and 3) 


\subsubsection{Development of Engineering Approaches to Calculate Effective Moment for Piping Systems Experiencing Combined Loading}

It is convenient to interpret combined bending and torsion load effects using effective moments, which provide a useful engineering estimation scheme. Several approaches may be considered:

(1) The effective moment, $M_{\text {eff }}$, can be determined as the square root of the sum of the squares of the torque, $T$, and the bending moment, $M_{B}$.

(2) The effective moment can be determined as the moment resulting from an effective stress obtained using the Von Mises stress from the bending stress, $\sigma_{\mathrm{B}}$, caused by a bending moment and the torsional stress, $\tau_{\mathrm{T}}$, caused by the torque.

(3) The effective moment can be determined as the moment resulting from an effective bending stress, $\sigma_{\text {eff }}$, obtained using square root of the sum of the squares of the bending stress, $\sigma_{\mathrm{B}}$, caused by the bending moment, and the torsional stress, $\tau_{\mathrm{T}}$, caused by the torque.

(4) The effective moment can be given by the bending moment only, ignoring the torque.

The four different approaches to handle combined torsion and bending can be cast in the form of a single equation, given below. Referring to the above numbered descriptions, mathematically they may be expressed as:

$$
M_{\text {eff }}=\sqrt{M_{B}^{2}+\left(c_{e} T\right)^{2}}
$$

(1) $c_{e}=1 \Rightarrow$ Effective moment from resultant of bending moment plus torque

(2) $c_{e}=\frac{\sqrt{3}}{2} \Rightarrow$ Effective moment calculated from $\dot{\sigma}_{\text {eff }}=\sqrt{\sigma_{B}^{2}+3 \tau_{T}^{2}}$

(3) $c_{e}=\frac{1}{2} \Rightarrow$ Effective moment calculated from $\sigma_{\text {eff }}=\sqrt{\sigma_{B}^{2}+\tau_{T}^{2}}$

(4) $c_{e}=0 \Rightarrow$ Effective moment calculated ignoring torque

In Equation 4-2, $c_{\mathrm{e}}$ defines the effective moment parameter. The upper and lower bounds for calculating the effective moment are defined by $c_{e}=1$ and $c_{e}=0$. The other two approaches lie in between these two extremes as indicated by Equation 4-2. 


\subsection{Finite Element Modelling of Circumferential TWC Pipe}

\subsubsection{Pipe Geometry and Finite Element Meshes}

The finite element analyses were conducted for straight circumferential TWC pipe as well as for TWC pipe with angled cracks, where the crack tip was oriented at three different angles, $\Omega$, namely 25,45 , and 65 degrees, with respect to the circumferential plane. The term angled crack used throughout this section refers to a circumferential TWC with a small fraction of its total length near the tip of the crack (including the crack tip) inclined at some angle, defined as $\Omega$, to the circumferential plane (see Figure 4.4). For the finite element analysis the mean pipe diameter, $D_{m}$, was $101.6 \mathrm{~mm}$ (4 inches) and the thickness of the pipe was $8.56 \mathrm{~mm}(0.337 \mathrm{inch})$ and the through-wall crack occupied 37 percent of the circumference. The outer surface of the finite element mesh is shown in Figures 4.5 and 4.6. It can be seen that the mesh is well refined at the crack tip. The minimum edge length of the smallest element near the crack tip is about $0.05 \mathrm{~mm}(0.002 \mathrm{inch})$. Four layers of elements were used through the thickness with biasing toward the free surfaces. In the case of the angled crack-tip, the smallest element near the tip is about $0.005 \mathrm{~mm}(0.0002 \mathrm{inch})$ and the length of the angled crack-tip region modeled was $0.018 \mathrm{~mm}(0.0007 \mathrm{inch})$. It was desired to keep this length very small to represent near initiation values, and the length was chosen to correspond to the mean inclusion spacing for the Pipe DP2-F11. Details of the angled crack-tip region are shown in Figure 4.7. In all the cases, the length of the pipe modelled was $704 \mathrm{~mm}$ (27.7 inches). The loads were applied at the end of the pipe. Since the ratio of length-to-mean radius was about 14 , end effects due to the application of loads were negligible.

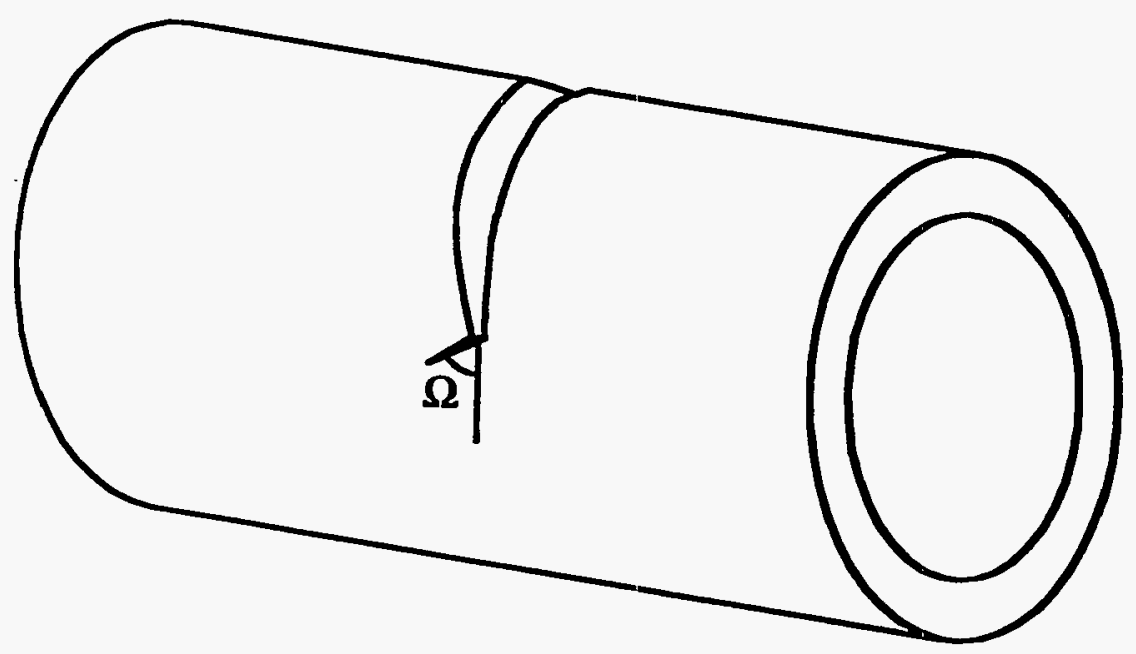

Figure 4.4 Illustration of an angled circumferential TWC in a pipe 


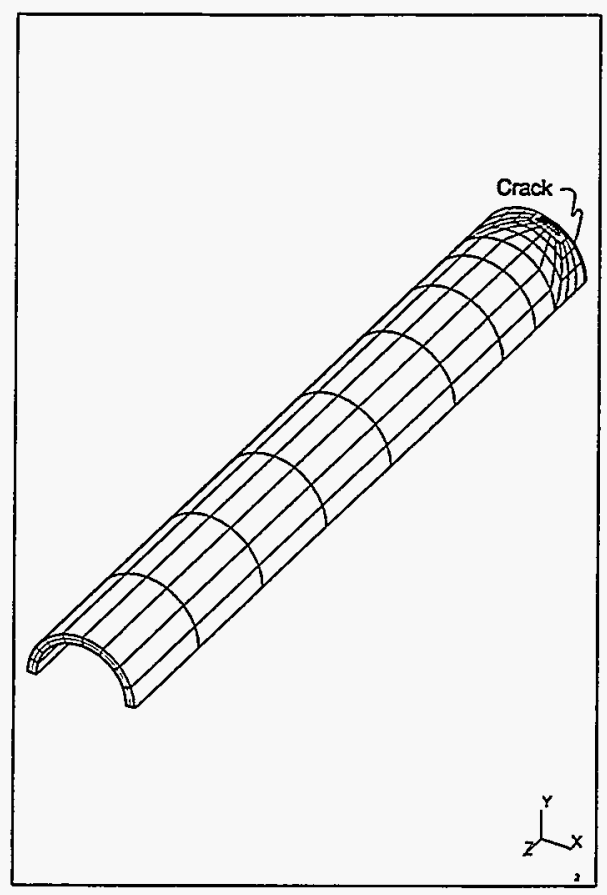

(a) Total model

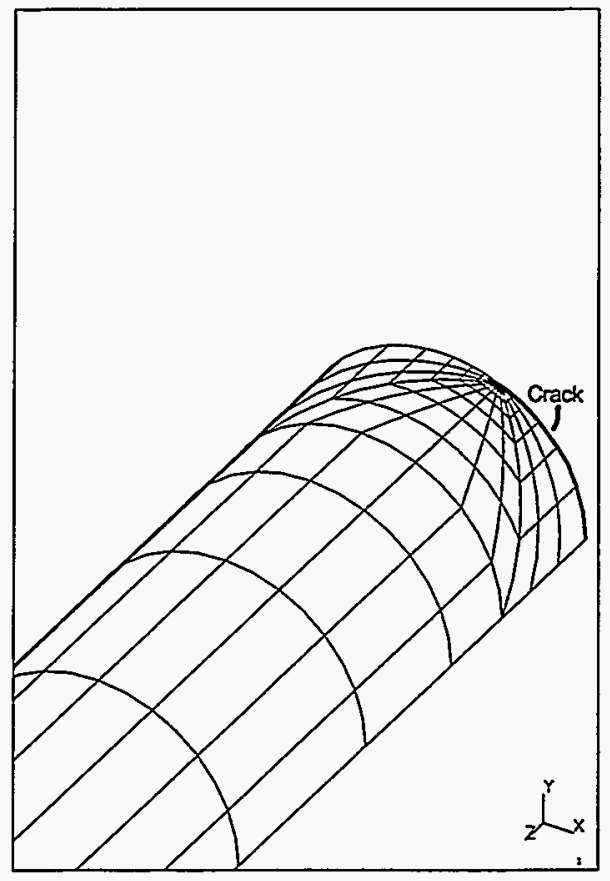

(b) Close up

Figure 4.5 Finite Element Mesh for straight circumferential TWC pipe 


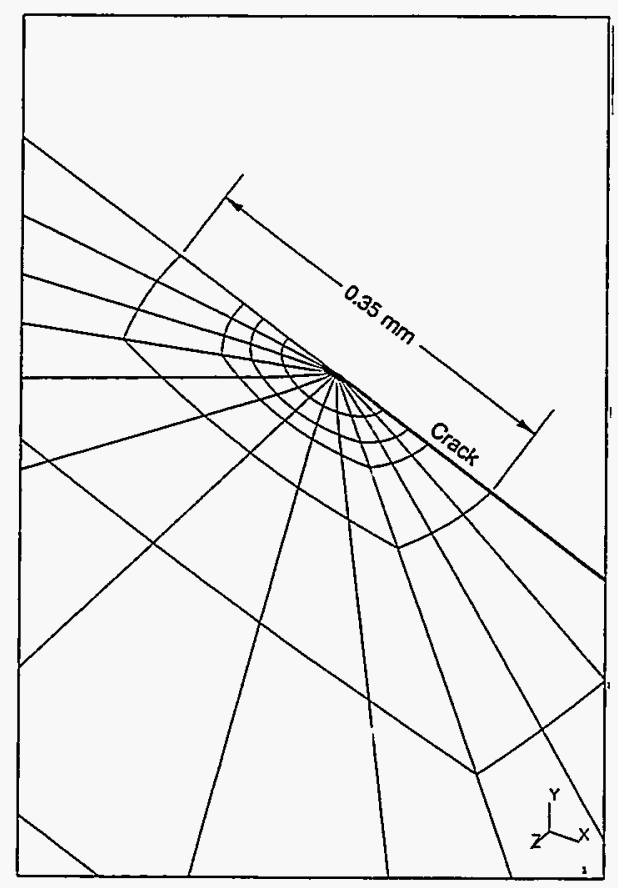

Figure 4.6 Detailed view of Figure 4.5

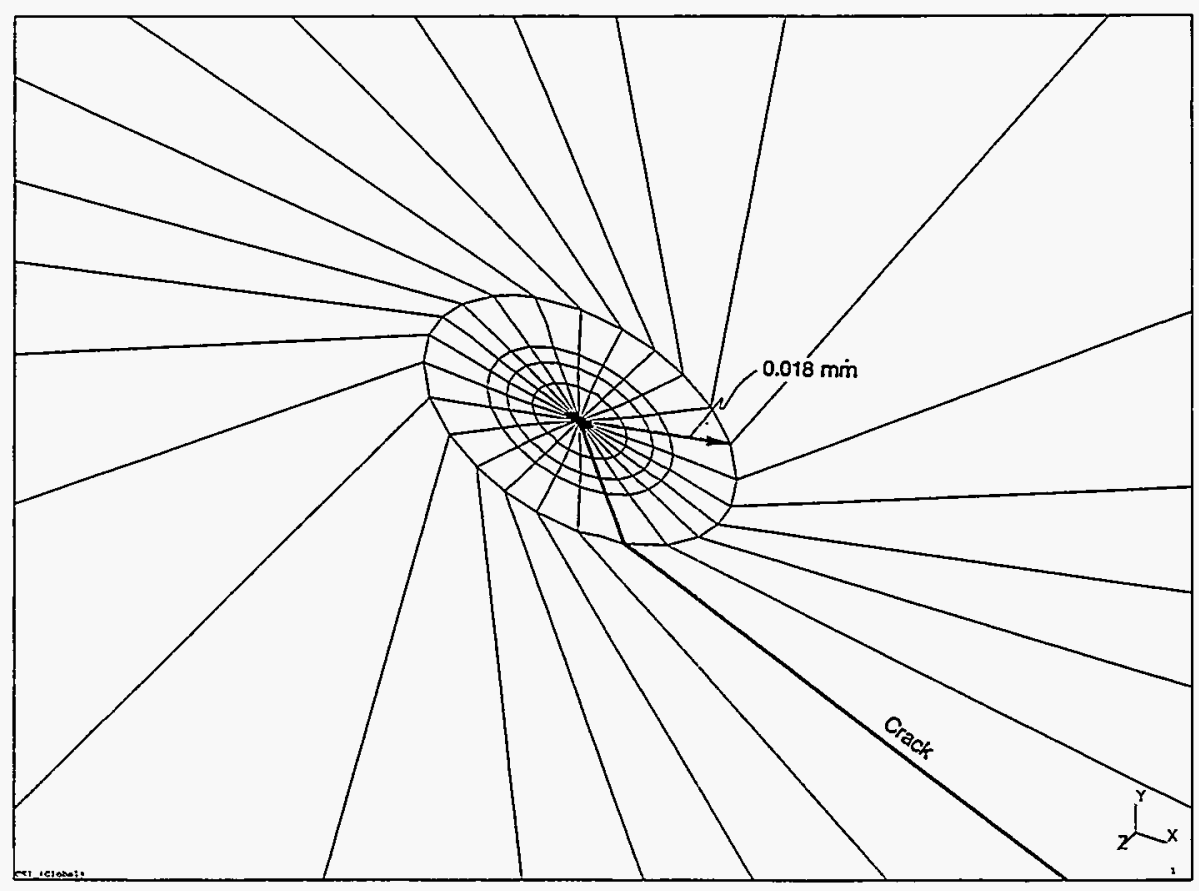

Figure 4.7 Detail of the angled crack-tip region for the angled crack 


\subsubsection{Boundary Conditions for the Loading Cases Considered}

\subsubsection{Straight Cracks}

This analysis involved a circumferential TWC pipe subjected to arbitrary combined tension, bending, and torsion under nonlinear conditions. The crack coincides with the $\mathrm{z}=0$ plane. For this combined loading case, the only symmetry that can be exploited is a rotational symmetry about the $y$ axis (see Fig. 4.8). This implies that one-half of the pipe (either $z \leq 0$ or $z \geq 0$ ) needs to be modelled. The rotational symmetry conditions dictate that on the uncracked region of the $\mathrm{z}=0$ plane the following relations on the displacements hold:

$$
\begin{aligned}
& U_{x}(-x)=-U_{x}(x) \\
& U_{y}(-x)=U_{y}(x) \\
& U_{z}(-x)=-U_{z}(x)
\end{aligned}
$$

These conditions simply ensure the compatibility of displacements across the $z=0$ plane. Note, along the $x=0$ line on the uncracked side, the above conditions imply $U_{x}=U_{z}=0$. Additionally, the cracked region is considered to be stress free.

The conditions listed in Equation 4-3 are enforced on the uncracked region of the $z=0$ plane through penalty functions invoking the *EQUATION option in ABAQUS $B$, the commercially available FEA software that was used. In addition to the above boundary conditions, all remaining

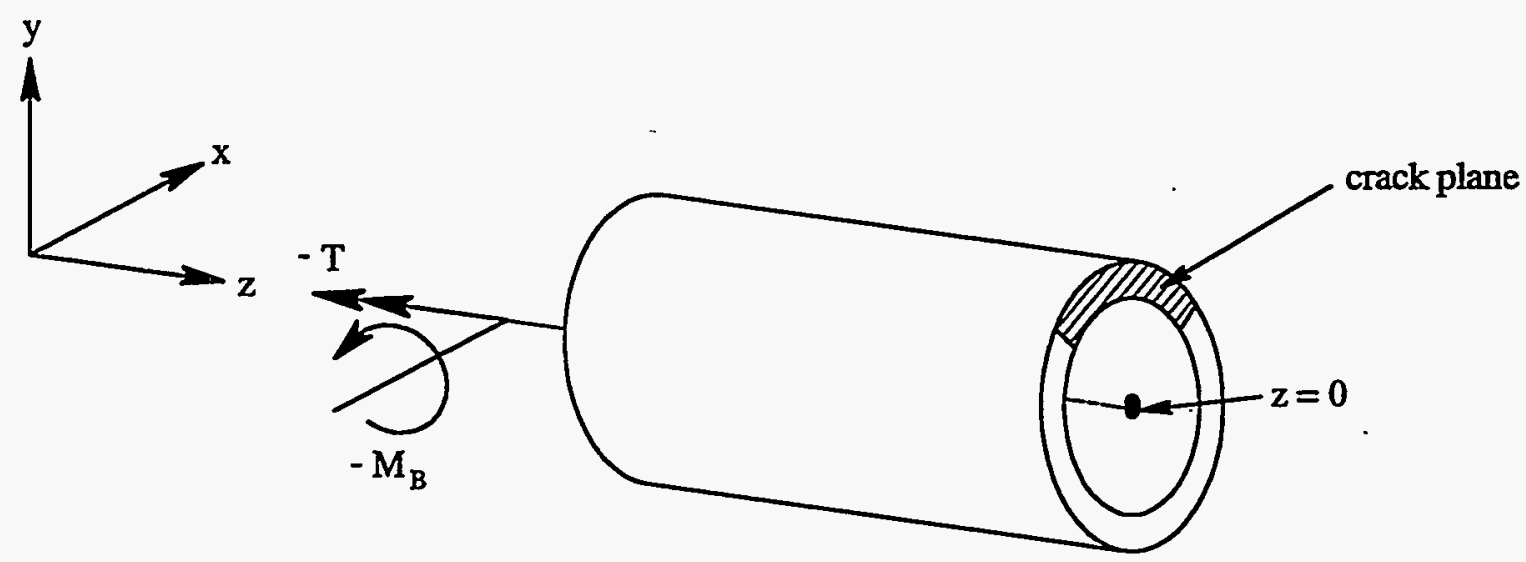

Figure 4.8 Boundary conditions for combined tension, bending, and torsion of straight circumferential TWC pipe 
rigid body translations and rotations are suppressed by prescribing $U_{y}=0$ on one node, say on the $x=$ 0 line on the uncracked region of the $\mathrm{z}=0$ plane.

In the cases of pure bending, pure tension, or combined bending plus tension, two planes of symmetry exist, namely the $z=0$ plane and the $x=0$ plane. Thus, only one-fourth of the pipe needs to be modelled (see Fig. 4.9). On the uncracked region of the $z=0$ plane, $U_{z}=0$ and on the $x=0$ plane, $U_{x}=0$. The cracked region of the $z=0$ plane is considered stress free. In addition to the above boundary conditions, the remaining rigid body translation in the y-direction is suppressed by prescribing $U_{y}=0$ at one node on the uncracked region.

For pure torsional loading, the plane $z=0$ represents an anti-symmetry plane with the crack experiencing pure Mode II conditions. Though the conditions enumerated in Equation 4-3 are strictly valid, additional simplication can be made, such that only one-quarter of the cracked pipe (say $z \geq 0$ and $x \geq 0$ ) needs to be modelled. Under pure torsional loading, the uncracked region of the $z=0$ plane experiences no circumferential displacement $\left(U_{\Theta}=0\right.$ in this region). The compatibility of displacements across the $\mathrm{z}=0$ plane as given by Equation 4-3 is required. For the case when a torque $\mathrm{T}$ is applied at the far end of the cracked pipe, consider two material points $\mathrm{P}$ and $\mathrm{Q}$ with $\mathrm{X}=\mathrm{X}$ and $-X$ on the uncracked side of the $z=0$ plane. Let us assume the in-plane displacement field shown in Figure 4.10a. Note $U_{\Theta}=0$ for the uncracked region on this plane, as mentioned earlier. The displacement field shown in Figure 4.10a indicates that $U_{r}{ }^{P}$ and $U_{r}{ }^{Q}$ point away from the center of the pipe. Now consider the case when the torque is reversed (torque of $-T$ ). With the displacement field assumed in Figure 4.10a for material points $P$ and $Q$ and for torque $T$, the displacement field for

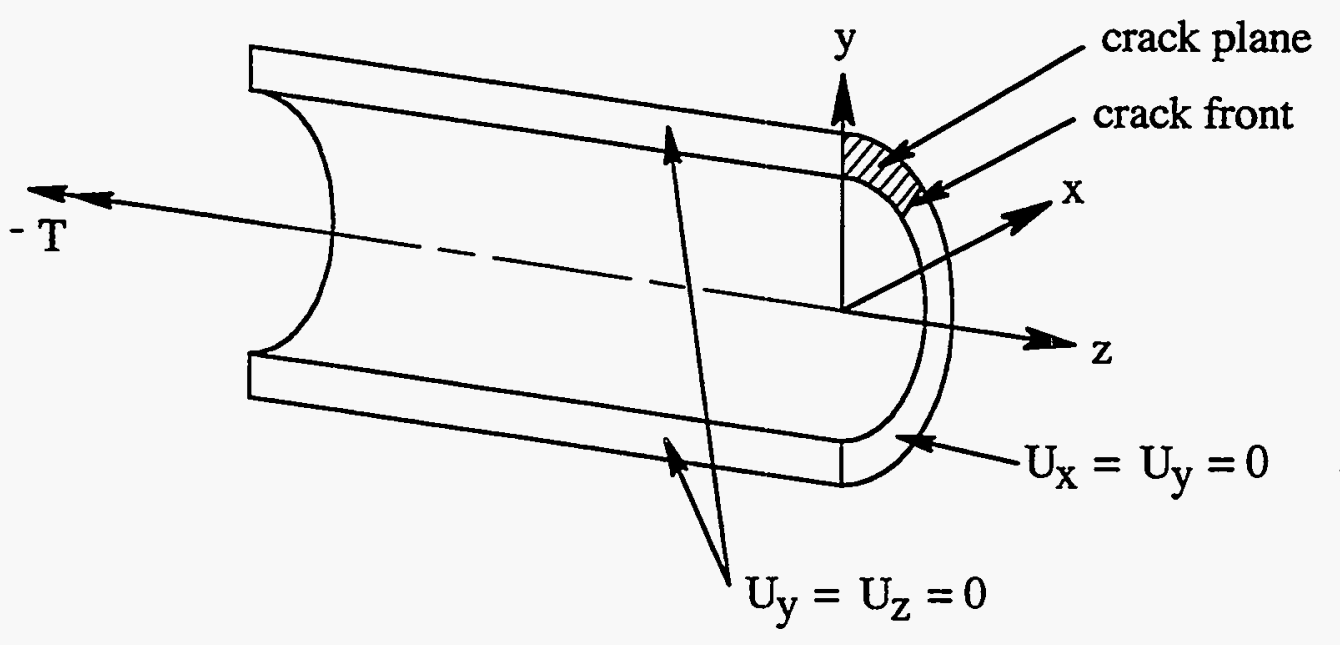

Figure 4.9 Boundary conditions for pure bending, pure tension, or combined bending plus tension of straight circumferential TWC pipe 


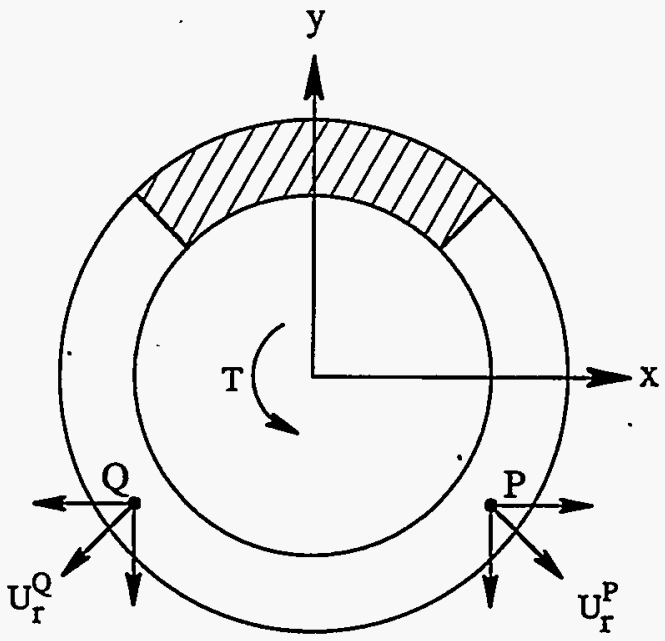

(a) Torque $\mathbf{T}$

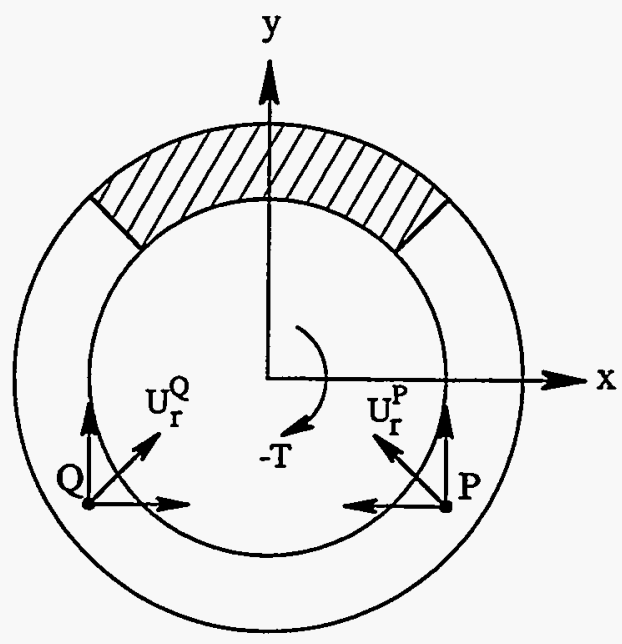

(b) Torque $-\mathbf{T}$

Figure 4.10 Schematic illustration of in-plane displacement field at two material points with $|x|=X$ on the uncracked portion of the $z=0$ plane for pure torsional loading 
these two points under the action of a torque $-\mathrm{T}$ is shown in Figure $4.10 \mathrm{~b}$. Note that in the latter case the radial displacements point toward the center of the pipe. Clearly the latter radial displacements are inconsistent with the former and cannot be explained as a mere result of reversal of sign of torque.

Thus, for consistency, in the case of pure torsion, the uncracked region of the $z=0$ plane will experience no in-plane displacements, i.e.,

$$
\left.\begin{array}{l}
U_{x}=0 \\
U_{y}=0
\end{array}\right\} \text { for the uncracked region of the } z=0 \text { plane }
$$

Similar arguments can be made to identify another plane of anti-symmetry, namely the $x=0$ plane on which the in-plane displacements vanish, i.e.,

$$
\left.\begin{array}{l}
U_{y}=0 \\
U_{z}=0
\end{array}\right\} \text { on the } x=0 \text { plane }
$$

The above boundary conditions are shown in Figure 4.11.

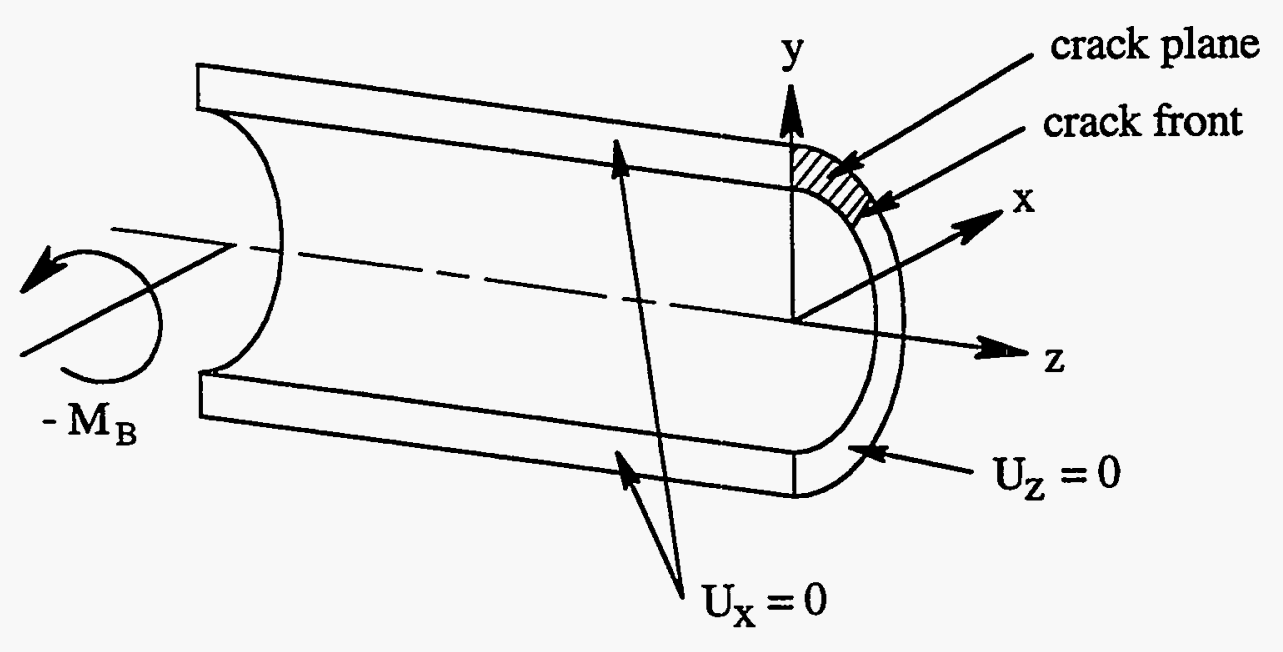

Figure 4.11 Boundary conditions for pure torsion of straight circumferential TWC pipe 


\subsubsection{Angled Cracks}

Angled cracks were analyzed under pure bending, pure tension, pure torsion and combined bending plus torsion. Half the pipe is modeled, since we no longer have symmetry about $z=0$. For the case of combined bending and torsion, one-half symmetry no longer applies. Hence, the full pipe is modeled. The boundary conditions for all of these cases are shown in Figures 4.12(a) through 4.12(c).

\subsubsection{Material Properties}

The elastic properties for the material were $E=193 \mathrm{GPa}(28,000,000 \mathrm{psi})$ and $v=0.29$, which were the properties for Pipe DP2-F11 at $288 \mathrm{C}(550 \mathrm{~F})$. The plastic behavior was obtained as a RambergOsgood fit of the average stress-strain response of the curves for the several tensile specimen orientations shown in Figure 2.3. This fit is shown in Figure 4.13. According to this fit and with $\sigma_{\mathrm{o}}=210 \mathrm{MPa}(30.45 \mathrm{ksi})$, the Ramberg-Osgood parameters are $\mathrm{n}=4.061$ and $\alpha=2.6$.

\subsubsection{Finite Element Analysis Code}

The commercial code ABAQUS@ was employed for all the analyses, with preprocessing for meshes being accomplished via the I-DEAS-ABAQUS interface. I-DEAS® was also used for post-processing tasks such as extracting stress contours, examining crack-opening displacements, and checking the overall deformed shape for conformity with expected results.

\subsubsection{Matrix of Calculations}

The following table lists the matrix of analyses performed for both straight and angled cracks.

Table 4.1 Matrix of finite element analyses ${ }^{(a)}$

\begin{tabular}{ccccccccc}
\hline $\begin{array}{c}\text { Angle } \\
(\Omega),\end{array}$ & & & & & & & \multicolumn{2}{c}{$\mathbf{M}_{\mathbf{B}}+$ Ten $+\mathbf{T}$} \\
\cline { 5 - 8 } degrees & $\mathbf{M}_{\mathbf{B}}$ & Ten & $\mathbf{T}$ & $\mathbf{M}_{\mathbf{B}}+\mathbf{T e n}$ & $\mathbf{M}_{\mathbf{B}}+\mathbf{T}$ & $\mathbf{T e n}+\mathbf{T}$ & $\mathbf{M}_{\mathbf{B}} / \mathbf{T}=\mathbf{1}$ & $\mathbf{M}_{\mathbf{B}} / \mathbf{T}=\mathbf{3}$ \\
\hline 0 & El, E-P & - & El-P & El, E-P & El, E-P & El, E-P & El, E-P & E, E-P \\
25 & El, E-P & El & El & - & - & - & - & - \\
45 & El, E-P & El & El & - & E-P & - & - & - \\
65 & El, E-P & El & El & - & - & - & - & - \\
\hline
\end{tabular}

(a) $\mathrm{M}_{\mathrm{B}}=$ bending moment, $\mathrm{Ten}=$ tension, $\mathrm{T}=$ torsion, $\mathrm{El}=$ elastic, $\mathrm{E}-\mathrm{P}=$ elastic-plastic. 


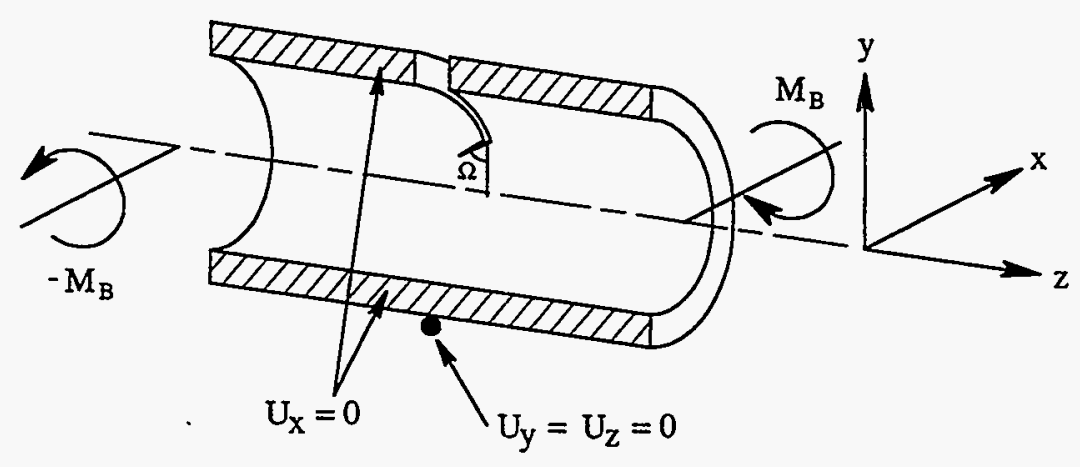

(a) Pure bending or pure tension

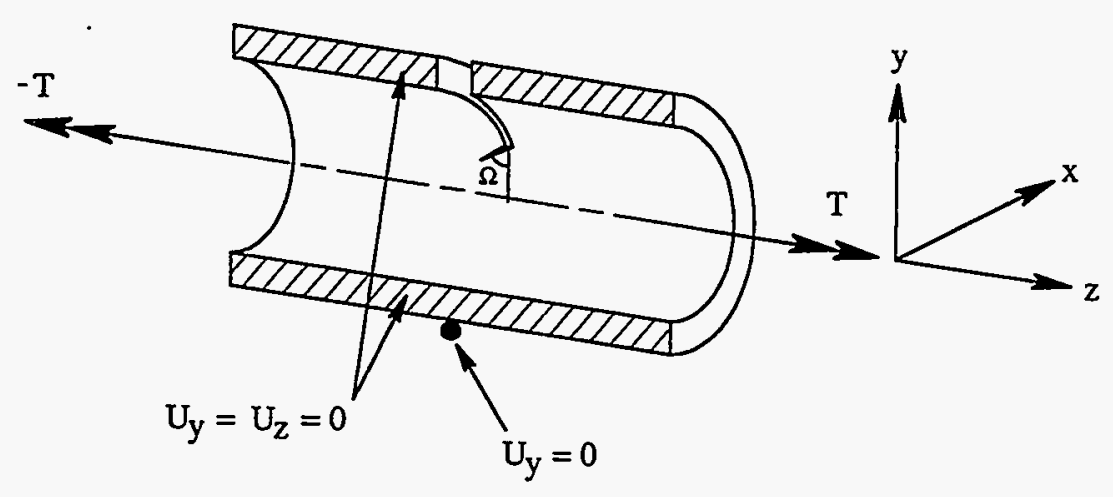

(b) Pure torsion

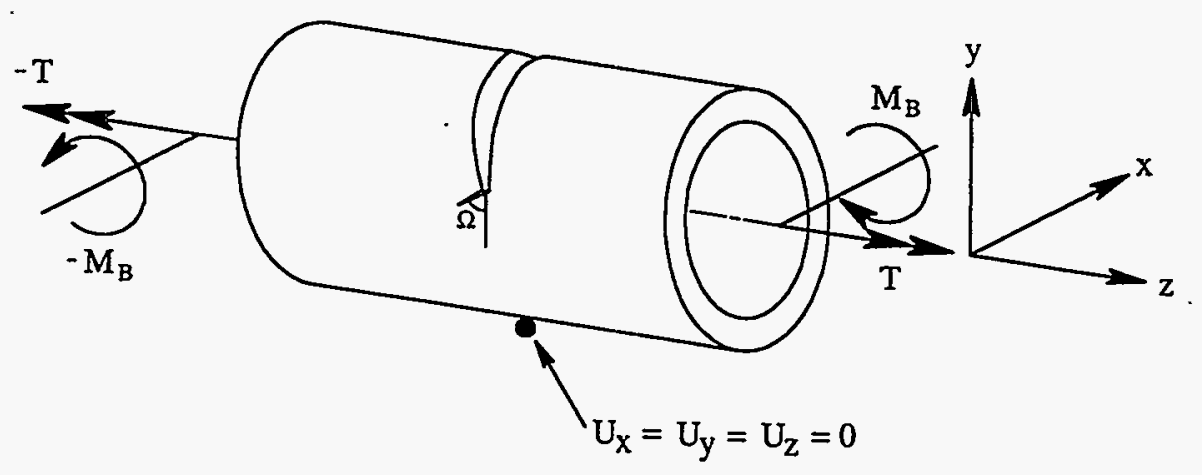

(c) Combined bending and torsion

Figure 4.12 Boundary conditions for angled cracks 


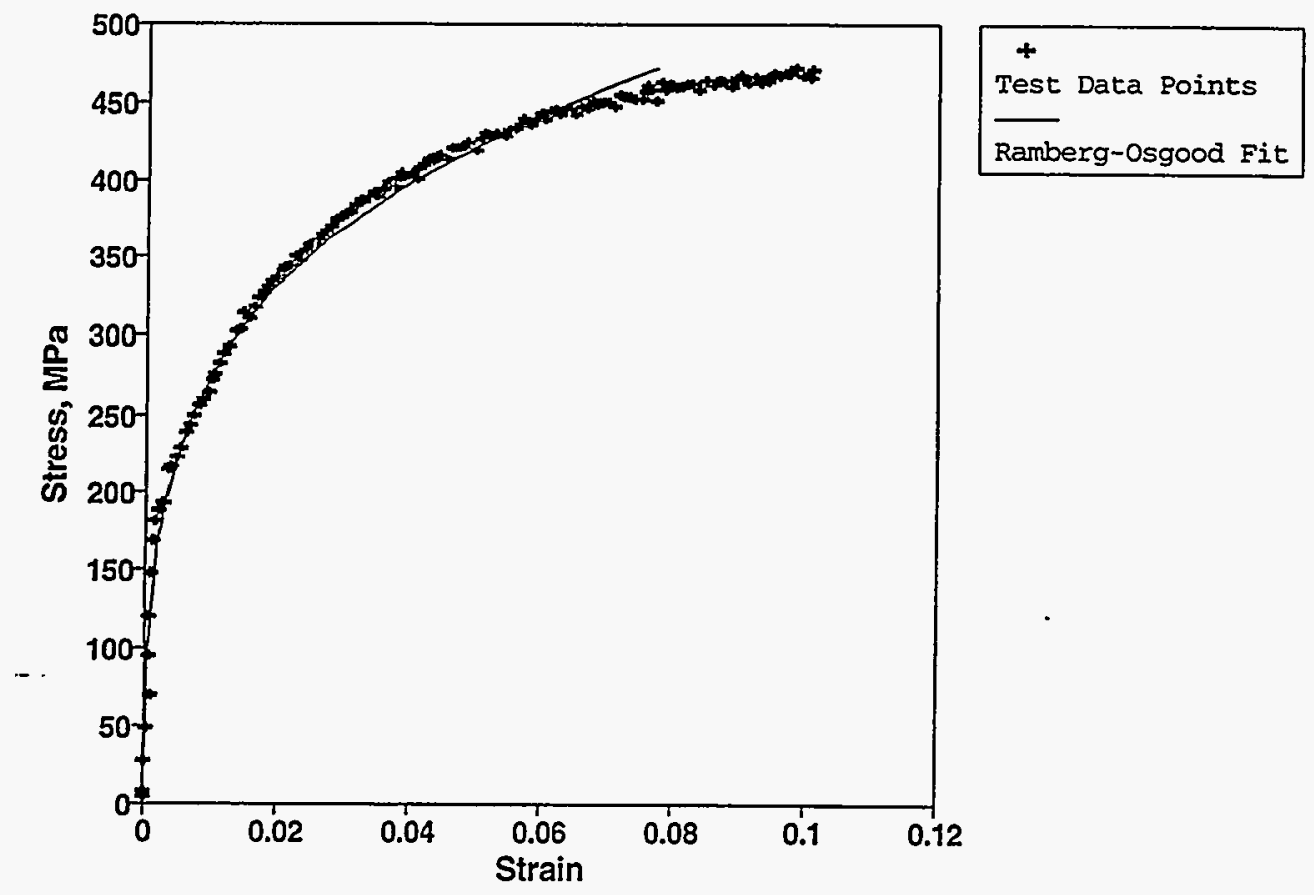

Figure 4.13 Ramberg-Osgood fit of the average engineering stress-engineering strain curve of Pipe DP2-F11 material at 288 C (550 F) (Specimen F11-T3)

\subsection{The Use of $\mathrm{J}$ as a Fracture Parameter for Straight and Angled Cracks}

Some comments regarding the use of $\mathrm{J}$ as a fracture parameter for straight and angled cracks under pure or mixed mode loadings are made in this section. Consider a straight (planar) crack in a linear elastic, homogeneous, material subjected to arbitrary combination of Mode I (opening mode), Mode II (in-plane sliding mode), and Mode III (out-of-plane tearing mode), as shown in Figure 4.14. Let the strength of the field at the tip of the crack be characterized by the stress-intensity factors, $\mathrm{K}_{\mathrm{I}}, \mathrm{K}_{\mathrm{II}}$, and $\mathrm{K}_{\mathrm{III}}$ for these three modes, respectively. The potential energy-release rate, $\mathcal{G}$, per unit crack extension in the $x_{1}$ direction is related to the stress-intensity factors by

$$
\mathcal{G}=\frac{\beta}{\mathrm{E}}\left(\mathrm{K}_{\mathrm{I}}^{2}+\mathrm{K}_{\mathrm{II}}^{2}\right)+\frac{1+v}{\mathrm{E}} \mathrm{K}_{\mathrm{III}}^{2}
$$

where $\beta=1$ for plane stress and $\beta=1-v^{2}$ for plane strain.

Rice (Ref. 4.2) showed that the J-integral taken along a material curve around the crack-tip, is precisely equal to $\mathcal{G}$. The J-integral has proved to be of great value in fracture testing. The J-integral as given by Rice (Ref. 4.2) is actually the first component of the vector (Refs. 4.3 and 4.4)

$$
F_{k}=\int_{\Gamma}\left(W n_{k}-t_{i} U_{i, k}\right) d \ell
$$

with $\mathrm{F}_{1}=\mathrm{J}$. 


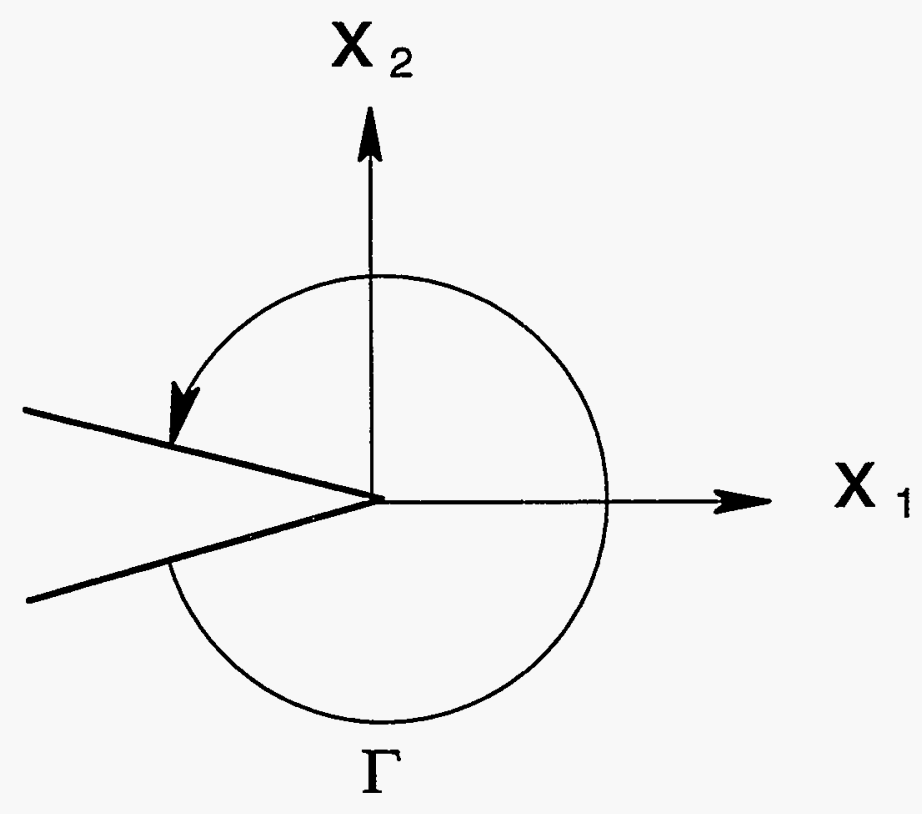

Figure 4.14 Integration path around the crack-tip for evaluation of $\mathbf{J}$

In Equation 4-7, $\mathrm{W}$ is the strain-energy density, $\mathrm{n}_{\mathrm{k}}$ is the unit outward normal to $\Gamma$, $\mathrm{t}_{\mathrm{i}}$ is the traction acting on the outer side of $\Gamma$ and $U_{i}$ are the displacements. As mentioned earlier, the first component of the above integral, $\mathrm{J}$, has a precise and clear physical meaning as the energy release rate associated with unit crack extension in the $\mathrm{x}_{1}$ direction for self-similar propagation. The fact that $\mathrm{J}$, or equivalently $F_{1}$, characterizes the driving force for cracks extending along $x_{1}$ direction, makes it tempting to argue that the second component of the integral given in Equation 4-7 may determine the driving force for the crack to grow at some angle with respect to the $x_{1}$ axis. In fact, several authors have adopted this approach (Refs. 4.5 and 4.6). Restricting attention to a two-dimensional linear elastic straight crack problem, it can be shown that (Ref. 4.7)

$$
F_{2}=-2 \frac{K_{I} K_{I I}}{E}
$$

However, this is strictly valid only when $\mathrm{F}_{2}$ is calculated around the immediate neighborhood of the crack. It has been shown that $\mathrm{F}_{2}$ is not path independent for finite contours surrounding the crack tip in the same sense as $F_{1}$ or $J$ (Ref. 4.8). A modification of $F_{2}$, which incorporates terms involving the strain-energy density, W, along the crack faces, has been shown to result in path independence (Ref. 4.9). Even though $\mathrm{F}_{2}$ can be made to be path independent by this modification, does it characterize the driving force for angled growth of the crack? Before an answer to this question is attempted, it is useful to examine the physical meaning of the $F_{k}$ integral given in Equation 4-7. $F_{k}$ characterizes the energy-release rate when a crack tip is translated in position relative to the material (Refs. 4.3 and 4.4). This physical interpretation of $F_{k}$ is completely consistent with the interpretation of $J$ or $F_{1}$. However, it also means that $F_{2}$ characterizes the energy-release rate with unit translation of the crack 
tip and crack as a whole along the $\mathrm{x}_{2}$ direction. Thus, $\mathrm{F}_{2}$ cannot characterize the energy-release rate for angled growth of the crack. In fact, there is no crack-tip integral which can characterize the energy-release rate associated with angled growth of the crack.

To understand the onset of angled crack growth under elastic-plastic loading, it is necessary to perform analyses of the angled crack with the length of angular region much smaller than the main crack. It should be mentioned that for linear elastic materials, it is still possible to define stress-intensity factors at the tip of the angled crack (Ref. 4.10), and that $\mathrm{J}$ as evaluated around the angled-crack region still characterizes the energy-release rate for unit extension of the crack-tip along that angle.

Under elastic-plastic conditions, $\mathrm{J}$ has been successfully used as a valid fracture parameter for straight cracks experiencing pure or mixed-mode loading (Refs. $4.11-4.14$ ). Strictly speaking, this validity is based on the theory of deformation plasticity (where unloading is precluded). In addition, proportional loading is assumed. Under these assumptions, the deformation of plasticity can be viewed as nonlinear elasticity. Of course, this is a gross assumption of actual material behavior. Notwithstanding, $\mathrm{J}$ has proved successful in the experimental characterization of the onset of crack growth. Though such validity of $\mathrm{J}$ has not been proven for angled cracks, $\mathrm{J}$ has been used in this report for angled cracks. It is believed that this choice is valid provided $\mathrm{J}$ is computed along contours within the angular region of the crack.

\subsection{Straight Circumferential TWC Analyses}

In order to gain an insight into the effects of combined loading, the variation of $\mathrm{J}$ along the crack front as well as the evolution of stresses ahead of the crack-tip for straight circumferential TWC pipes were performed under pure bending, pure torsion, combined bending and tension, combined torsion and bending, and combined tension, bending and torsion. The tension loading was performed to simulate the end-cap loading due to internal pressure. This loading was assumed to be caused by an internal pressure of $15 \mathrm{MPa}(2,250 \mathrm{psi})$. In all the combined loading cases involving tension, the tension loading was applied first, followed by the application of bending moment or torque or the desired ratio of these two.

\subsubsection{Verification of J-Values Using Analytical Techniques}

The J-integral is computed using a contour beginning on one side of the cracked face and ending at the other side. For linear elastic conditions, the J-integral is related to the crack-tip stress intensity factors (see Equation 4-6). This gives an analytical technique for validating the accuracy of the finite element results obtained through ABAQUS.

Under pure bending, the straight crack experiences Mode I (opening) conditions. The stress intensity factor, $\mathrm{K}_{\mathrm{I}}$, and $\mathrm{J}$ are related by, 


$$
J=\beta \frac{K_{I}^{2}}{E}
$$

where $\beta=1$ for plane stress and $\beta=1-v^{2}$ for plane strain conditions.

$\mathrm{K}_{\mathrm{I}}$ is computed using the near crack-tip-displacement fields by

$$
\mathrm{K}_{\mathrm{I}}=4 G \frac{\sqrt{2 \pi}}{\eta_{\mathrm{u}}} \frac{\mathrm{U}_{\mathrm{z}}}{\mathrm{r}^{1 / 2}}
$$

where $G=E / 2(1+v), \eta_{u}=8(1-v)$ for plane strain, and $\eta_{u}=8 /(1+v)$ for plane stress conditions.

In Equation 4-10, $\mathrm{U}_{\mathrm{z}}$ is the displacement in the $\mathrm{z}$ direction and $\mathrm{r}$ is the distance from the crack tip. In addition, using a modified crack-closure integral (Ref. 4.14), the J-integral is related to the reaction force $R_{f}$ that is obtained when a crack extends in length by $\Delta a$, by

$$
\mathrm{J}=\mathrm{R}_{\mathrm{f}} \frac{\delta_{\mathrm{t}}}{2 \Delta \mathrm{a}}
$$

where $\delta_{t}$ is the crack-tip-opening displacement.

Table 4.2 shows the J-values along the crack front as calculated by ABAQUS@ compared with estimates using Equations 4-10 and 4-11. Since plane stress or plane strain conditions may not be exactly satisfied except at the center of the crack front, estimates using both states of stress are

\begin{tabular}{|c|c|c|c|}
\hline \multirow{2}{*}{$\begin{array}{c}\mathbf{J} \text { from } \\
\mathbf{k J} / \mathbf{m}^{2}\left(\mathbf{i n}-\mathrm{lb}_{\mathbf{b}} \mathbf{i n}^{2}\right)\end{array}$} & \multicolumn{2}{|c|}{$J=\frac{\beta K_{I}^{2}}{E}, k J / m^{2}\left(i n-l b / i^{2}\right)$} & \multirow{2}{*}{$\begin{array}{l}J=R_{f} \delta_{t} /(2 \Delta a), \\
k J / m^{2}(\text { in-lb/in })\end{array}$} \\
\hline & Plane Stress & Plane Strain & \\
\hline $4,320(24,700)$ & $4,950(28,200)$ & $4,530(25,900)$ & \\
\hline $3,950(22,600)$ & $3,750(21,400)$ & $3,440(19,600)$ & $3,790(21,600)$ \\
\hline $3,570(20,400)$ & $4,120(23,500)$ & $3,770(21,500)$ & \\
\hline $3,060(17,500)$ & $2,930(16,700)$ & $2,680(15,300)$ & $2,940(16,800)$ \\
\hline $2,580(14,700)$ & $3,030(17,300)$ & $2,770(15,800)$ & \\
\hline
\end{tabular}
provided.

Table 4.2 Straight $\mathrm{TWC}$ pipe pure bending $\mathrm{J}$ values 
These comparisons are reasonably good, and hence, the ABAQUS $\circledast$ results appear to be valid for more complex analyses.

\subsubsection{Variation of J Through the Thickness of Pipe}

The results of the analyses indicated that there existed a variation of $\mathrm{J}$ along the crack front through the thickness of the pipe. These results are summarized in Figures 4.15 and 4.16. Figure 4.15 shows the variation of normalized $J$ (normalized with respect to the $J$ value at the inner surface) as a function of the normalized distance from the inner wall (normalized with respect to the wall thickness) for the cases of bending and bending plus torsion. In the case of elastic behavior of the material under bending, the normalized $\mathrm{J}$ monotonically decreases from the inner to the outer surface. However, when plasticity is included the normalized $J$ reaches a maximum at the mid-thickness. Also, in the case of bending plus torsion the normalized $J$ reaches a maximum at the mid-thickness for both ratios of torsion to bending. For pure torsion, the increase in normalized $J$ is significant from $R_{i}$ to $R_{0}$ (Figure 4.16) in the elastic as well as the plastic cases.

For further analysis describing the results, it is convenient to select one value of $\mathrm{J}$ through the thickness so as to enable comparisons. Clearly, when plasticity is included, maximum $J$ is attained at the center of the crack front (mid-thickness of pipe) for pure bending and bending plus torsion. Hence, the mid-thickness $J$ value is selected, since it is the most critical, at least under these loading conditions.

I.D.

O.D.

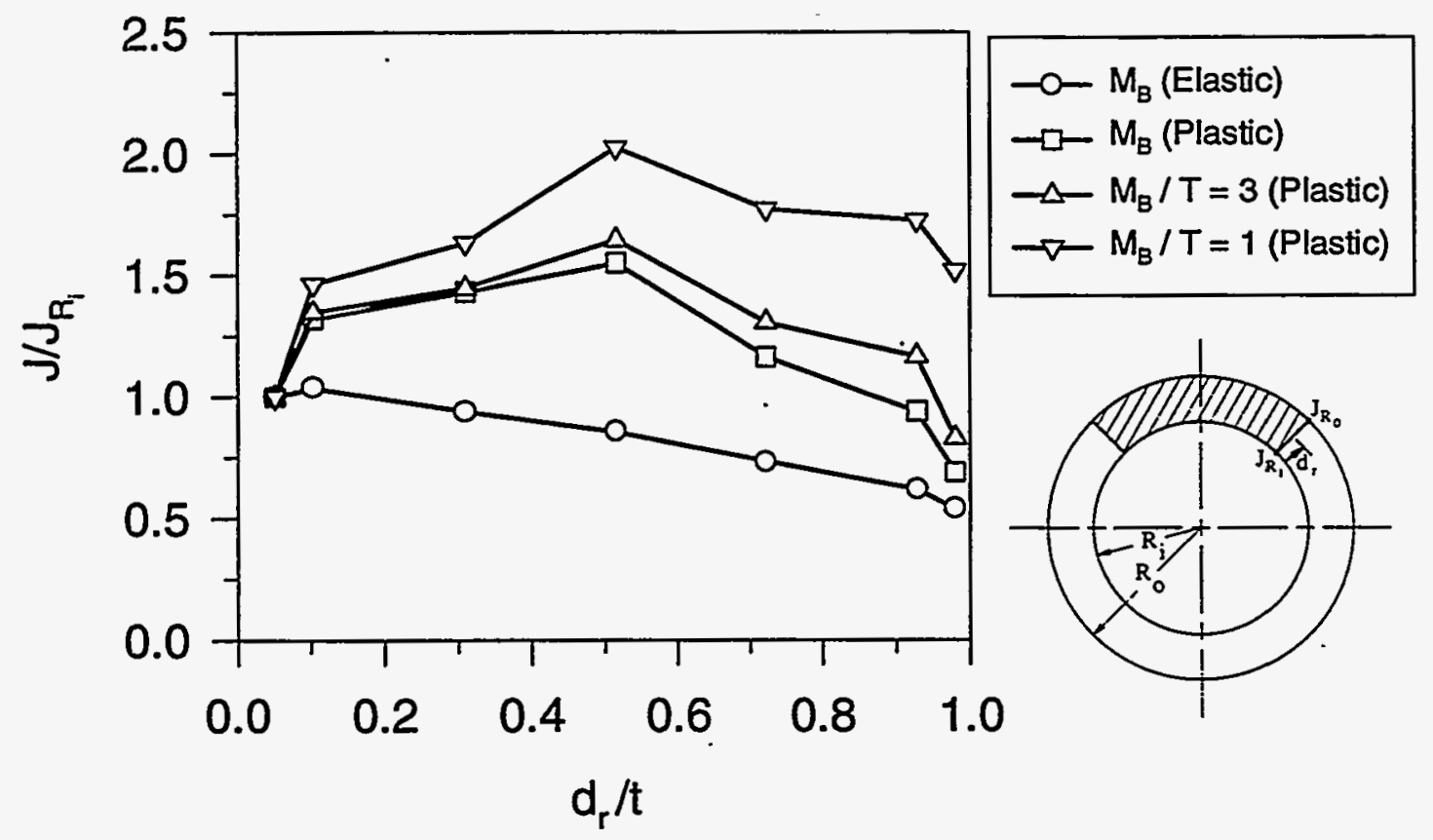

Figure 4.15 $J$ normalized by $J_{R i}$ (value of $J$ at the inner pipe surface) versus distance, $d_{r}$, from inner surface normalized by the pipe wall thickness, $t$, for pure bending and combined bending and torsion 
I.D.

O.D.

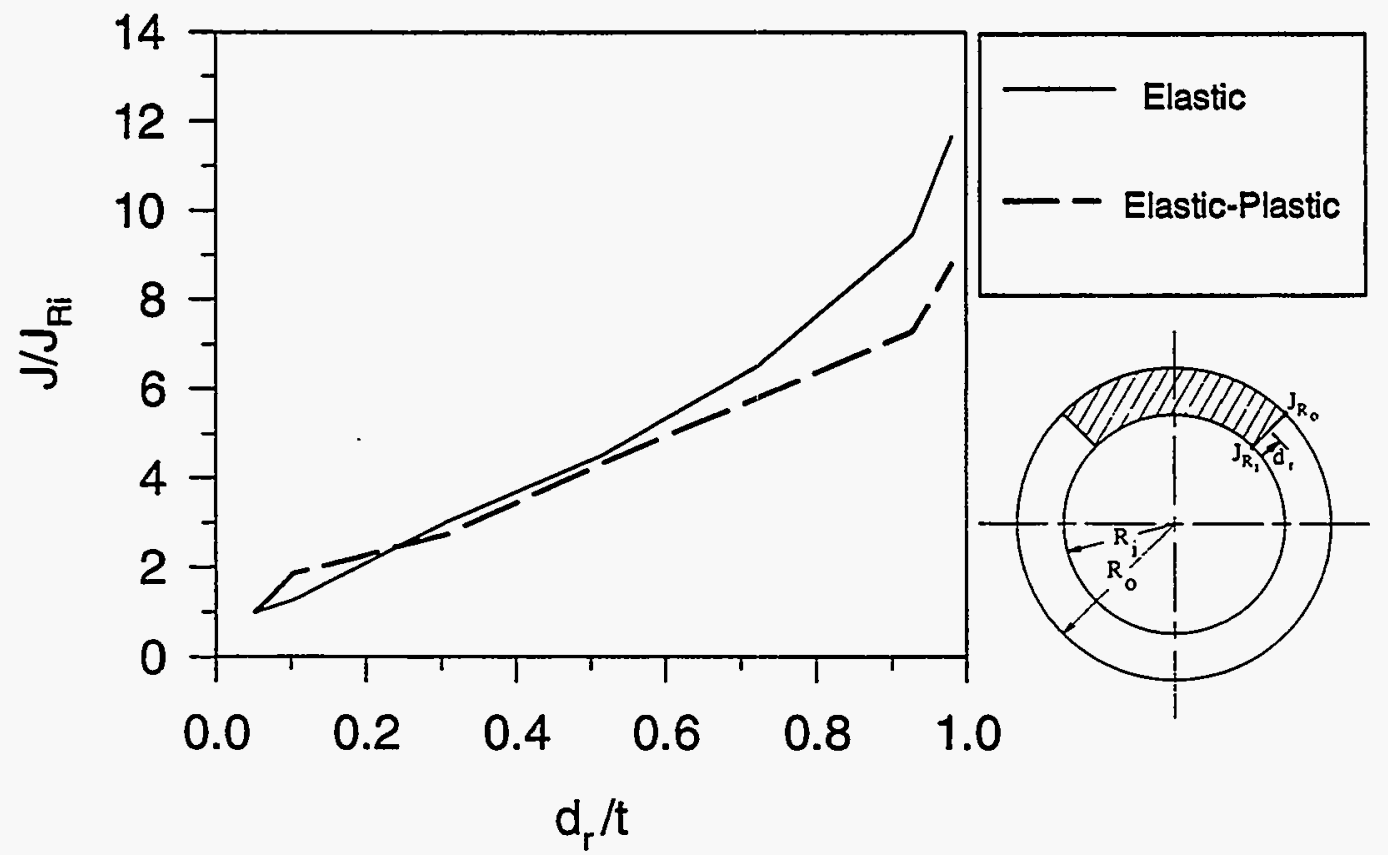

Figure 4.16 $J$ normalized by $J_{R i}$ (value of $J$ at the inner pipe surface) versus distance, $d_{r}$, from inner surface normalized by the pipe wall thickness, $t$, for pure torsion

\subsubsection{Variation of J with Applied Loading}

Figures 4.17 and 4.18 illustrate the effect of tension due to internal pressure with subsequent bending or torsion, on the variation of $\mathrm{J}$ at the mid-thickness. The value of $\mathrm{J}$ at a given bending moment is larger for combined bending and tension loading compared to pure bending. The magnitude of this difference increases with the level of applied bending moment. On the other hand, the effect of tension on the variation of $\mathrm{J}$ with applied torsional moment appears negligible, see Figure 4.18.

The effect of combined tension and subsequent bending and torque on the variation of $\mathrm{J}$ is illustrated in Figures 4.19a and $\mathrm{b}$. The variation of $\mathrm{J}$ at the mid-thickness with effective moment for the case of tension plus bending, as well as the case of combined tension, bending, and torsion with a ratio of bending moment-to-torque of 3 is shown in Figure 4.19a. For comparison purposes the variations of $J$ at the mid-thickness with applied pure bending and pure torque are also shown in Figure 4.19a.

As discussed in Section 4.2.1, the effective moment for combined bending and torsion can be computed in several ways, with $c_{e}=0$ and $c_{e}=1$ representing the extremes. The cases for which $c_{e}=$ $1 / 2$ and $c_{e}=\sqrt{3} / 2$ lie in between these extremes. When the effective moment, for a bending momentto-torque ratio of 3.0, is calculated, either with $c_{e}=0$ or 1 (see Equation 4-2), the variation of $J$ with effective moment for combined tension, bending, and torsion shows very little difference with the 


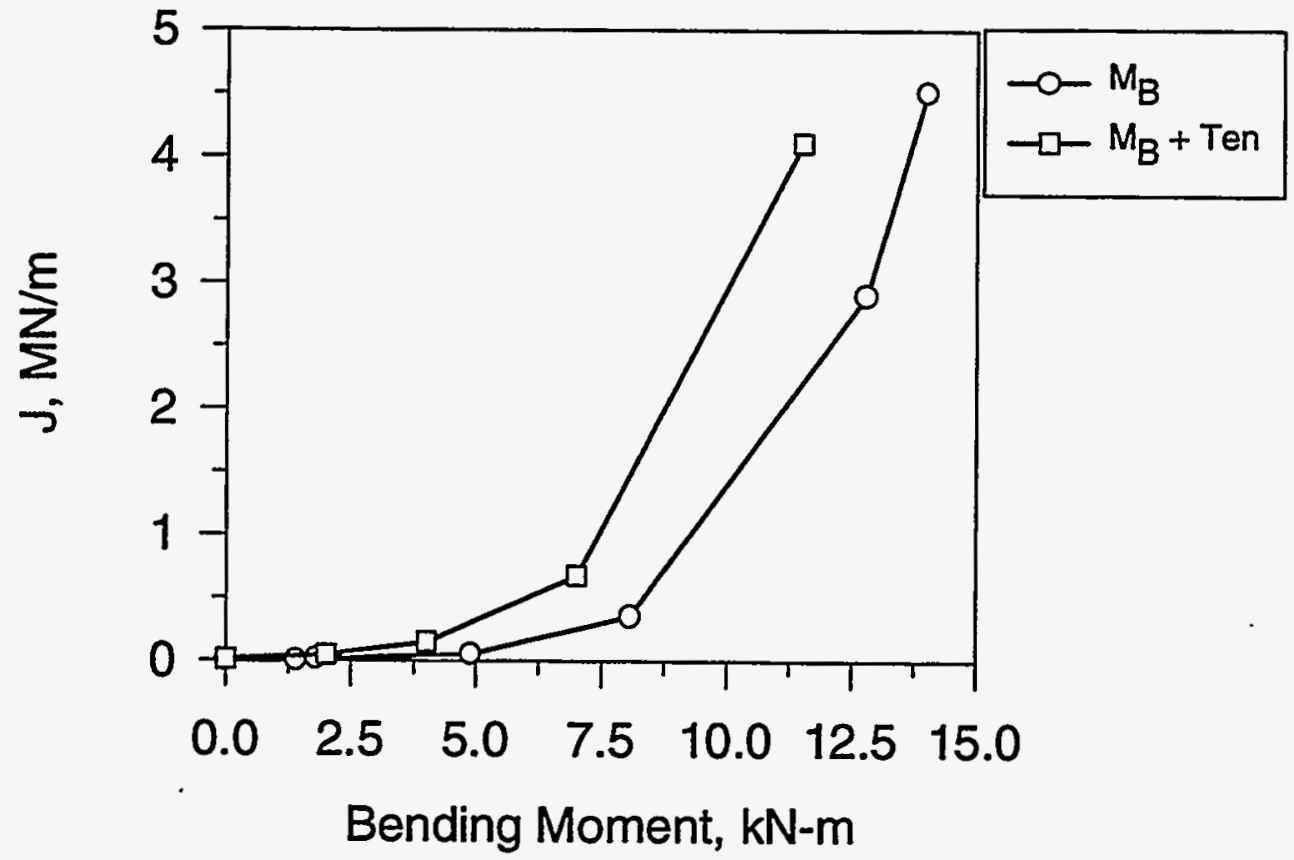

Figure 4.17 Effect of prior tension due to pressure on the variation of $\mathbf{J}$ at the mid-thickness with subsequent bending

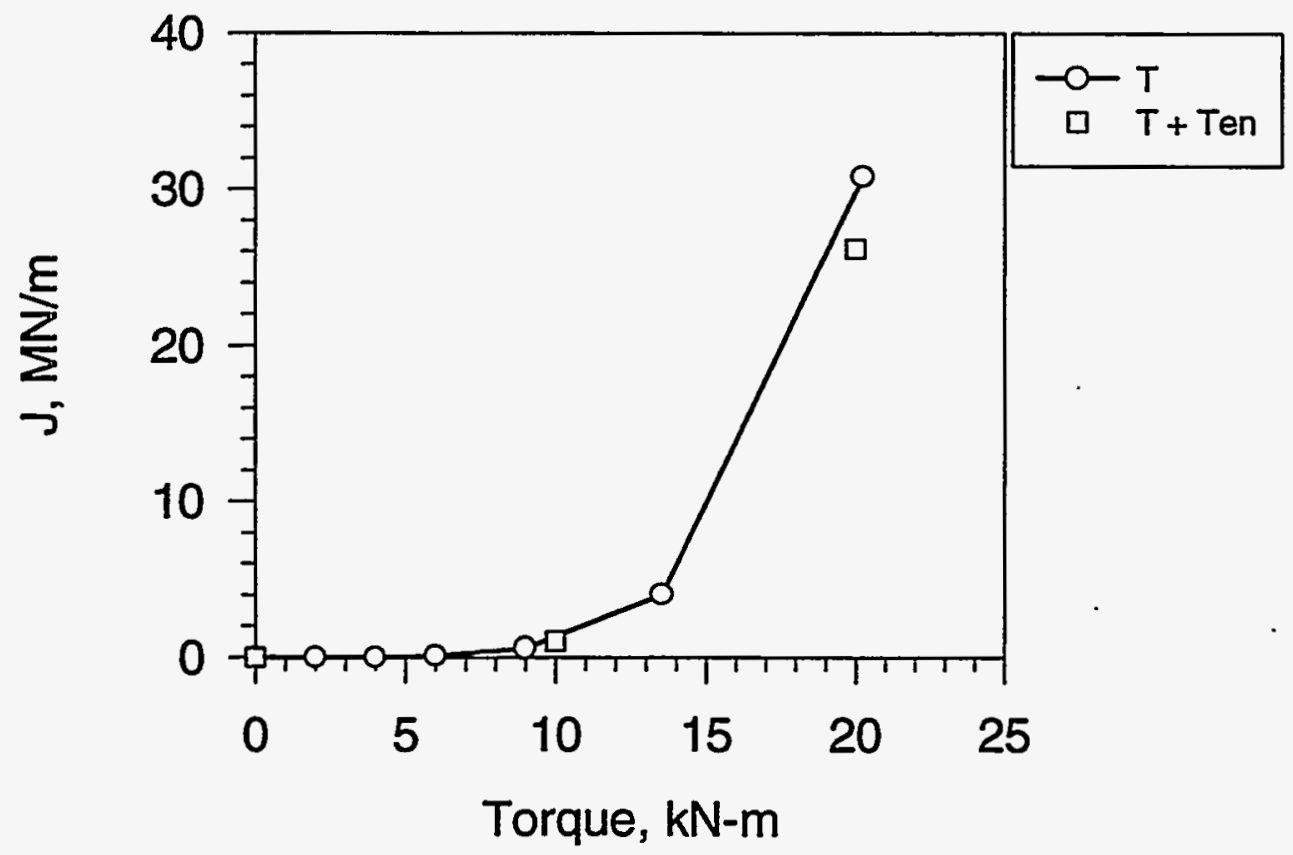

Figure 4.18 Effect of prior tension due to pressure on the variation of $J$ at the mid-thickness with subsequent torsion 


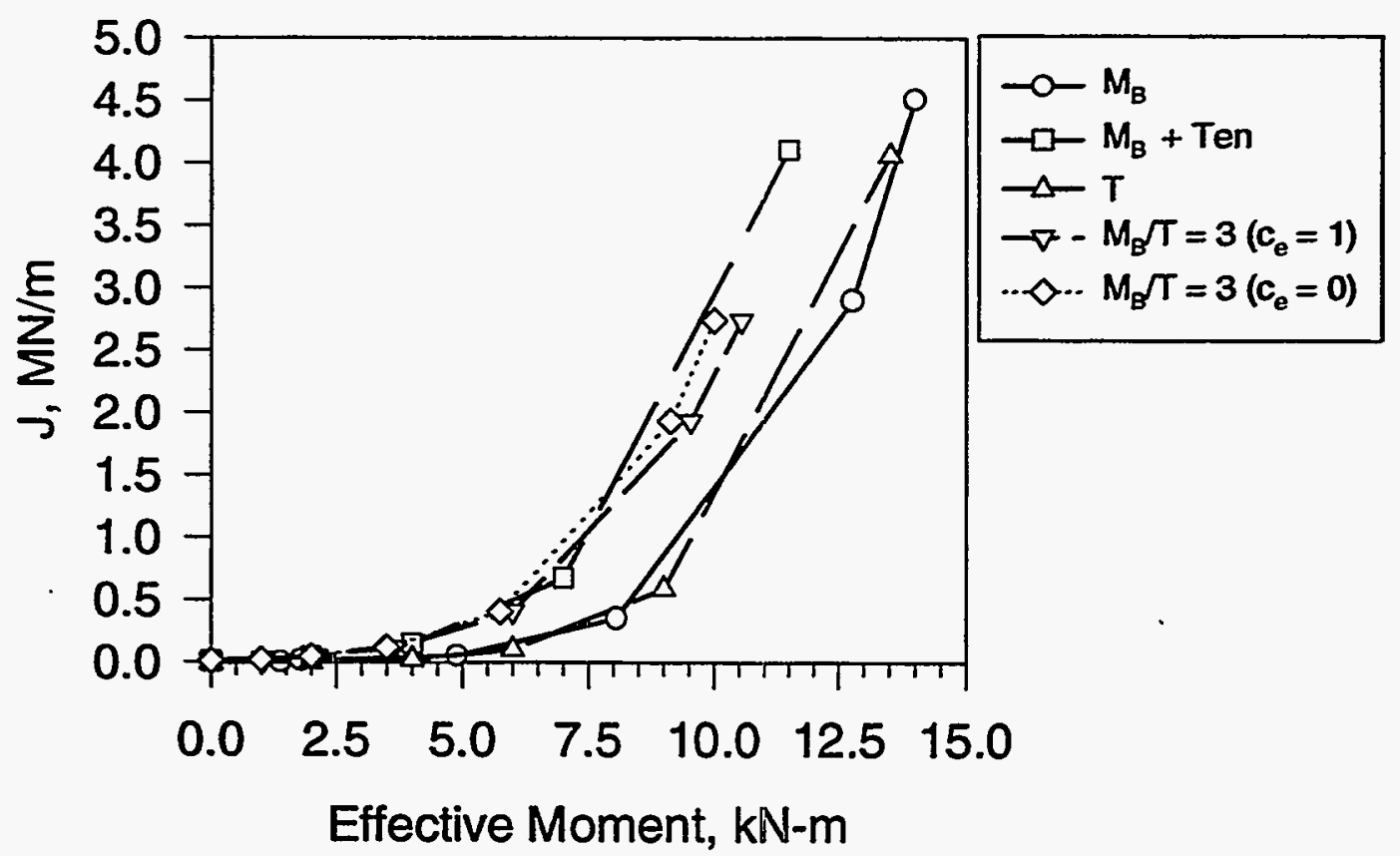

(a) Pure bending; pure torsion; combined bending and tension; and combined tension, bending, and torsion $\left(M_{B} / T=3.0\right)$

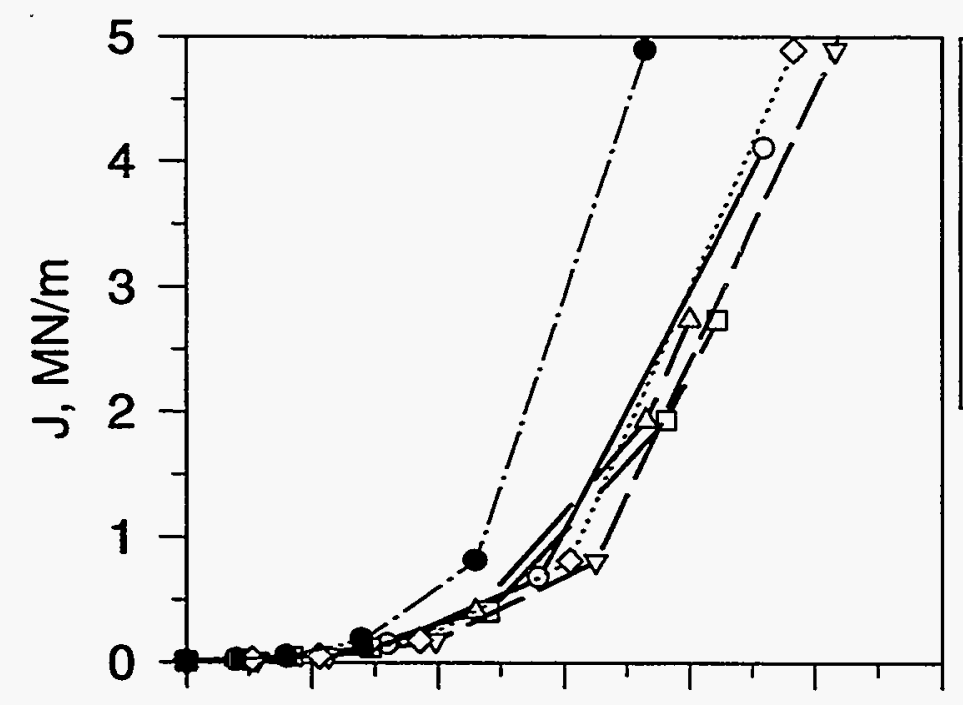

$$
\begin{aligned}
& \multimap-M_{B}+\text { Ten } \\
& \square-M_{B} / T=3\left(c_{e}=1\right) \\
& \triangle-M_{B} / T=3\left(c_{e}=0\right) \\
& \rightarrow-M_{B} T=1\left(c_{e}=1\right) \\
& \therefore \diamond-M_{B} / T=1\left(c_{e}=0.86\right) \\
& \rightarrow-M_{B} / T=1\left(c_{e}=0\right)
\end{aligned}
$$

$\begin{array}{lllllll}0.0 & 2.5 & 5.0 & 7.5 & 10.0 & 12.5 & 15.0\end{array}$

Effective Moment, kN-m

(b) Combined bending and tension; combined tension, bending, and torsion cases $\left(M_{B} / T=3.0\right.$ and $\left.M_{B} / T=1\right)$

Figure 4.19 Effect of combined loading on the variation of $J$ at the mid-thickness versus effective moment for various pure and combined loading cases 
corresponding variation for tension plus bending, see Figure 4.19a. This shows the dominance of bending over torsion effects on $\mathrm{J}$. However, when the ratio of bending moment-to-torque is 1 , the variation of $\mathrm{J}$ with effective moment for combined tension, bending, and torsion deviate significantly from the corresponding variation obtained for the case of tension plus bending, when the effective moment is calculated using $c_{\mathrm{e}}=0$ [Figure $4.19 \mathrm{~b}$ ]. When $c_{\mathrm{e}}$ is taken to be unity, the variation of $\mathrm{J}$ with effective moment for this combined tension, bending, and torsion loading falls slightly below the corresponding variation obtained for bending plus tension loading. However, better agreement between these two variations is obtained when $c_{e}$ is taken to be $\sqrt{3} / 2$ in calculating the effective moment for this combined loading case. These results for bending plus torsion loading demonstrate that when the effective moment is calculated assuming $c_{e}=\sqrt{3} / 2, \mathrm{~J}$-solutions for bending may be adopted for cracked pipes experiencing bending plus torsional loading. The crack tip experiences pure Mode I under combined bending and tension, while it experiences Modes $\mathrm{II}$ and $\mathrm{II}$ under pure torsion. Thus for torsion with either bending or tension or both, all three modes are present. As a result, even though the crack-tip conditions change from Mode I to mixed Modes I, II, and III, when the cracked pipe experiences torsion plus bending, the above results demonstrate that reasonable estimates of $\mathrm{J}$ can be obtained from the J-solution for the bending case. Here, the effective moment is calculated using $c_{e}=\sqrt{3} / 2$. Note that this conclusion applies only when the torque is equal to or less than the bending moment.

\subsubsection{Crack-Opening Displacements and Areas}

It has been shown (Ref. 4.15) that in the case of pure bending of a straight circumferential TWC pipe, that the projected crack-opening profile may be described by an ellipse when the crack is not growing. Similar elliptic profiles are obtained for the case of tension plus bending at several bending moment levels as shown in Figure 4.20. When torsional loading is involved this symmetry of crack-opening profile is lost. For the ratio of bending moment-to-torque of 3 , the crack-opening profiles for various

effective moments (calculated using a value of $\sqrt{3} / 2$ for $c_{e}$ ) show very little deviation from an elliptic profile (Figure 4.21a). This is not surprising since bending dominates torsion for this load ratio.

However, when the ratio of bending moment-to-torque is 1.0 , the crack-opening profiles show larger deviations from elliptic configurations especially at higher effective moments (Figure 4.21b). Careful examination of Figure $4.21 \mathrm{~b}$ also reveals that the maximum total crack-opening displacements may still occur at the center of the crack. Note also that the crack experiences more twisting for this load ratio of 1.0 due to equal dominance of torsion. Though the crack-opening profile deviates from an elliptic configuration for a ratio of bending moment-to-torsion of 1.0, it is more useful for LBB applications to examine the variation of total crack-opening area with effective moment for the three cases considered above. The variations of crack-opening area (COA) with effective moment $\left(\mathrm{c}_{\mathrm{e}}=\right.$ $\sqrt{3} / 2$ ) for the combined tension, torsion, and bending cases, as well as the combined bending and tension case are shown in Figure 4.22. This figure reveals close agreement between all the three variations. Thus, the variation of COA with bending moment for bending plus tension case can be 


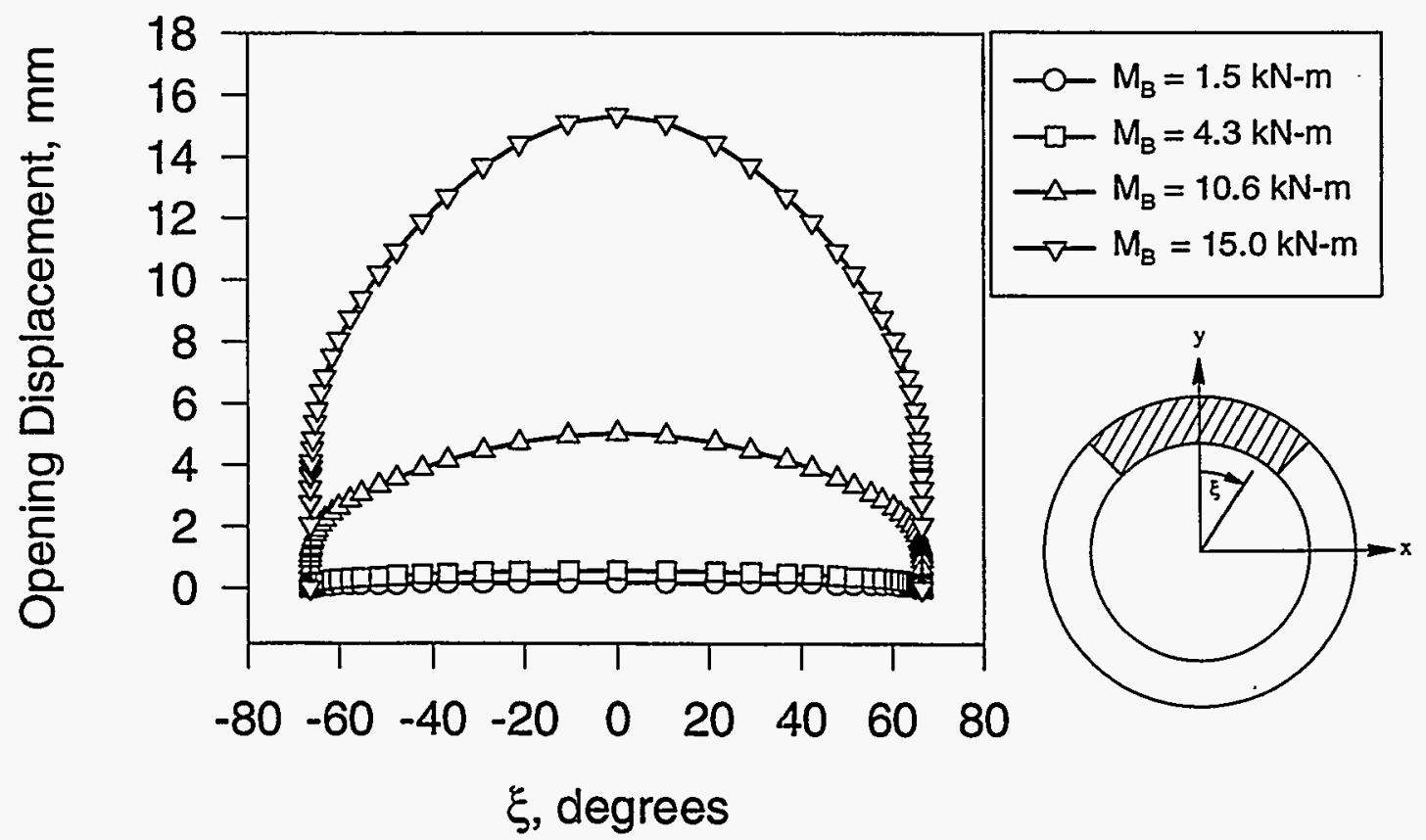

Figure 4.20 Crack-opening profiles at various applied bending moments for tension plus bending 


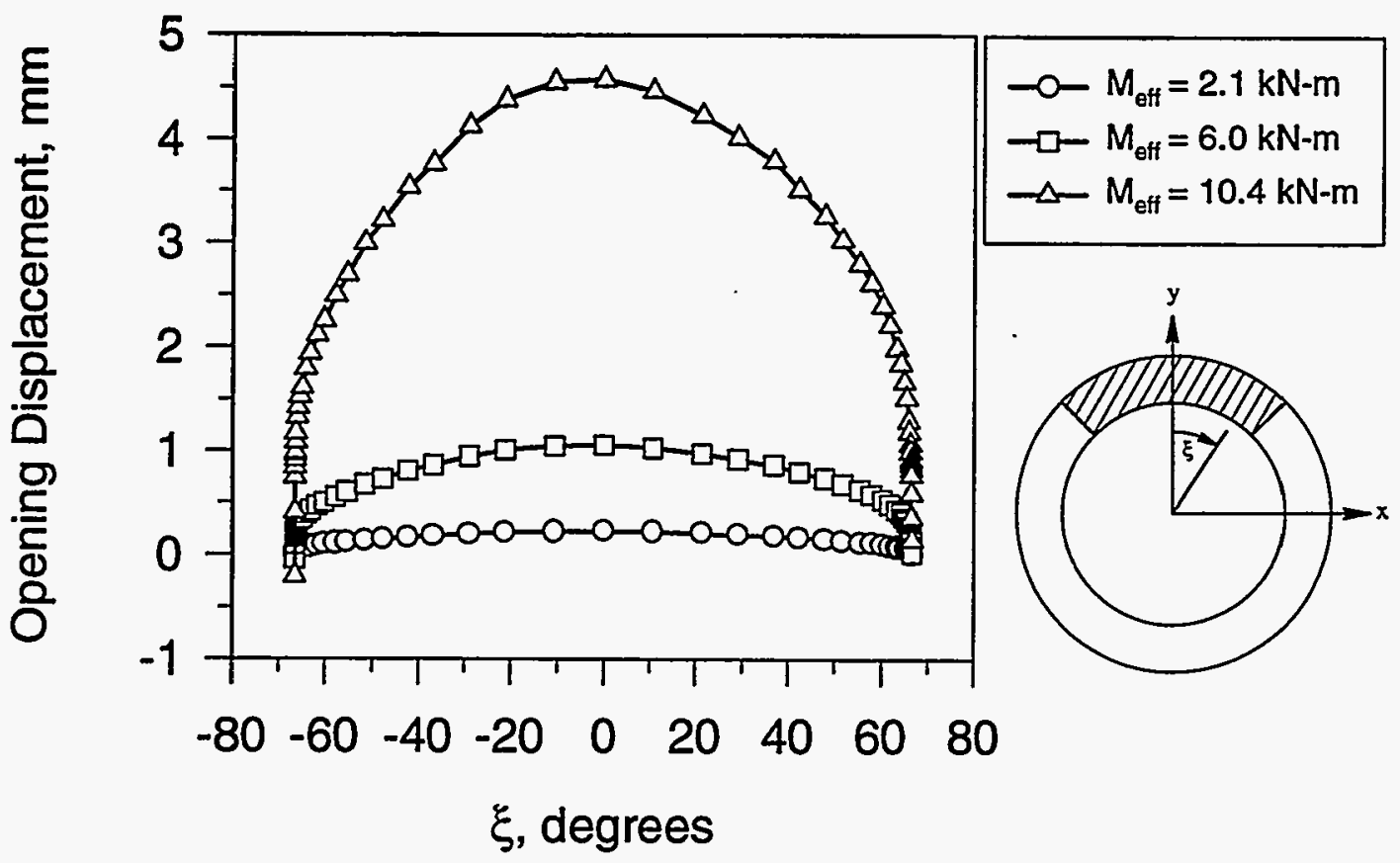

(a) $\mathrm{M}_{\mathrm{B}} / \mathrm{T}=\mathbf{3 . 0}$

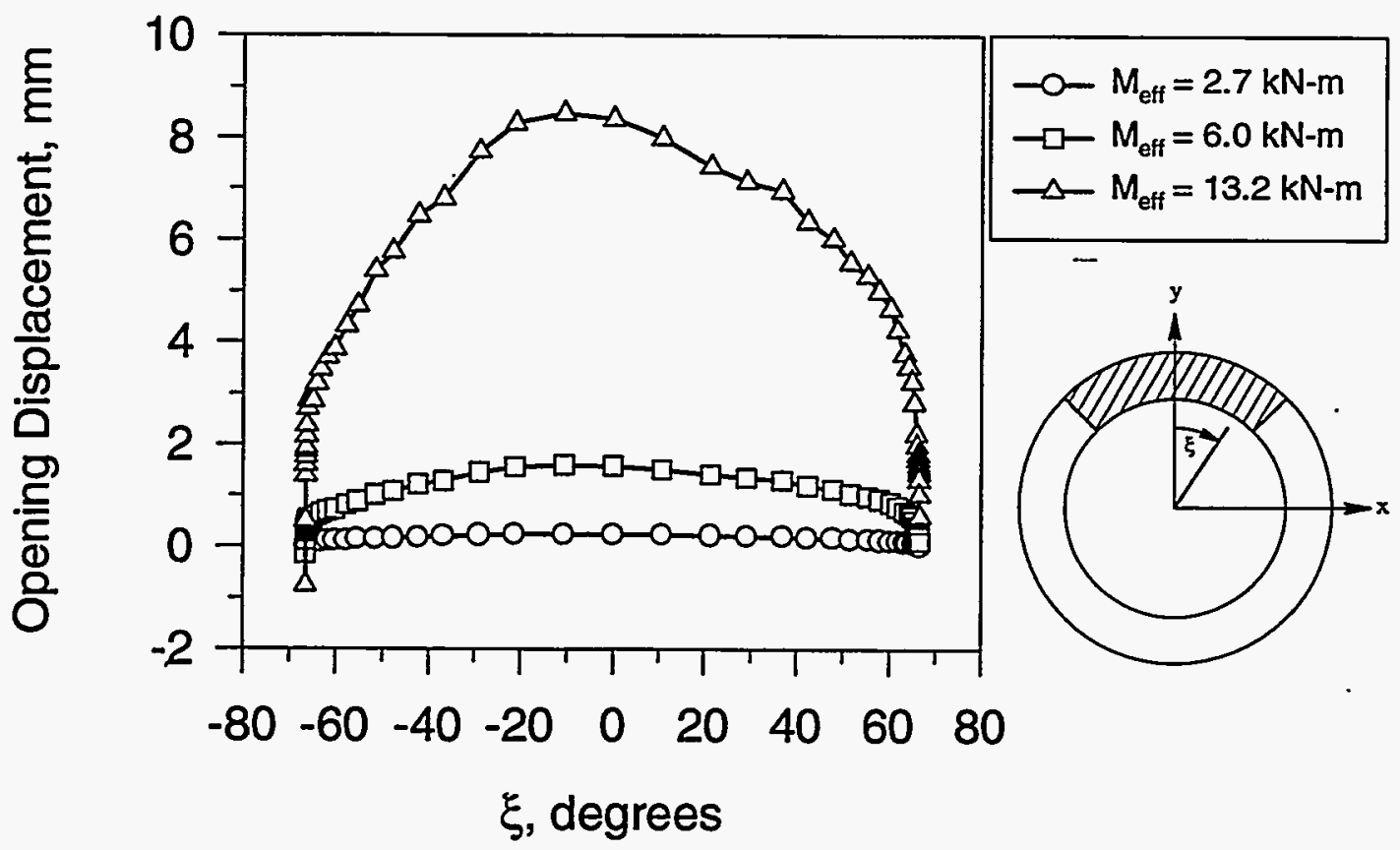

(b) $\mathrm{M}_{\mathrm{B}} / \mathrm{T}=\mathbf{1 . 0}$

Figure 4.21 Crack-opening profiles at various effective moments (calculated using $\left.c_{e}=\sqrt{3} / 2\right)$ for combined tension, bending, and torsion 


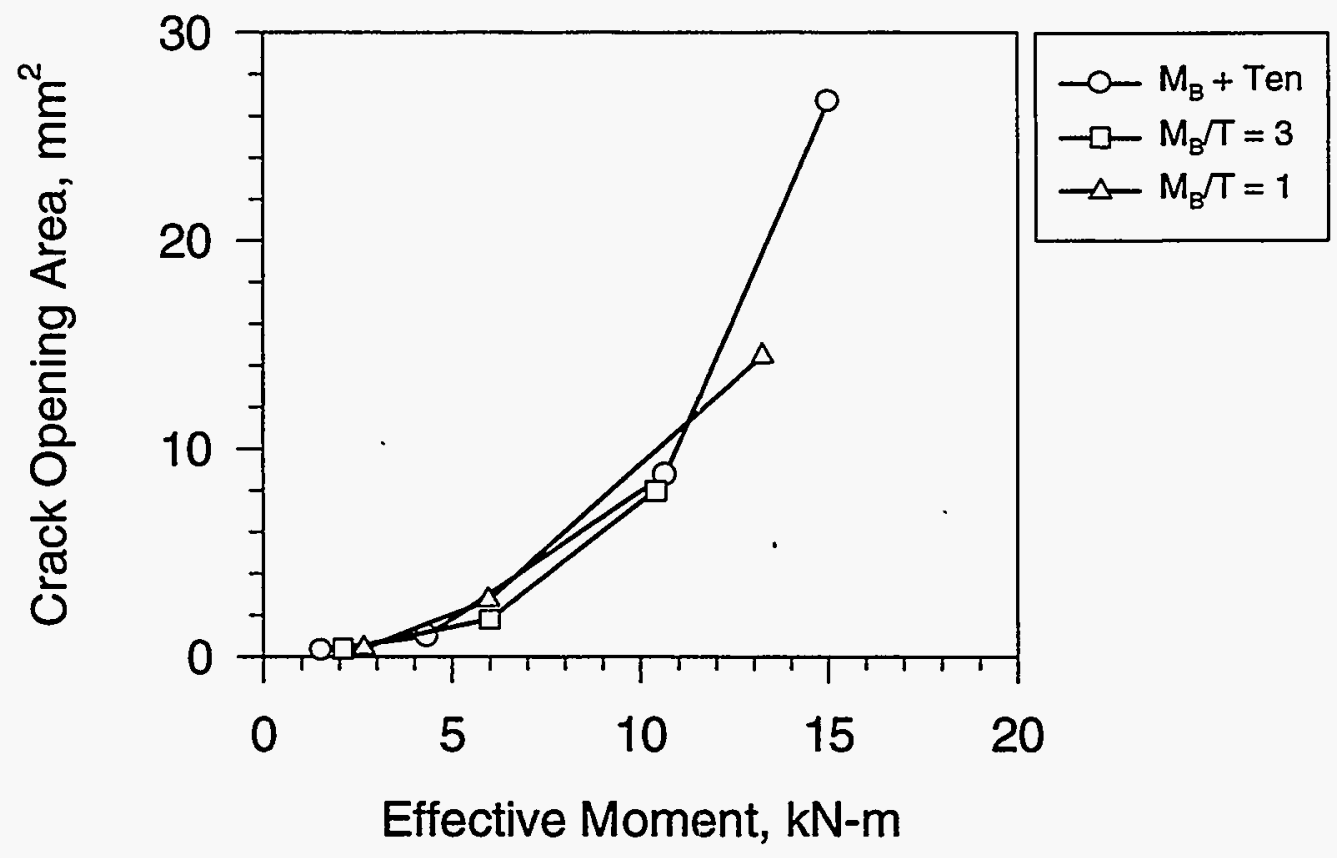

Figure 4.22 Comparison of the variations of total crack-opening area with effective moment for the combined load cases of tension plus bending and tension plus bending plus torsion $\left(c_{e}=\sqrt{3} / 2\right)$

used to determine the corresponding variation for combined tension, bending, and torsion cases by adopting the definition of effective moment given in Equation $4-2$, with $c_{e}=\sqrt{3} / 2$.

The variations of $C O D$ with effective moment, calculated using several values of $c_{e}$ for the loading cases of tension plus bending and combined tension, bending, and torsion $\left(M_{B} / T=3.0\right.$ and $M_{B} / T=$ 1.0) are shown in Figure 4.23. When bending dominates over torsion $\left(M_{B} / T=3.0\right)$, the variation of COD with effective moments, calculated using $c_{e}=0$ or 1 , show very little difference with the corresponding variation for tension and bending. For the combined loading case with $M_{B} / T=1.0$, the variation of COD with effective moment calculated using $c_{e}=\sqrt{3} / 2$ compares well with the corresponding variation for tension and bending. This figure reinforces the conclusion that for combined loading of cracked pipe, involving torsion, a value of $\sqrt{3} / 2$ for the effective moment parameter $c_{e}$ should be used in calculating the effective moment. This result is significant for LBB applications since existing J-estimation schemes for bending plus tension can be used for combined tension, bending and torsion with the adoption of effective moment.

\subsubsection{Crack-Tip Stress Fields for Pure and Combined Loadings}

It is useful to examine the crack-tip stress fields for the pure and combined loading cases to enable comparisons with published results. To accomplish this, the stresses are transformed to a local 


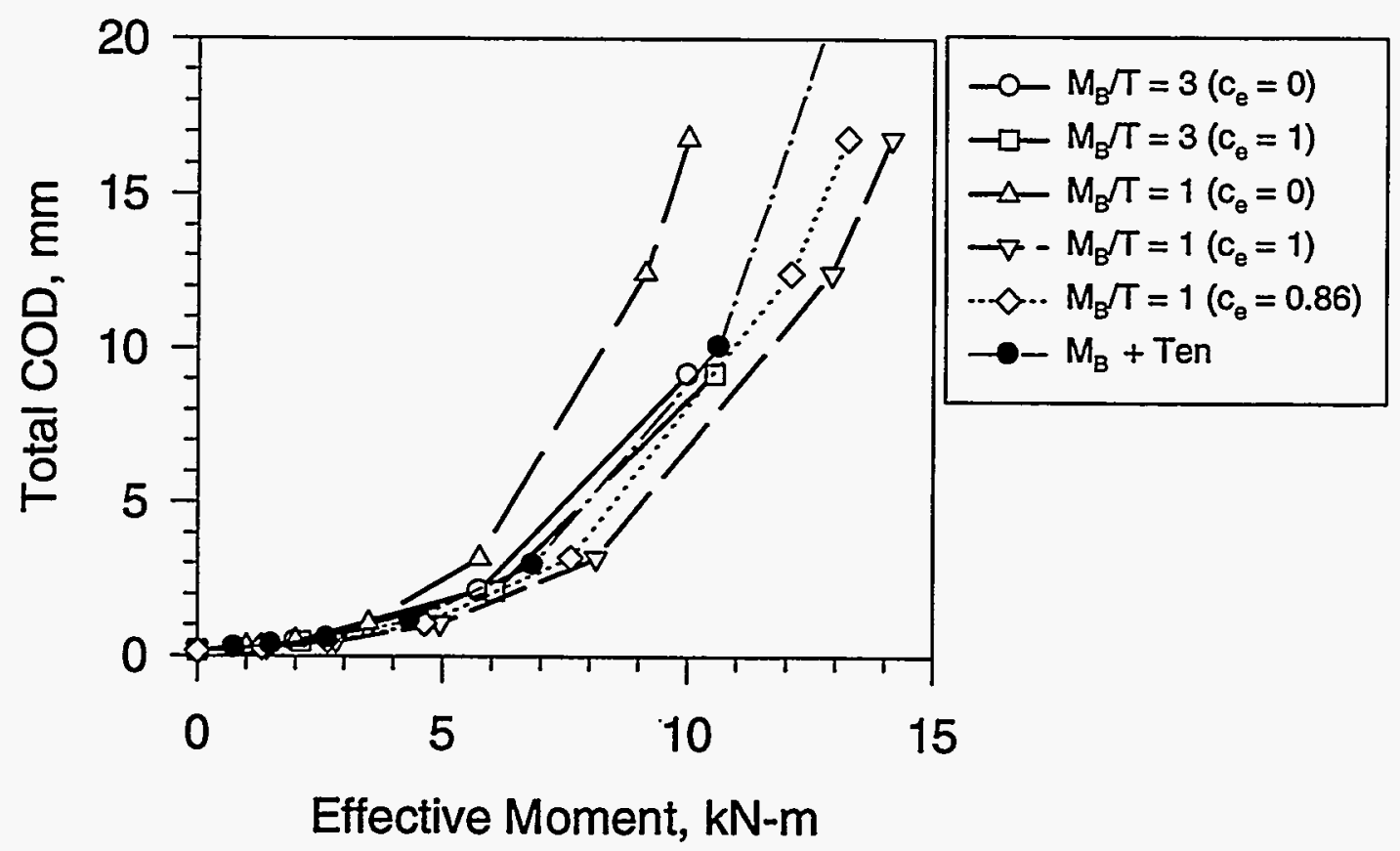

- Figure 4.23 Variation of total crack-opening displacement with effective moment for the load cases of tension plus bending and combined tension, bending and torsion (The effective moment for the latter cases is calculated for several values of $c_{e}$ )

cylindrical coordinate system centered at the mid-plane crack tip, as shown in Figure 4.24. Since a Ramberg-Osgood relation was assumed, the stresses referred to in this local coordinate system have been normalized by

$$
\sigma_{0}\left(\frac{J E}{\alpha \sigma_{o}^{2} I_{n} r}\right)^{\frac{1}{n+1}}
$$

to be consistent with the HRR representation (Refs. 4.11 and 4.12). Here, $\mathrm{I}_{\mathrm{n}}$ denotes the integration constant dependent on $n$ (Ref. 4.16) and HRR stands for Hutchinson, Rice, and Rosengren.

The angular variations of normalized stress for all the considered load cases are shown in Figures 4.25 through 4.29. It is heartening that these variations are nearly identical to the HRR fields reported by several workers (see, for example, References 4.13 and 4.16), thereby reinforcing confidence in the results obtained. It should be noted that in the case of pure bending (Figure 4.25) the local hoop stress, $\sigma_{\psi}$ is a maximum at 0 degrees, whereas the shear stress component, $\sigma_{\mathrm{r} \psi}$, is high in the range of 60 to 90 degrees. The latter fact may have some implication on the shear cracking under pure Mode I conditions. As mentioned in the introduction, the shear cracking would be promoted by decohesion of the matrix and inclusion interfaces. Such shear cracking may, in fact, contribute to the fracture 


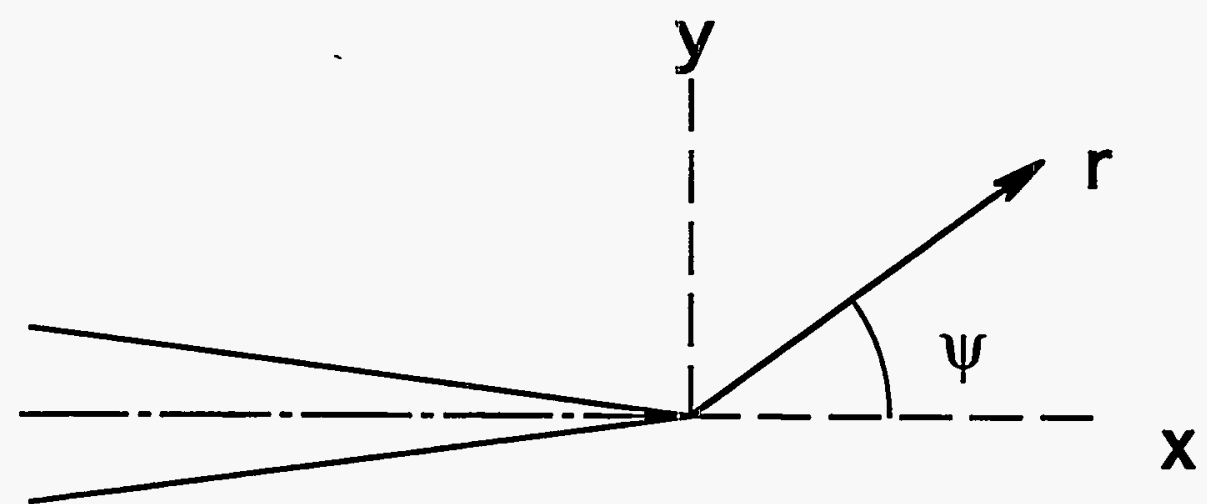

Figure 4.24 Local crack-tip cylindrical coordinate system

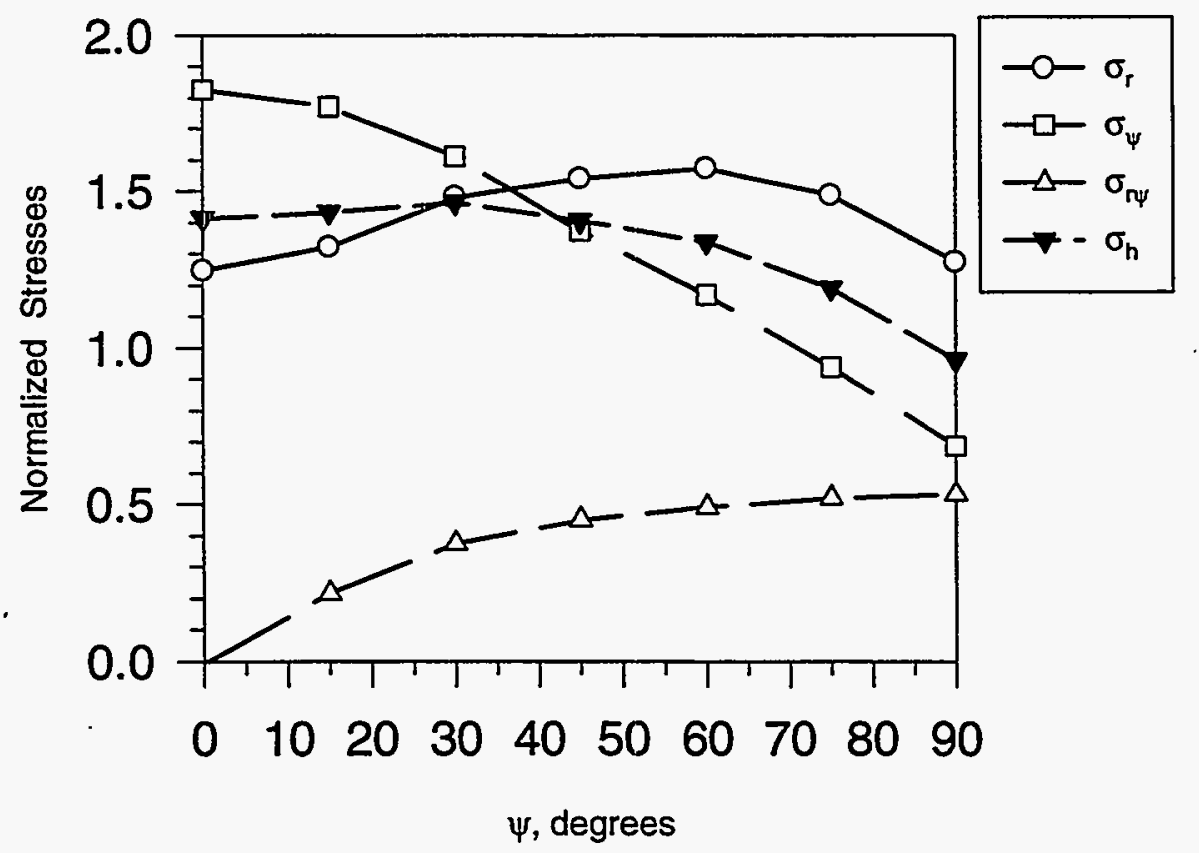

Figure 4.25 Angular variation of normalized stresses at a fixed radius (0.2 $\mathrm{mm}$ [0.008 inch]) from the crack tip for pure bending 


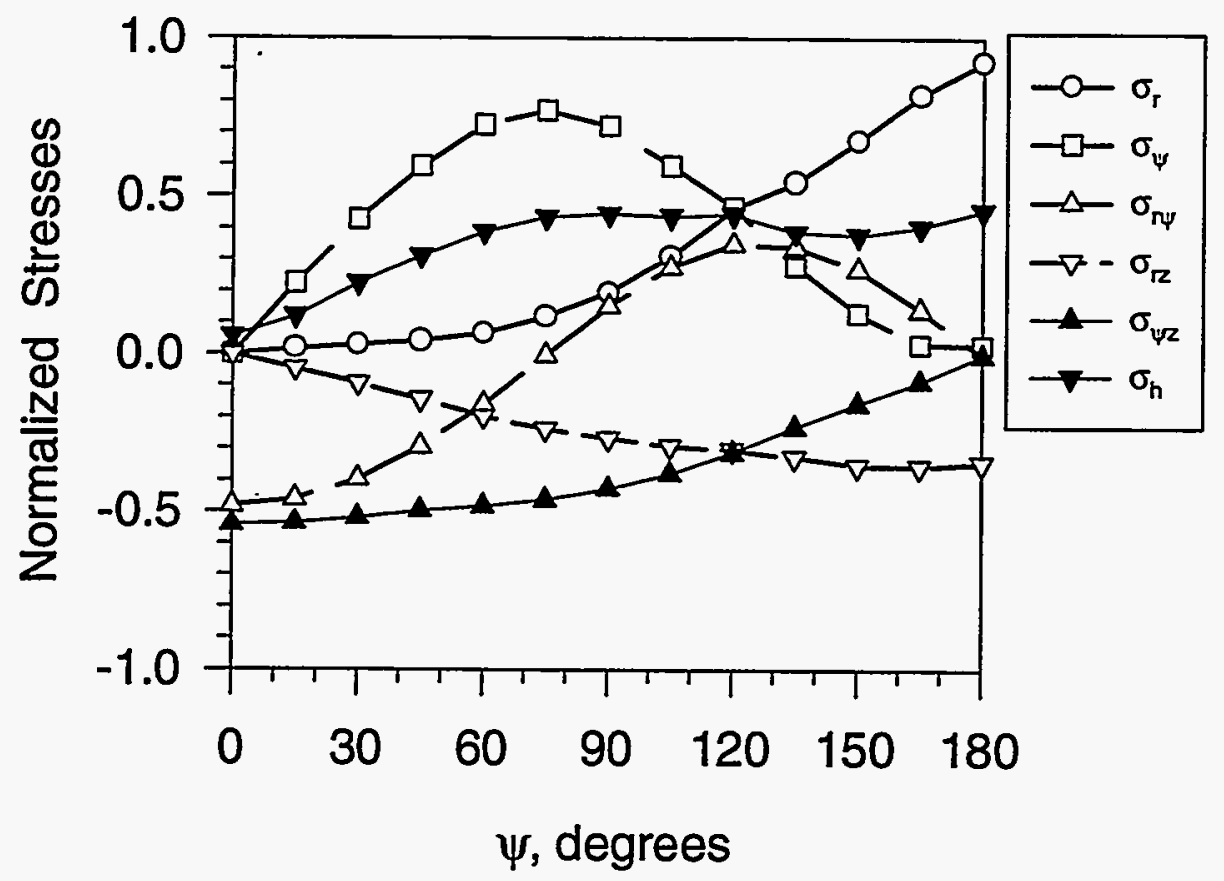

Figure 4.26 Angular variation of normalized stresses at a fixed radius (0.2 mm [0.008 inch]) from the crack tip for pure torsion

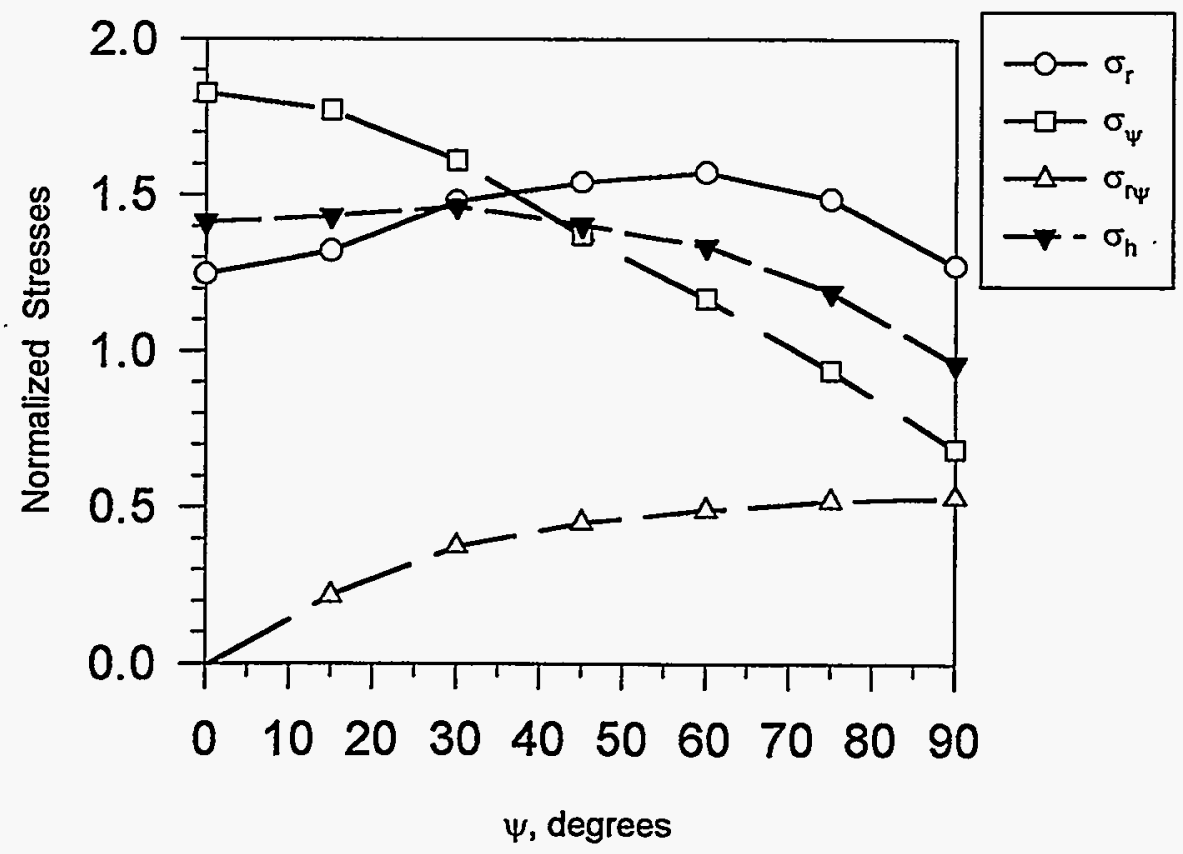

Figure 4.27 Angular variation of normalized stresses at a fixed radius ( $0.2 \mathrm{~mm}[0.008 \mathrm{inch}])$ from the crack tip for combined bending plus tension 


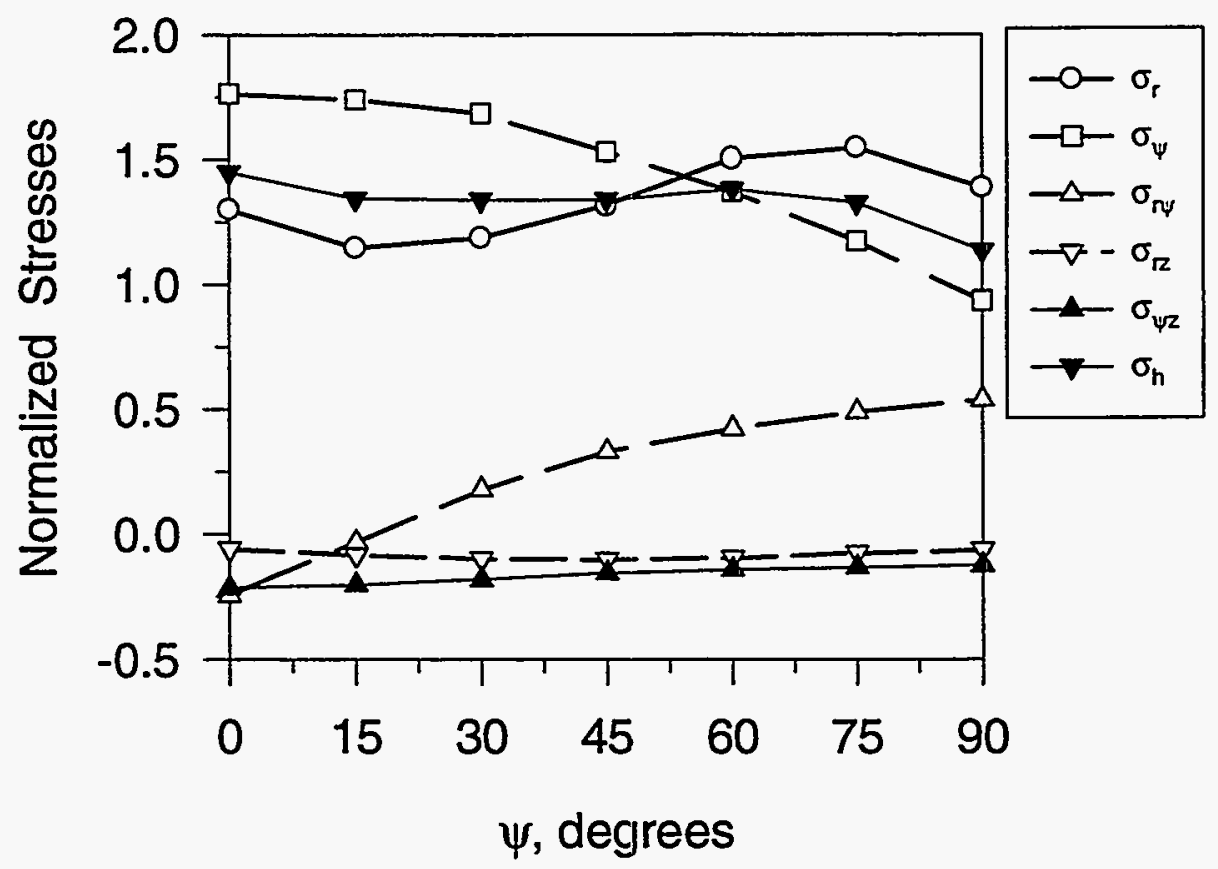

Figure 4.28 Angular variation of normalized stresses at a fixed radius (0.2 $\mathrm{mm}$ [0.008 inch]) from the crack tip for combined tension, bending, and torsion $\left(M_{B} / T=3.0\right)$

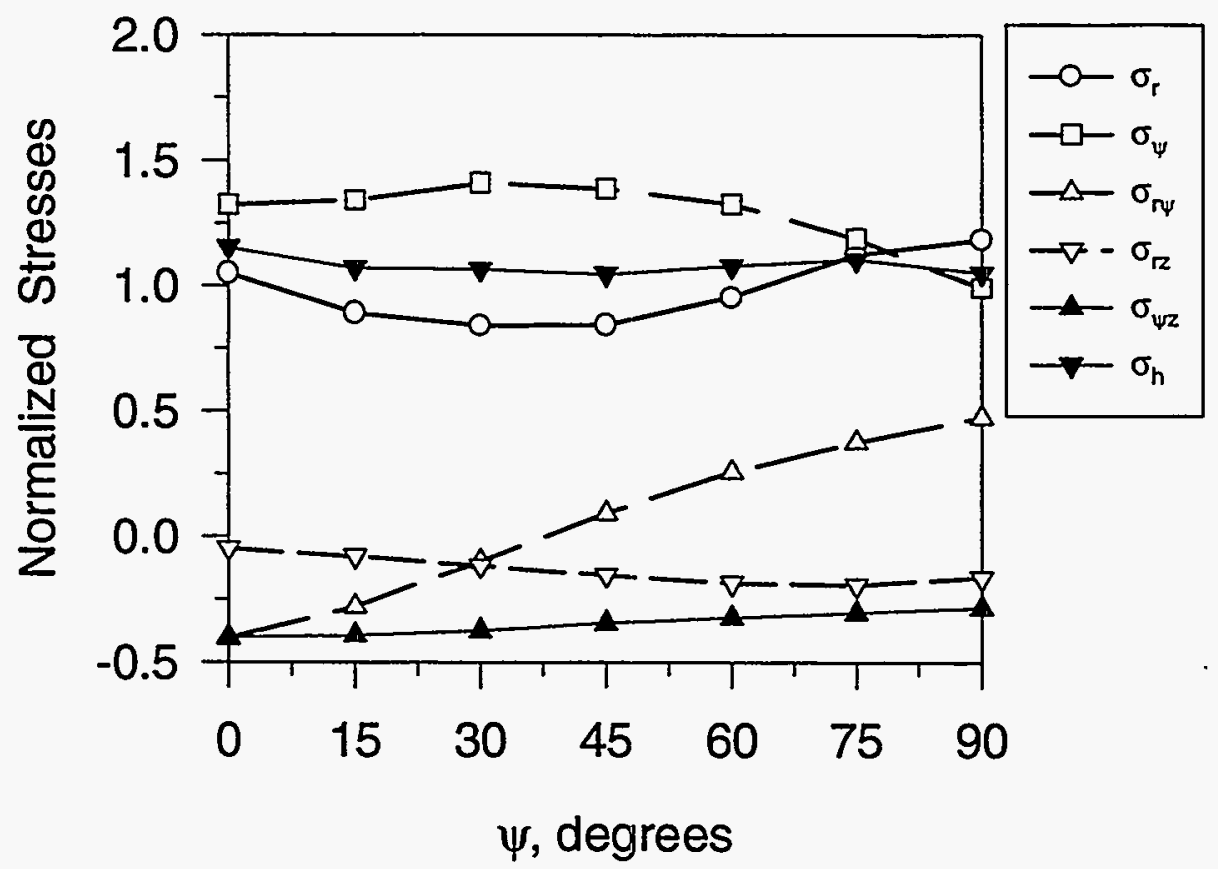

Figure 4.29 Angular variation of normalized stresses at a fixed radius (0.2 mm [0.008 inch]) from the crack tip for combined tension, bending, and torsion ( $\left.\mathrm{M}_{\mathrm{B}} / \mathrm{T}=1.0\right)$ 
anisotropy of carbon steels, when the orientations of the inclusions are favorable enough to cause angled crack growth. It is also worth noting that although the shear stress is highest around 90 degrees, the variation of shear stress over the range of 60 degrees to 90 degrees is small. In the case of pure torsion, the crack-tip experiences combined Mode II and Mode III conditions. This can be evidenced in the angular variation of normalized stresses shown in Figure 4.26. It should be noted that the shear-stress components $\sigma_{\mathrm{rz}}$ and $\sigma_{\psi z}$ contribute to shearing along the thickness direction of the pipe. Hence, they are not likely to contribute to the observed angular crack growth phenomenon. In the case of pure torsion (Figure 4.26), the hoop stress, $\sigma_{\psi}$, reaches a maximum around 70 degrees, whereas the shear stress component, $\sigma_{\mathrm{r} \psi}$, reaches a maximum at 0 degrees. Thus, if shear cracking is a predominant mode of failure in the case of pure torsion of an initially straight circumferential crack in the pipe, the crack may exhibit a tendency to propagate along the circumferential plane. However, such cracking may not be possible since the inclusions are aligned perpendicular, or in one case aligned at 66 degrees, to the circumferential plane of the pipe. In the case of combined bending plus tension (Figure 4.27), trends similar to the case of bending (Figure 4.25) are observed. The angular variations of normalized stresses for the cases of combined tension, bending and torsion are shown in Figures 4.28 and 4.29 .

\subsection{Angled Crack Analyses}

\subsubsection{Elastic Analyses of Angled Cracks}

Elastic analyses were performed of angled cracks under pure bending, pure tension, and pure torsion to observe the effect of crack-tip angle, $\Omega$, on the resulting $\mathrm{J}$ values at the center of the crack front. The variations of normalized angular driving force, $\mathrm{J}_{\Omega} / \mathrm{J}_{\Omega=0}$, with crack-tip angle, $\Omega$, for the loading cases considered are shown in Figure 4.30. Since only three angled cracks were analyzed, any conclusive statements regarding the most critical crack-tip angle cannot be made. However, the trends shown in Figure 4.30 may throw some light on the angled crack growth phenomenon. Note that higher $\mathrm{J}$ values are obtained for the 25-degree crack for pure bending and pure tension. For both of these loadings, the angled crack experiences mixed-mode conditions, while the 0-degree crack is under pure Mode I. As $\Omega$ increases, the intensity of Mode I decreases monotonically whereas the intensity of Mode II increases from 0 for $\Omega=0$ to a maximum value for $\Omega=45$ degrees. Since contributions to $\mathrm{J}$ comes from both Mode I and Mode II, a maximum $J$ will be reached for $\Omega$ ranging from 0 to 45 degrees, when the cracked pipe is subjected to pure bending or pure tension under elastic conditions. It is important to note that for angled cracks subjected to pure bending or pure tension, Mode III may also exist. On the other hand, the variation of normalized $J$ with crack-tip angle monotonically increases with $\Omega$ for pure torsion loading. Though this trend is not entirely clear, it is probably caused by increasing the Mode I contribution, and to a lesser extent increasing the Mode III contribution to J, with increasing crack-tip angle.

\subsubsection{Elastic-Plastic Analyses: Pure Bending}

The variation of $\mathrm{J}$ versus bending moment is shown in Figure 4.31 for the straight crack ( 0 degree) as well as for the angled-crack cases, for loading in the elastic-plastic range under pure bending. It is significant that the variation of $\mathrm{J}$ with bending moment is almost identical for the 0 -degree and the 


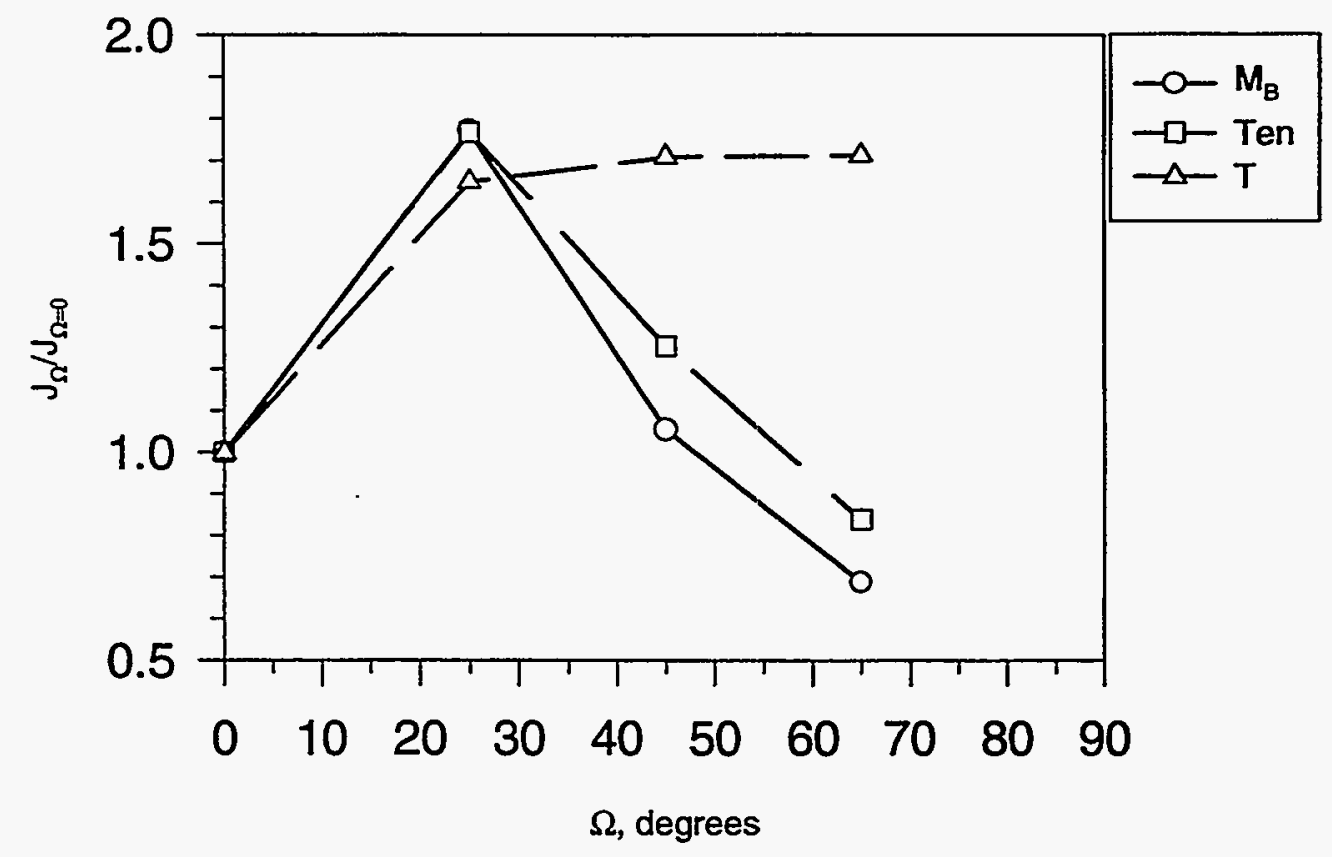

Figure 4.30 Variation of normalized angular driving force, $J_{\Omega} / J_{\Omega=0}$, versus crack-tip angle, $\Omega$, under pure bending, pure tension, plus pure torsion

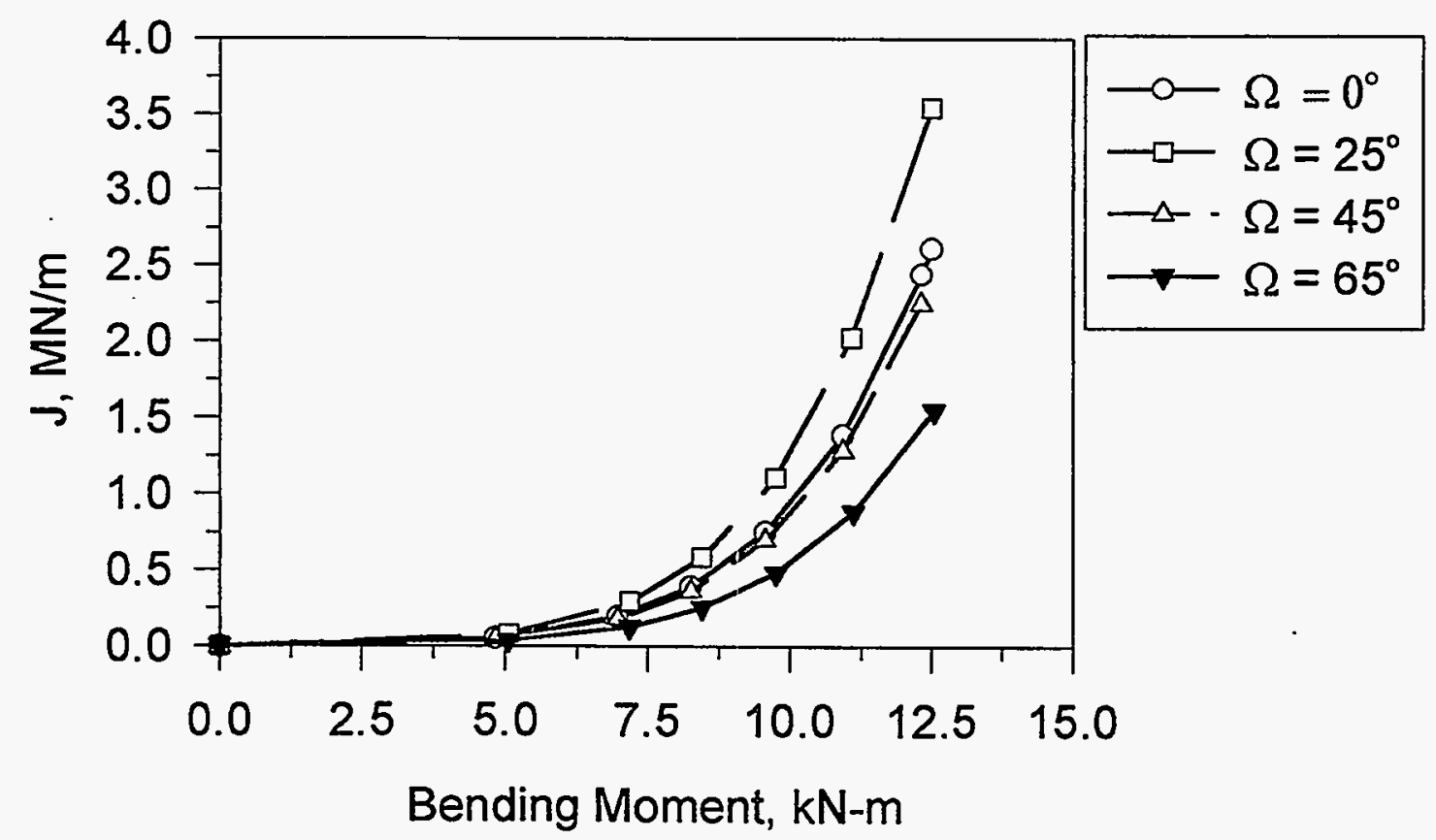

Figure 4.31 Variation of $\mathrm{J}$ versus bending moment for straight as well as angled cracks for pure bending loading under elastic-plastic conditions 
45-degree cases. Even in the elastic case, it was seen that the $\mathrm{J}$ values in pure bending are very similar for the 0 degree crack and 45-degree crack, as reflected in Figure 4.30. Also, in Figure 4.31, we see that the 25-degree crack experiences the highest J-value relative to the 0-degree crack, indicating that the plastic case parallels the elastic case.

For the elastic-plastic case, the variation of normalized angular driving force, $\mathrm{J}_{\Omega} / \mathrm{J}_{\Omega=0}$, with bending moment, shown in Figure 4.32, indicates that $\mathrm{J}_{\Omega} / \mathrm{J}_{\Omega=0}$ reaches a saturation value for all three angled cracks examined. The saturation value of $\mathrm{J}_{\Omega} / \mathrm{J}_{\Omega=0}$ versus crack-tip angle, $\Omega$, exhibits a similar trend as the elastic case shown in Figure 4.30 for the case of pure bending, see Figure 4.33. The trend of $\mathrm{J}_{\Omega} / \mathrm{J}_{\Omega=0}$ to saturate is significant in that it offers a convenient measure to predict angled crack growth occurrence in carbon steel pipes which exhibit fracture anisotropy. A discussion on this topic is deferred until later.

While the above noted trends of normalized angular driving force, $\mathrm{J}_{\Omega} / \mathrm{J}_{\Omega}=0$, are important by themselves, they do not provide a direct explanation for the onset of angled crack growth observed in carbon steel pipes. Since the preceding analyses are specifically aimed at modelling Experiment 4111 1 , it is useful to examine the orientation dependent J-initiation values measured from C(T) tests of specimens obtained from this pipe (see Figure 2.6). The orientation dependent J-initiation values and the normalized angular fracture resistance, $\mathrm{J}_{\mathrm{i} \Omega} / \mathrm{J}_{\mathrm{i} \Omega=0}$ values are given in Table 4.3.

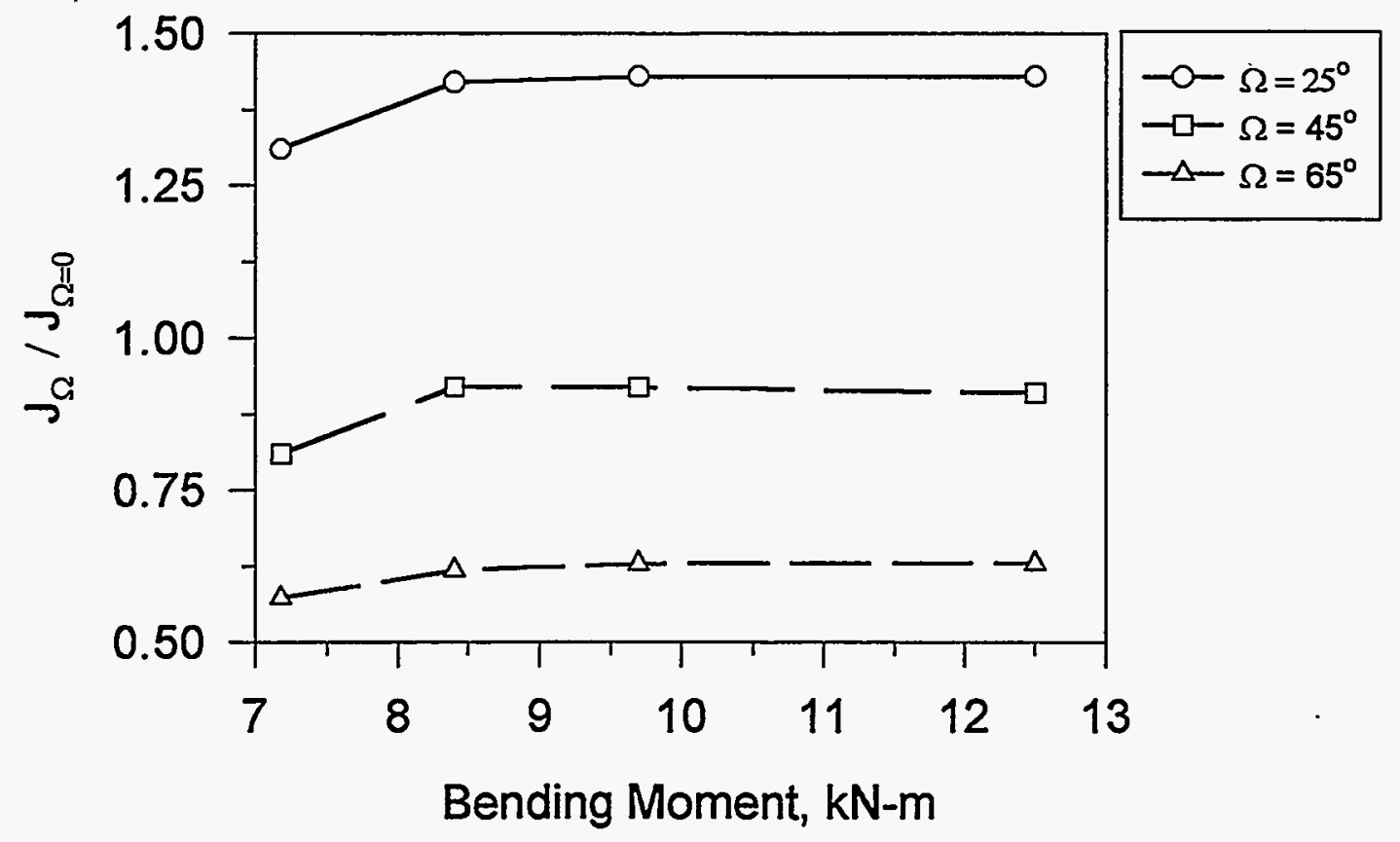

Figure 4.32 Normalized angular driving force, $\mathrm{J}_{\Omega} / \mathrm{J}_{\Omega=0}$, as a function of bending moment (This figure illustrates the saturation obtained by these values) 


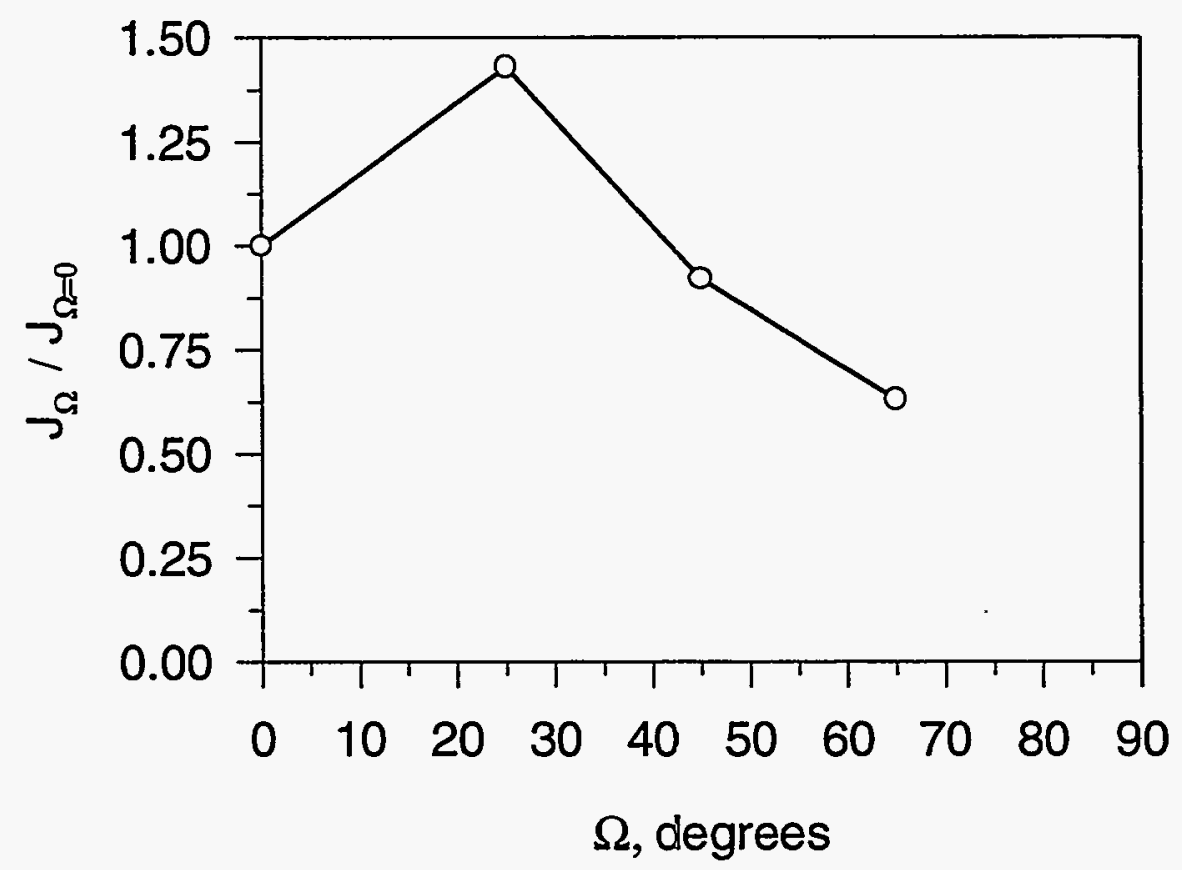

Figure 4.33 The saturation values of $\mathrm{J}_{\Omega} / \mathrm{J}_{\Omega=0}$ as a function of crack-tip angle, $\Omega$

Table 4.3 Orientation dependent J-initiation values measured from $\mathrm{C}(\mathrm{T})$ tests of specimens obtained from Pipe DP2-F11

\begin{tabular}{ccc}
\hline$\Omega$, degrees & $\mathbf{k J} / \mathbf{m}^{\mathbf{2}}\left(\mathbf{\mathbf { j }} \mathbf{\mathbf { j }}-\mathbf{l} \mathbf{b} / \mathbf{i n}^{2}\right)$ & $\frac{\mathbf{J}_{\mathbf{i} \Omega}}{\mathbf{J}_{\mathbf{i} \Omega=0}}$ \\
\hline 0 & $120(685)^{(\mathbf{a})}$ & 1.000 \\
25 & $90(514)$ & 0.583 \\
45 & $60(343)$ & 0.500 \\
65 & $40(228)$ & 0.330 \\
\hline
\end{tabular}

(a) This value is $J_{i} \Omega=0$. 
Knowing the bending moment required to initiate the crack for this pipe test (Experiment 4111-1), the applied $\mathrm{J}$ values for the straight and angled cracks, $\mathrm{J}_{\text {applied }}$, can be obtained from Figure 4.31 . When the $J_{\text {applied }}$ values are normalized with respect to the orientation dependent $J$-initiation $\left(J_{i}\right)$ values given in Table 4.3 and plotted as a function of the crack-tip angle from the circumferential plane, the variation shown in Figure 4.34 is obtained. This figure reveals that the ratio $\mathrm{J}_{\text {applied }} / \mathrm{J}_{\mathrm{i}}$ is higher for all crack-tip angles compared with the straight crack. This fact indicates that an initially straight crack can grow stably at an angle even under pure bending (Mode I) conditions owing to the nature of the fracture anisotropy of this material. Additionally, this figure reveals that the range of angle over which the crack may exhibit angular growth is very wide. Hence, the tendency for a straight crack to grow at an angle is high provided similar fracture anisotropy exists.

The mid-thickness crack-opening displacement for the angled cracks as a function of the applied bending moment are nearly identical for the different crack angles considered in this analysis, see Figure 4.35. The bending moment versus end rotation for the angle-cracked pipes, shown in Figure 4.36, indicate nearly identical response. These two figures reveal that while the near crack-tip fields are strongly influenced by the crack-tip angle, the far-field deformations are not. Considering the size of the angled crack-tip region (one inclusion spacing) compared with the overall dimensions, this is hardly surprising.

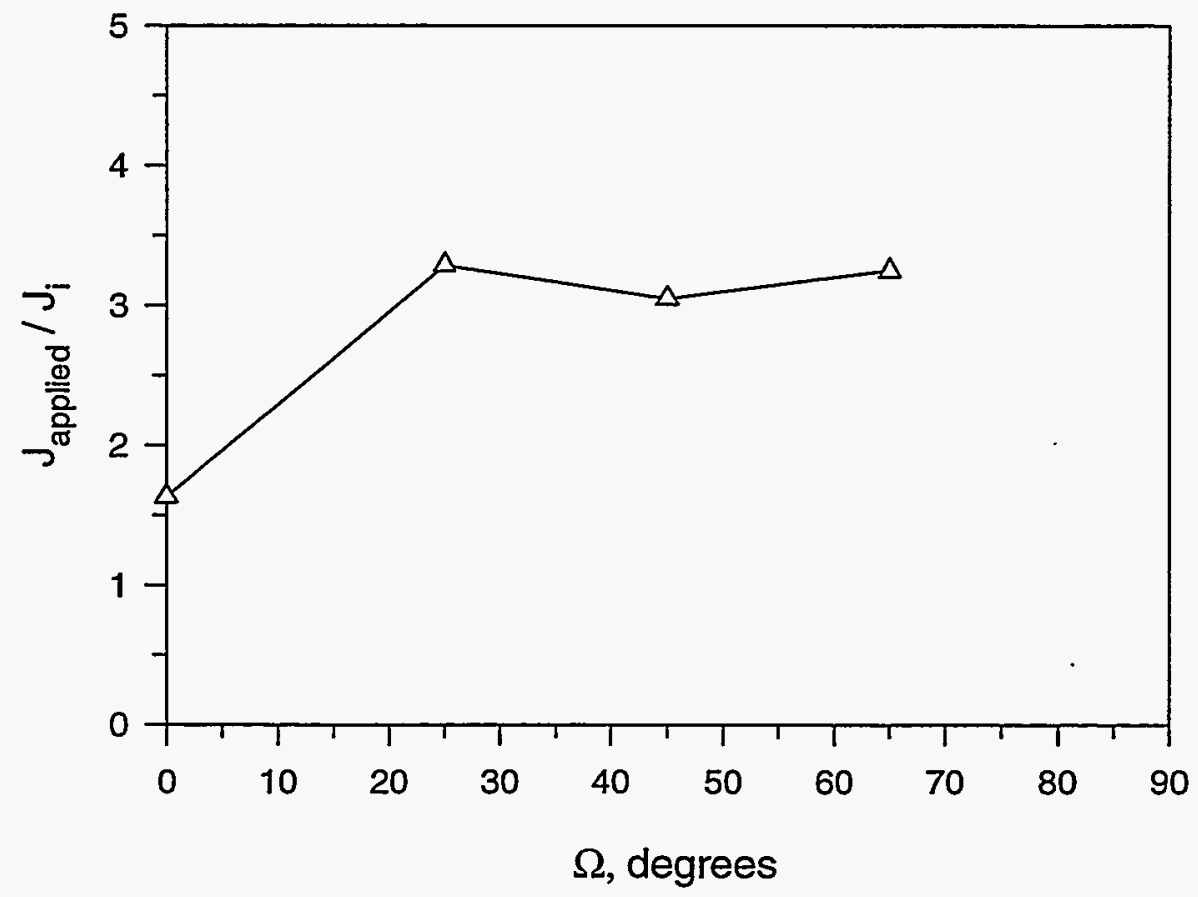

Figure 4.34 The variation of $-J_{\text {applied }} / J_{\mathbf{i}}$ (for Pipe DP2-F11) with crack-tip angle from the circumferential plane 


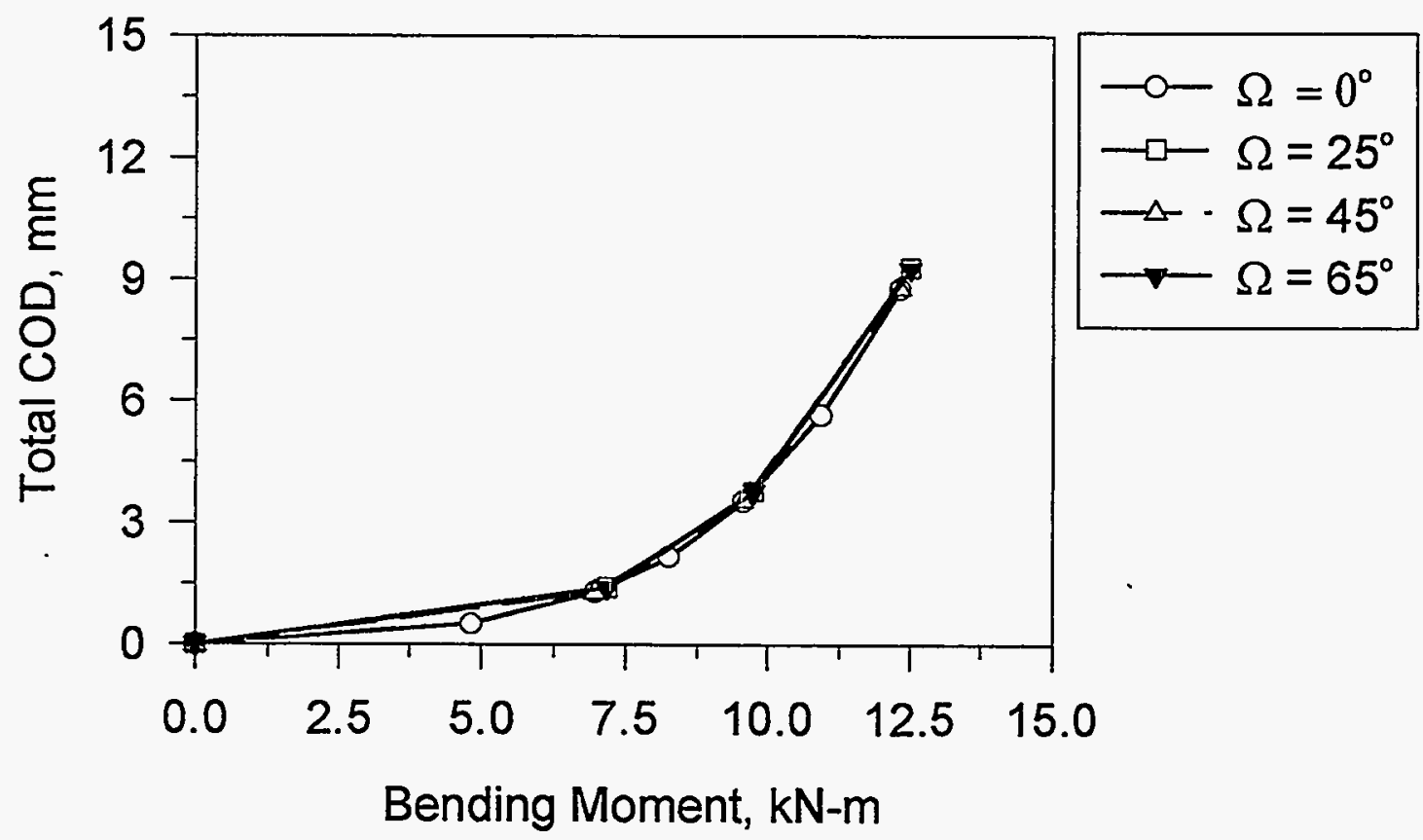

Figure 4.35 Center COD versus bending moment for straight as well as angled cracks subjected to pure bending

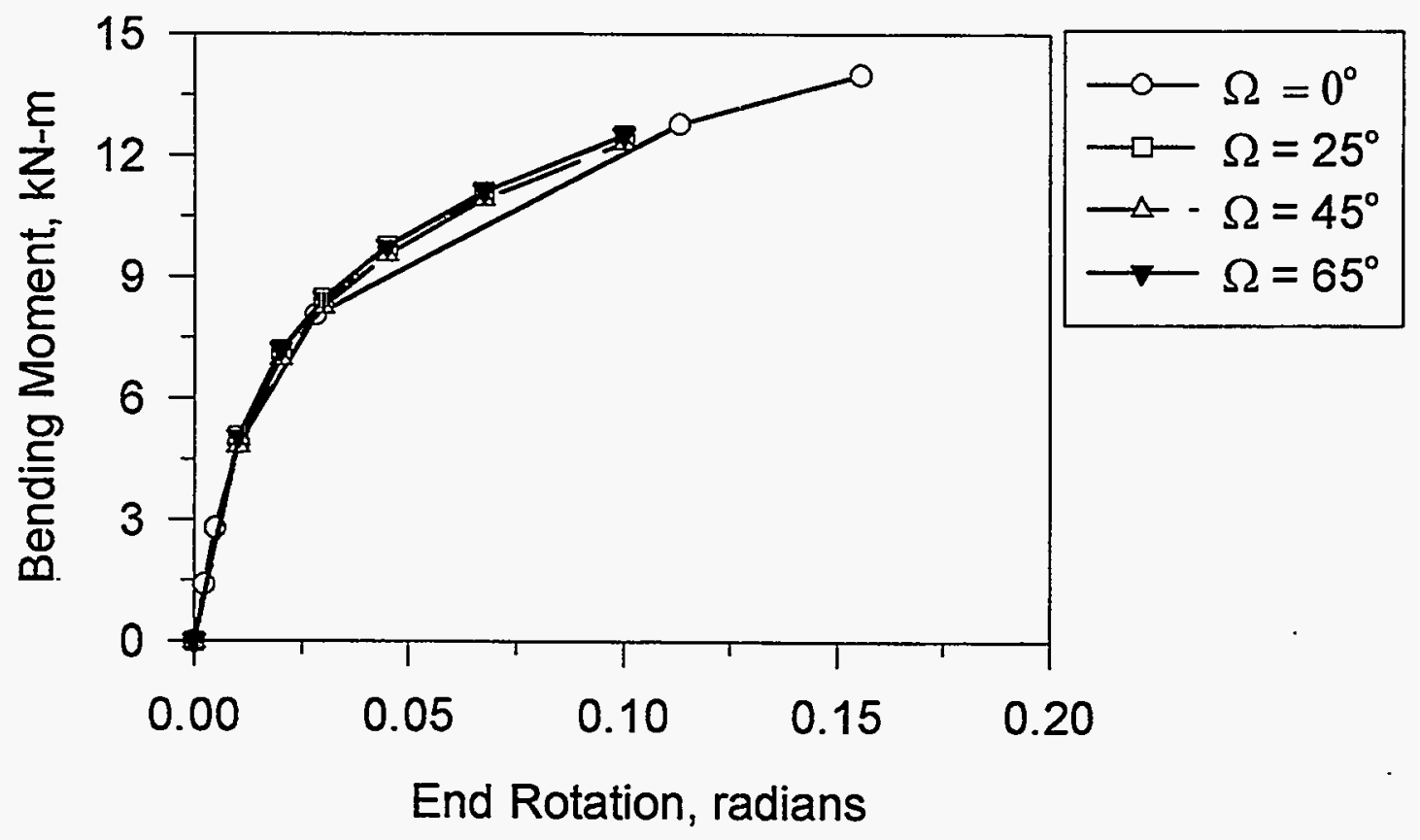

Figure 4.36 Bending moment versus end rotation for straight as well as angled cracks subjected to pure bending 


\subsubsection{Elastic-Plastic Analyses: Combined Loads}

As indicated in Section 4.3.5, only the case of combined bending and torsion for the 45-degree-kinked crack was considered. The variations of $J$ with effective moment for the straight and for the angled crack, $\Omega=45$ degrees, are shown in Figure 4.37, for the case of a combined bending moment-totorque $\left(M_{B} / T\right)$ ratio of 1.0. The figure indicates that nearly identical variations are obtained for these two cracks regardless of the value of the effective moment parameter used. This leads to the conclusion that the mode mixity experienced by the straight crack is nearly identical to the mode mixity experienced by the angled crack $(\Omega=45$ degrees) for this combined load case. This conclusion is reinforced by observing the variations of COD with effective moment for the straight and the angled crack $(\Omega=45$ degrees), see Figure 4.38 .

In Section 4.4 on straight cracks, it was seen that existing J-estimation schemes for bending plus tension can be used for combined tension, bending and torsion with the adoption of effective moment. The next question is can the same argument be used for angled cracks? The affirmative answer to this question is evident in Figure 4.39, where the variation of COD for a 45-degree angled crack with effective moment for the combined bending plus torsion $\left(M_{B} / T=1.0\right)$ is compared with the corresponding variation for pure bending.

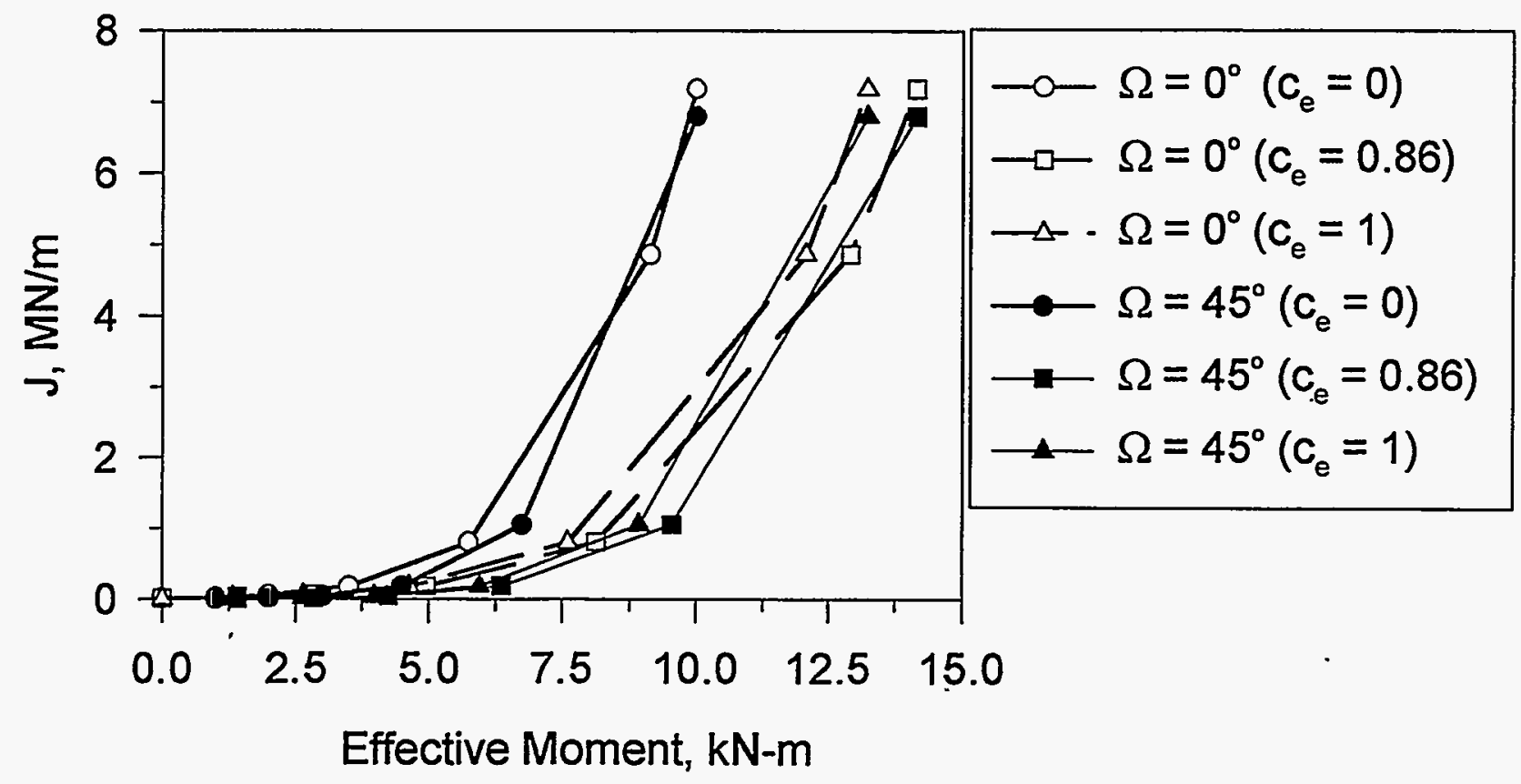

Figure 4.37 Variation of applied $J$ with effective moment for straight and 45-degree cracks subjected to a bending moment-to-torque ratio of 1.0 (The effective moment is calculated for several values of $c_{e}$ ) 


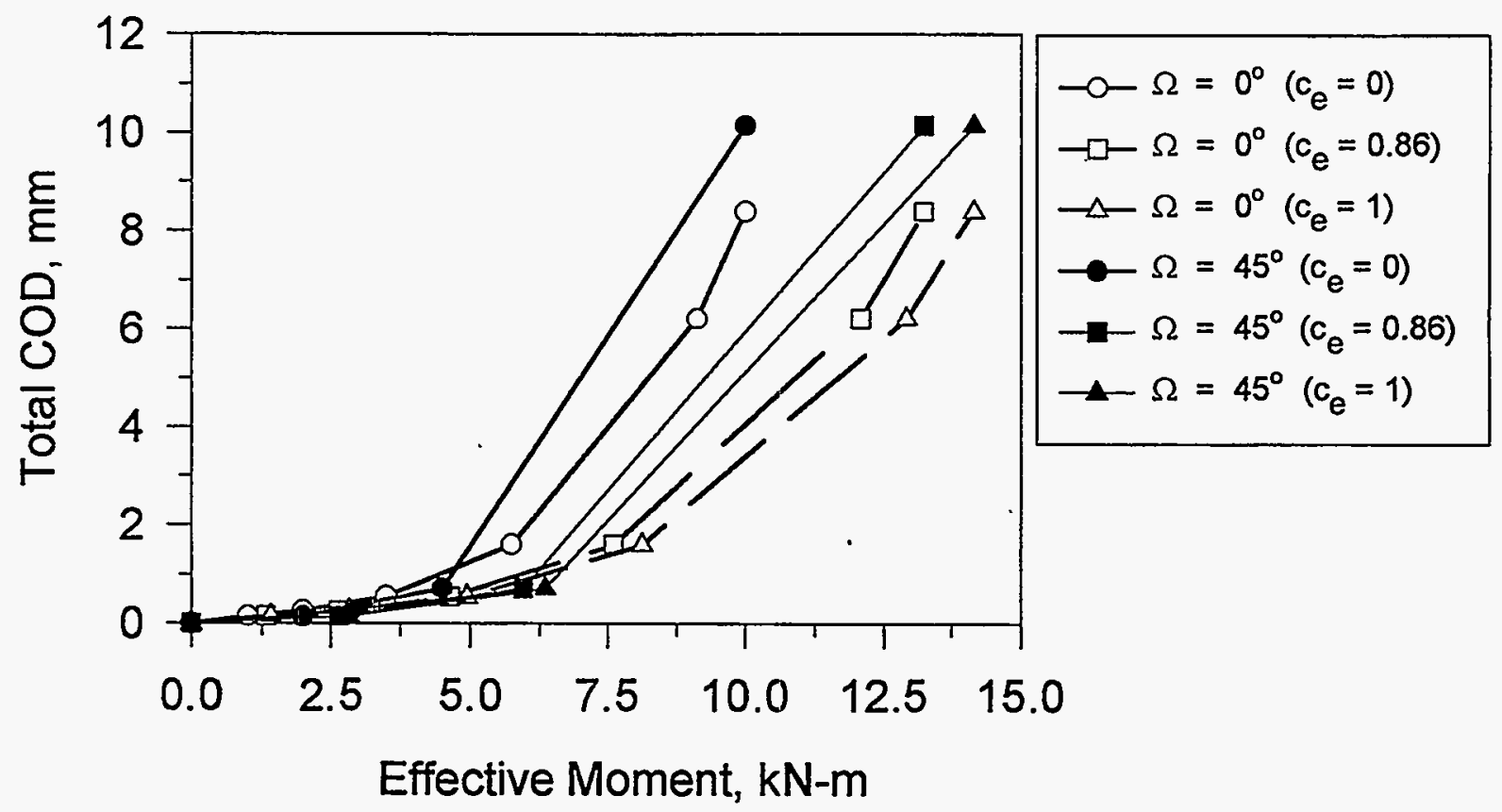

Figure 4.38 Center COD versus effective moment for straight and 45-degree cracks subjected to a combined bending moment-to-torque ratio of 1.0

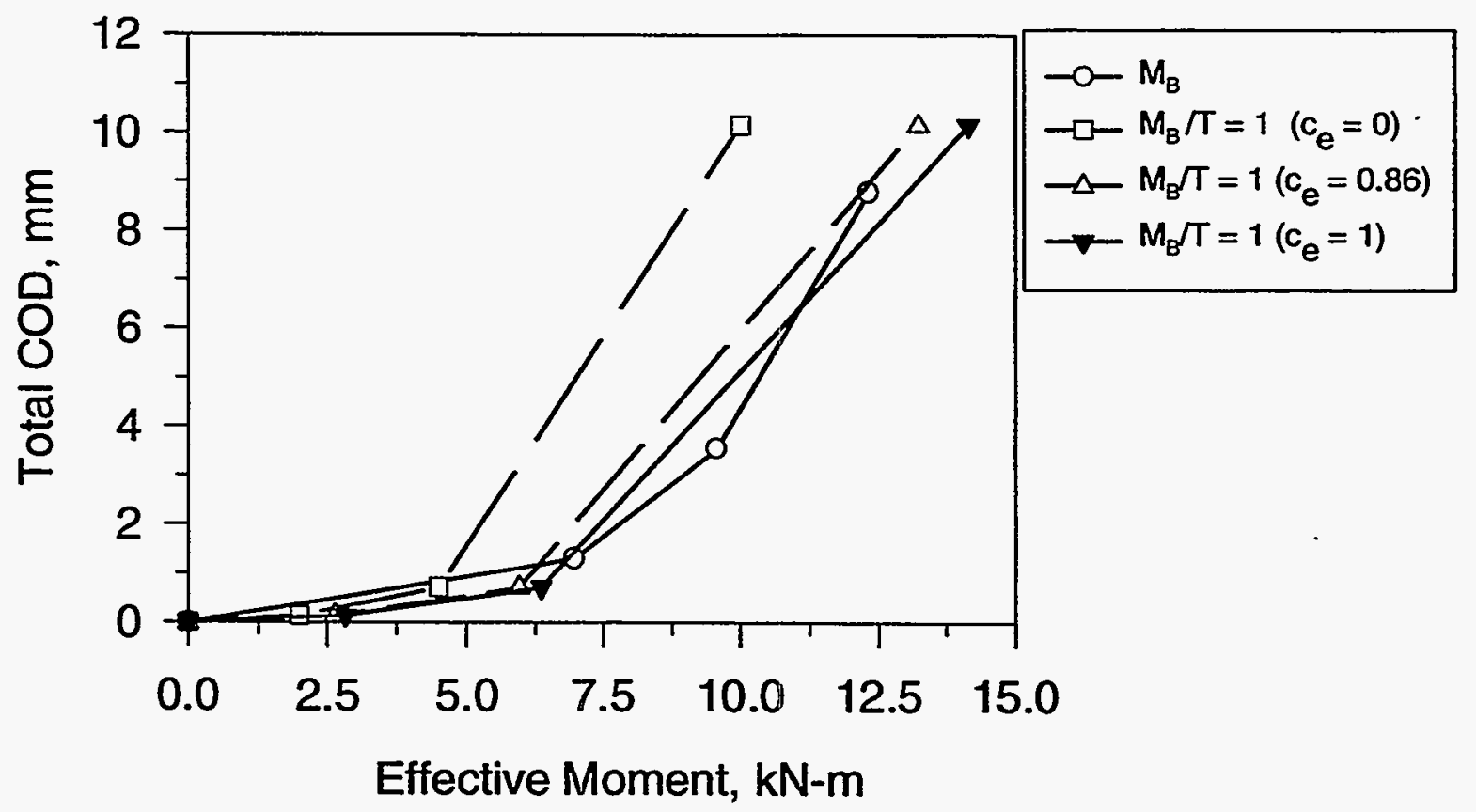

Figure 4.39 Effect of torsion on center COD for the 45-degree crack and straight crack 


\subsection{References}

4.1 Bhattacharjee, D. D., and Knott, J. F., "Ductile Fracture in HY100 Steel Under Mixed Mode I/Mode II Loading," Acta Metall. Mater., Vol. 42, pp 1747-1754, 1994.

4.2 Rice, J. R., "A Path-Independent Integral and the Approximate Analysis of Stress Concentration by Notches and Cracks," ASME Journal of Applied Mechanics, Vol. 35, pp 379-386, 1968.

4.3 Eshelby, J. D., "The Energy-Momentum Tensor in Continuum Mechanics," Inelastic Behavior of Solids, Ed. M. F. Kanninen et al., McGraw-Hill, pp 77-115, 1970.

4.4 Budiansky, B. and Rice, J. R., "Conservation Laws and Energy-Release Rates," ASME Journal of Applied Mechanics, Vol. 40, pp 187-211, 1973.

4.5 Strifors, H., "A Generalized Force Measure of Conditions at Crack Tips," International Journal of Solids and Structures, Vol. 10, p 1389-1404, 1974.

4.6 Kishimoto, K., Aoki, S., and Sakata, M., "Dynamic Stress Intensity Factors using $\hat{\mathrm{J}}$-Integral and Finite Element Method," Engineering Fracture Mechanics, Vol. 13, p 387-394, 1980.

4.7 Cherepanov, G. P., Mechanics of Brittle Fracture, Moscow Publishing House, "Nauka," English translation published by McGraw-Hill, 1974.

4.8 Hermann, A. G. and Hermann, G., "On Energy-Release Rates for a Plane Crack," ASME Journal of Applied Mechanics, Vol. 48, pp 525-528, 1981.

4.9 Atluri, S. N., "Energetic Approaches and Path-Independent Integrals in Fracture Mechanics," in Computational Methods in Mechanics of Fracture (Ed., S. N. Atluri), North-Holland Press, Amsterdam, pp 121-165, 1986.

4.10 Hayashi, $\mathrm{K}$ and Nemat-Nasser, S., "Energy Release Rate and Crack Kinking Under Combined Loading," ASME Journal of Applied Mechanics, Vol. 48, pp 520-524, 1981.

4.11 Hutchinson, J. W., "Singular Behavior at the End of a Tensile Crack in a Hardening Material," J. Mech. Phys. Solids, Vol. 16, pp 13-31, 1968.

4.12 Rice, J. R. and Rosengren, G. F., "Plane Strain Deformation Near a Crack Tip in a Power Law Hardening Material," J. Mech. Phys. Solids, Vol. 16, pp 1-12, 1968.

4.13 Pan, J., "Asymptotic Analysis of a Crack in a Power-Law Material Under Combined In-Plane and Out-of-Plane Shear Loading Conditions," J. Mech. Phys. Solids, Vol. 38, No. 2, pp 133$159,1990$.

4.14 Rybicki, E. F. and Kanninen, M. F., "A Finite Element Calculation of Stress Intensity Factors by a Modified Crack Closure Integral," Engineering Fracture Mechanics, Vol. 9, pp 931-938, 1977. 
4.15 Paul, D. D., Ahmad, J., Scott, P. M., Flanigan, L. F., and Wilkowski, G. M., "Evaluation and Refinement of Leak-Rate Estimation Models," NUREG/CR-5128, Rev. 1, June 1994.

4.16 Anderson, T. L., "Fracture Mechanics Fundamental and Applications," CRC Press, 1991. 


\section{DISCUSSION AND CONCLUSIONS}

\subsection{Understanding Why Angled Crack Growth Occurs in Ferritic Pipes}

The major impetus for this work stemmed from the observation that initially circumferential throughwall cracks in pipes made from carbon steels exhibited a high tendency for the cracks to grow at an angle to the circumference, when the cracked pipes were subjected to bending. A detailed summary of the pipe tests, type of crack and crack growth angles was presented in Table 3.1. It can be seen from this table that the angles over which crack growth occurred covered a wide range. Charpy and $C(T)$ tests conducted on these pipes indicated that these steels are capable of exhibiting fracture anisotropy, i. e. orientation-dependent fracture properties. Metallographic examinations of five of the pipes revealed that nonmetallic inclusions with large aspect ratios were aligned either at 66 degrees to the circumferential plane (in one case) or along the pipe axis. The pipe with inclusions aligned at 66 degrees to the circumferential plane was a seamless pipe with nonmetallic inclusions. Clearly, the preferred orientation of the inclusions contributes to the fracture anisotropy evidenced in these carbon steels, even though the global stress-strain response showed very little dependence on material orientation. This is because the microstructural mechanisms may play a dominant role in the fracture processes that occur near the tip of the crack where the stress state will be very high. If the physical mechanism of crack growth occurs by void nucleation and growth ahead of the crack-tip, it appears, from the earlier discussion on the crack-tip stress fields, that an initially straight circumferential crack would propagate in a ductile mode along the circumferential plane of the pipe. Indeed this would be the case for materials which do not show significant fracture anisotropy, such as austenitic stainless steels. Conversely, if the fracture mechanism is promoted by decohesion of the matrix and inclusion interface caused by high local shear stresses, then an initially straight circumferential crack is likely to propagate at an angle with respect to the circumferential plane. Though this explanation sheds some light into the angular through-wall-crack growth phenomenon observed in carbon steel pipes, it cannot directly explain the wide range of angles over which such growth occurs.

It was seen in Section 3 that the shape and aspect ratios of the sulfide inclusions do not provide a useful measure of the angled crack growth phenomenon. The anisotropy index, defined in Section 2, proved to yield highly scattered results (see Figure 3.3). On the other hand, the results of the elasticplastic analyses of straight and angled through-wall cracks presented in Section 4 indicated that the normalized angular driving force, $\mathrm{J}_{\Omega} / \mathrm{J}_{\Omega=0}$, (ratio of $\mathrm{J}$-value for angled crack and the corresponding value for straight crack) reached a constant value once plasticity occurred (Figure 4.32). In addition, the variation of the ratio of applied J-value and initiation J-value for this material with the angle from the circumferential plane indicated that an initially straight circumferential crack may exhibit a strong likelihood to propagate over a wide range of angles with respect to the circumferential plane (see Figure 4.34). While the trend exhibited by this ratio offers a good explanation for the observed angular growth phenomenon in carbon steel pipes, an even more meaningful ratio will be presented below. We define the normalized angular crack growth parameter, $\mathcal{A}$, as the ratio of the normalized angular fracture resistance to the normalized angular crack-driving force as follows:

$$
\mathcal{A}=\frac{\text { normalized angular fracture resistance }}{\text { normalized angular crack driving force }}=\frac{\mathrm{J}_{\mathrm{i} \Omega} / \mathrm{J}_{\mathrm{i} \Omega=0}}{\mathrm{~J}_{\Omega} / \mathrm{J}_{\Omega=0}}
$$


It is important to mention that this parameter is not a material parameter, but rather a combination of directional sensitivity of both the material properties and crack driving force. This parameter is useful in understanding the angular crack growth phenomenon as will be seen subsequently. When this parameter assumes a value of unity or higher for a given crack-tip angle, $\Omega$, from the circumferential plane, then the tendency for the crack to grow along the circumferential plane is higher than the tendency for it to propagate along that angle. Conversely, if this parameter is less than unity for a given angle, the crack is more likely to grow along that angle. The variation of this parameter with the crack-tip angle, from the circumferential plane for Pipe DP2-F11 analyzed in Section 4.0 is shown in Figure 5.1.

The normalized material resistance used in this figure for Pipe DP2-F11 was calculated from the orientation dependent values of J-initiation measured in $C(T)$ specimens. This figure indicates that for Pipe DP2-F11 an initially circumferential crack in this pipe is very likely to exhibit angular growth even under pure bending conditions, and the angular growth may occur over a wide range of angles. The value of the parameter, $\mathcal{A}$, is essentially the same from 25 to 65 degrees. This observation agrees with the experimental observation of scatter in the angles along which the crack propagated, i.e., 37

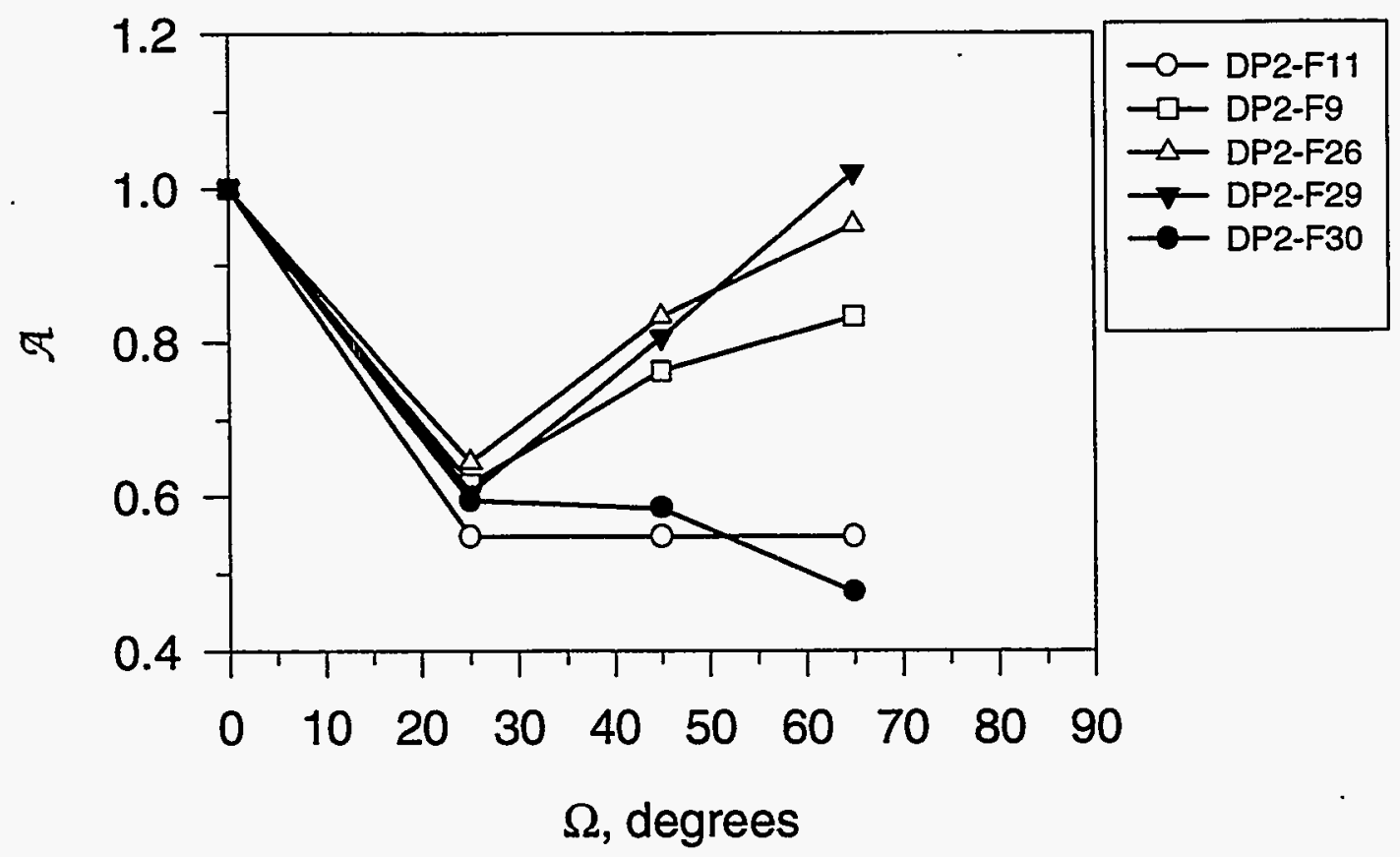

Figure 5.1 Variation of normalized angular crack growth parameter, $\mathcal{A}$, with crack-tip angle, $\Omega$, from the circumferential plane (If this parameter assumes a value of unity or higher for a given angle, then the tendency for the crack to propagate along the circumferential plane is higher than its tendency to propagate at that angle) 
and 59 degrees at the two crack tips. Since the analyses reported in this section pertain only to this pipe, strictly speaking the results obtained for the driving force for straight and angled cracks cannot be used to examine the experimental data obtained for the other pipes given in Table 3.1. This is because the $\mathrm{J}_{\text {applied }}$ term used in $\mathrm{J}_{\Omega} / \mathrm{J}_{\Omega=0}$ may be sensitive to crack length, pipe diameter-to-thickness ratios, and stress-strain characteristics of the material. However, since we have the normalized angular fracture resistance values from the Charpy tests on these other pipe materials (see Figure 2.12) and since the Ramberg-Osgood parameters used in the finite element analyses in Section 4 are reasonably close to these other pipe materials, one can pose the question that if pipes similar in geometry to Pipe DP2-F11 analyzed in Section 4 were made of these other ferritic steels, would these pipes exhibit angular crack growth and, if so, what would be the range of angular values over which the crack would propagate?

To address this question, the Charpy data, rather than $\mathrm{J}_{\mathrm{i}}$ values for the materials in Figure 2.12, were examined. This figure shows Charpy upper-shelf energy data as a function of $\Omega$. Since Charpy energy is proportional to $\mathrm{J}_{\mathrm{Ic}}$, then

$$
\mathrm{J}_{\mathrm{i} \Omega} / \mathrm{J}_{\mathrm{i} \Omega=0}=\mathrm{CVE}_{\Omega} / \mathrm{CVE}_{\Omega=0}
$$

where CVE is the Charpy V-notch upper-shelf energy. The subscript $\Omega$ is for any angle relative to the $\mathrm{L}-\mathrm{C}$ orientation and $\Omega=0$ is the L-C orientation specimen. With this information and the $\mathrm{J}_{\text {applied }}$ values of $\mathrm{J}_{\Omega} / \mathrm{J}_{\Omega=0}$ from Section 4, an answer to the above question lies in Figure 5.1. It can be seen in this figure that in all cases angular crack growth is predicted. However, the range of angles over which the crack may propagate varied considerably, even though the Charpy energy versus $\Omega$ trends in Figure 2.12 look similar. Hence, local variability in toughness anisotropy may significantly effect the direction of crack growth. Direct comparison of these predictions with the experimental observations of angular growth for the pipes listed in Table 3.1 is outside the scope of this investigation since the $\mathrm{J}_{\Omega} / \mathrm{J}_{\Omega=0}$ term may be sensitive to crack length, pipe $\mathrm{R} / \mathrm{t}$ ratio, and stress-strain properties. The development of the proposed, $\mathcal{A}$, parameter appears promising in explaining angled crack growth in ferritic pipes, but it is not generally validated for other crack length and pipe sizes. It should be noted that for experiments with angled crack growth, using the projected length in the analysis may not be appropriate.

\subsection{Analysis of Pipes Under Combined Tension, Bending and Torsion}

The other main objective of this program was to assess the fracture behavior of pipes subjected to torsional loads in addition to bending loads and internal pressure. This topic has been addressed in some detail in Section 4. It was seen that an effective moment can be defined in four different ways to account for torsional and bending moments (see Equation 4-2). By adopting a value of $c_{e}=\sqrt{3} / 2$ in the definition of an effective moment, it was seen that the solutions obtained for the crack-driving force, crack-opening area and crack-opening displacement under bending conditions may be used in evaluating the corresponding quantities for cracked pipes subjected to combined bending and torsion. The results presented in Section 4 demonstrate the validity of this approach for straight circumferential 
TWC as well as for angled circumferential TWC with a crack-tip angle $\Omega=45$ degrees. This significant conclusion enables the use of simple engineering estimation schemes for determining fracture parameters, when torsion is involved in addition to bending. The limitation to this, however is that the analyses conducted to date are limited to very small amounts of angular crack growth. Under large growth there may be some deviations from the results given here. For instance, the ratio of the $\mathrm{J}-\mathrm{R}$ curves at different orientations do not seem to be constant with crack growth, and the ratio of the $\mathrm{J}_{\text {applied }}$ values with crack-tip angle for a growing crack is unknown. Angled crack growth finite element analyses would be needed to assess the error and potential corrections for the predictive estimation schemes and $\eta$-factor analyses. Although analyses of crack growth for cracks growing straight under combined bending and torsion were not conducted, it is anticipated the effective moment approach would be applicable in this case. Nevertheless, the conclusion of using the effective moment concept for combined loads involving torsion is valid for all leak-rate calculations of concern to LBB analyses and for determining loads up to crack initiation. Finally, the results obtained are for a circumferential through-wall-cracked pipe, and surface-cracked pipe may behave quite differently under combined loads. 
APPENDIX A

\section{ILLUSTRATIONS OF FRACTURE PATHS IN CARBON STEEL PIPES WHICH CONTAINED CIRCUMFERENTIAL FLAWS}


Abbreviations used in Figure B-1:

$\mathrm{c}=$ half-crack length

$\mathrm{D}=$ pipe diameter

$\mathrm{d}=$ depth of surface crack

$\mathrm{t}=$ pipe wall thickness

SS = single shear fracture

$\mathrm{DS}=$ double shear fracture

$\mathrm{A}=$ blue oxide

$\mathrm{B}=$ no oxide

$\mathrm{C}=$ bronze-colored oxide

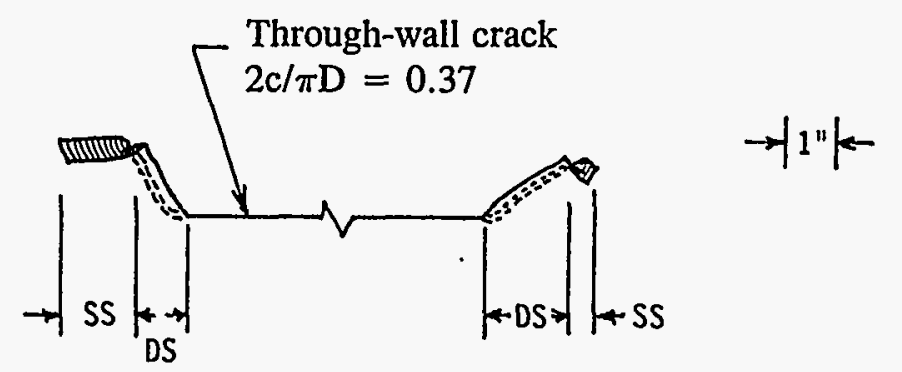

(a) Experiment No. 4111-1, four-point bending

Pipe DP2-F11, A333 Grade 6, 4.5-inch diameter, Schedule 80

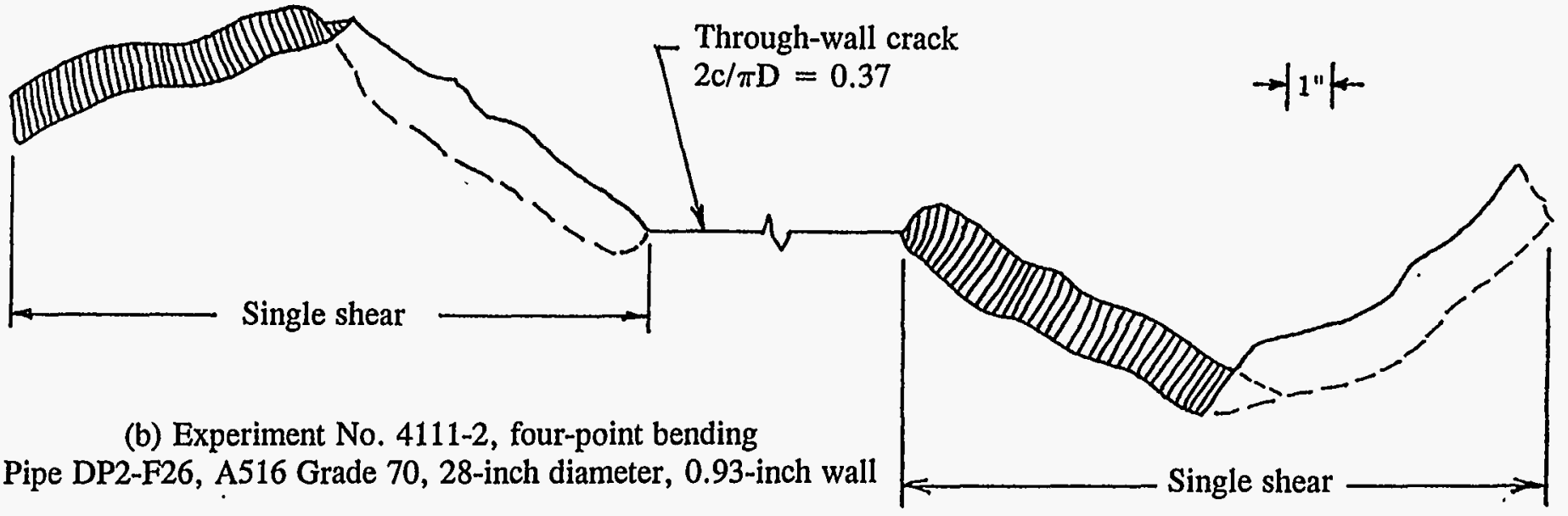

Figure A-1. Illustrations of fracture paths in carbon steel pipes which contained circumferential flaws

The sketches were made from outside the pipe as if the pipe had been flattened.

The shaded areas indicate fracture surfaces visible from outside the pipe. 


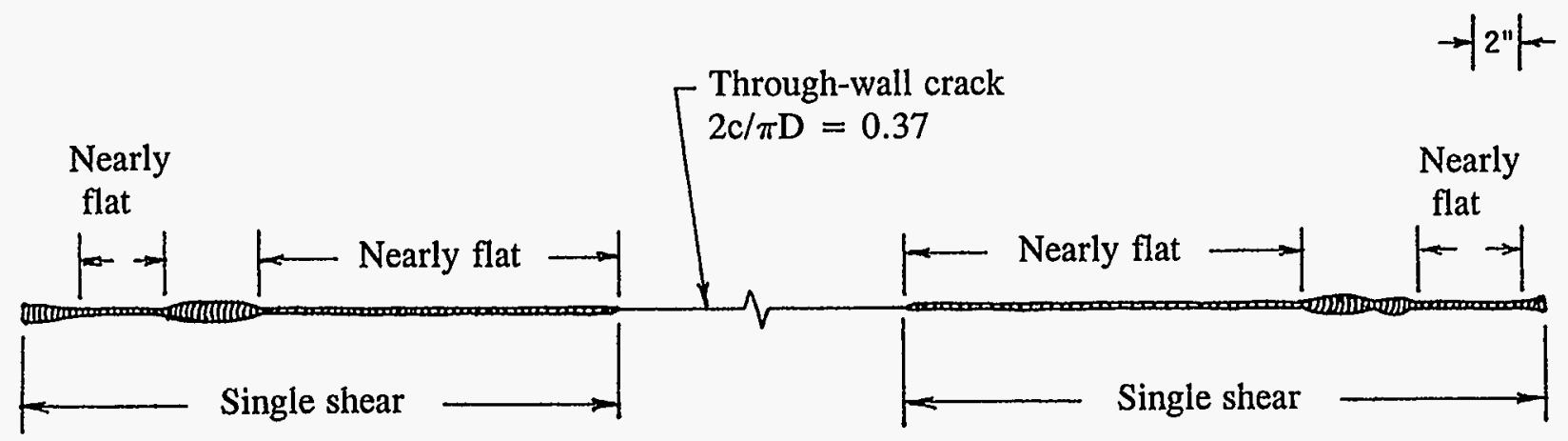

(c) Experiment No. 4111-4, four-point bending

Pipe DP2-F32, API 5LX65, 42-inch diameter, 0.625-inch wall

Figure A-1. (Continued) 


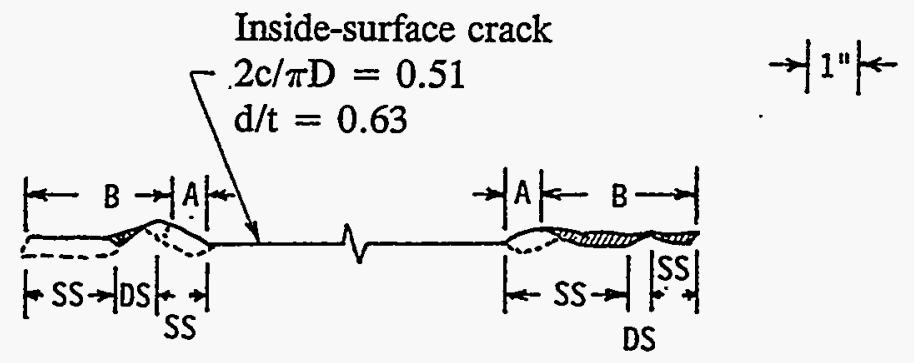

(d) Experiment No. 4112-5, four-point bending

Pipe DP2-F1, A106 Grade B, 6-inch diameter, Schedule 40

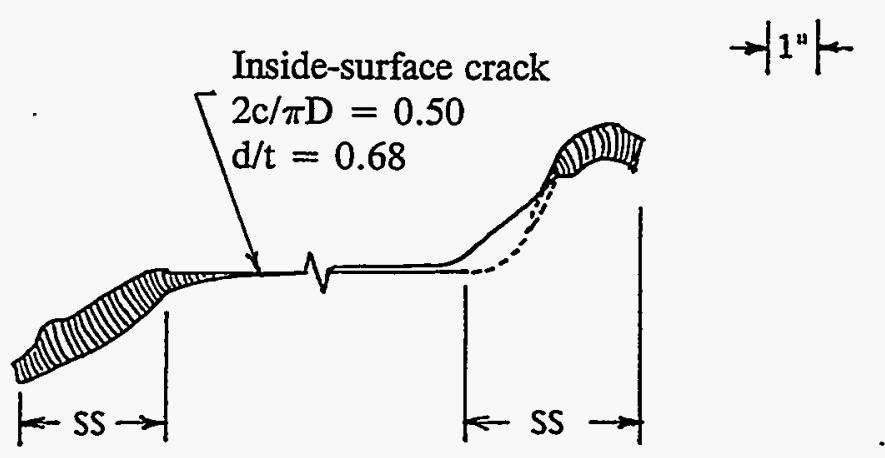

(e) Experiment No. 4112-6, four-point bending

Pipe DP2-F30, A106 Grade B, 6-inch diameter, Schedule 120

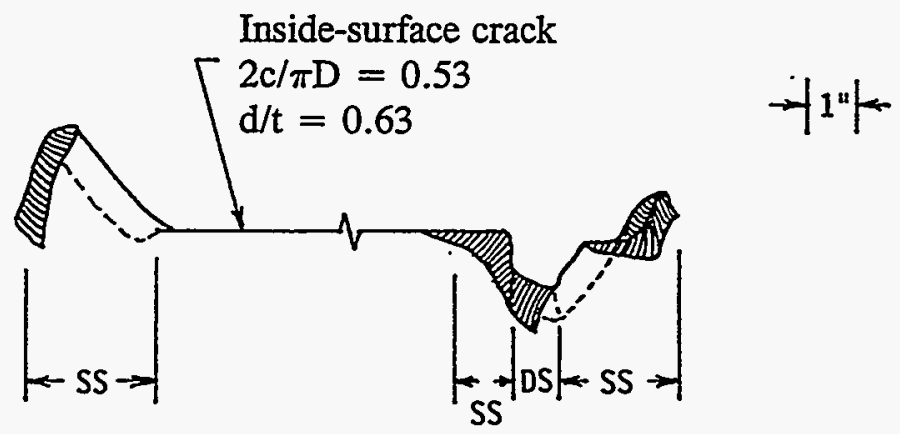

(f) Experiment No. 4112-7, four-point bending

Pipe DP2-F2, A106 Grade B, 6-inch diameter, Schedule XXS

Figure A-1. (Continued) 


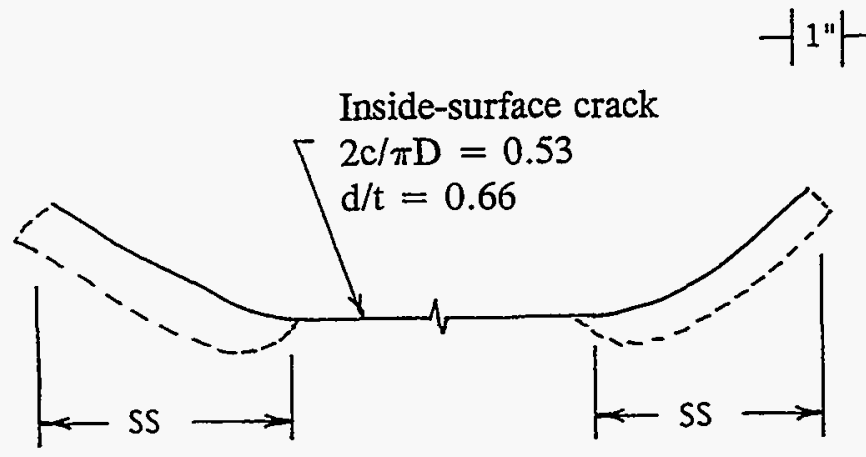

(g) Experiment No. 4112-8, four-point bending

Pipe DP2-F29, A106 Grade B, 16-inch diameter, Schedule 100

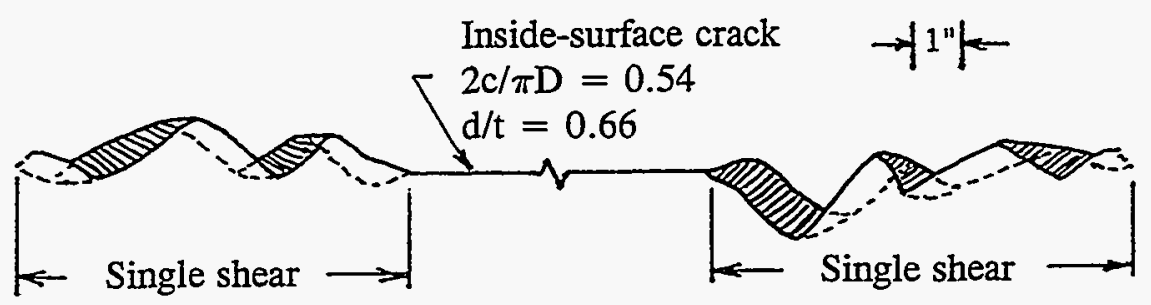

(h) Experiment No. 4112-9, four-point bending

Pipe DP2-F13, A106 Grade B, 16-inch diameter, Schedule 40

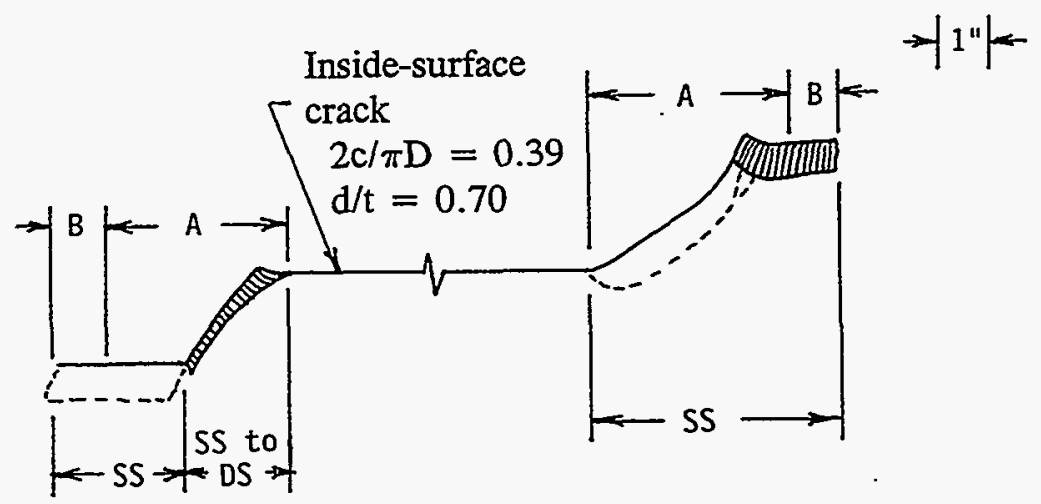

(i) Experiment No. 4115-1, four-point bending

Pipe DP2-F9, A333 Grade 6, 10-inch diameter, Schedule 100

Figure A-1. (Continued) 


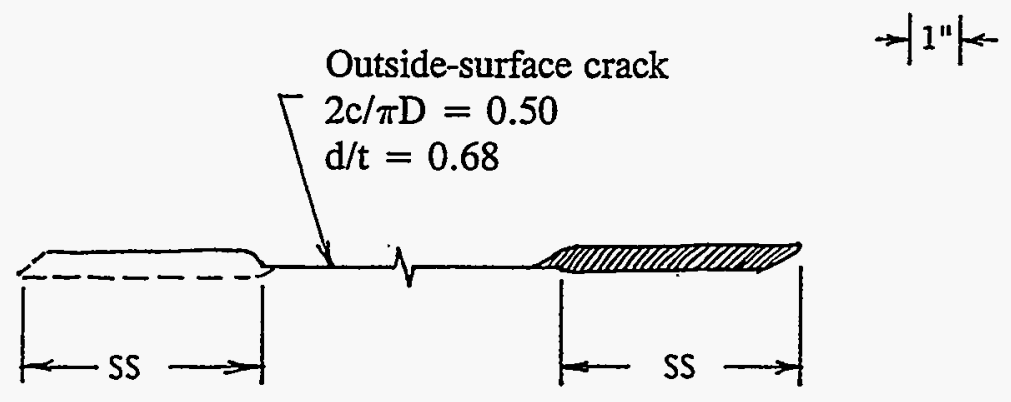

(j) Experiment No. 4121-6, internal pressure

Pipe DP2-F9, A333 Grade 6, 10-inch diameter, Schedule 100

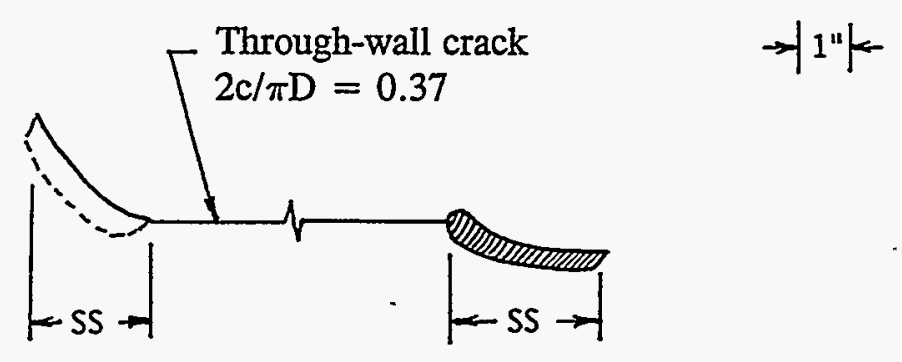

(k) Experiment No. 4131-3, four-point bending plus internal pressure Pipe DP2-F9, A333 Grade 6, 10-inch diameter, Schedule 100

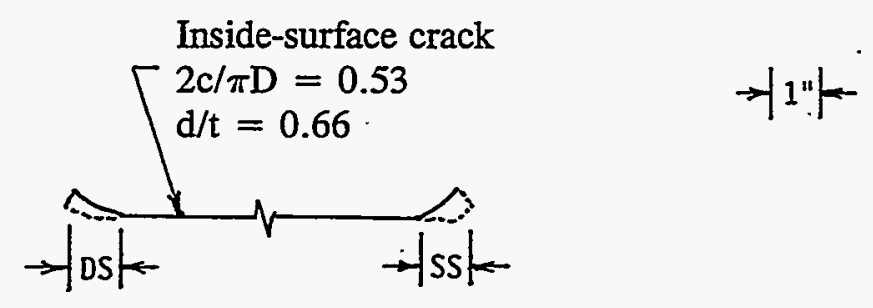

(1) Experiment No. 4131-4, four-point bending plus internal pressure Pipe DP2-F9, A333 Grade 6, 10-inch diameter, Schedule 100

Figure A-1. (Continued) 


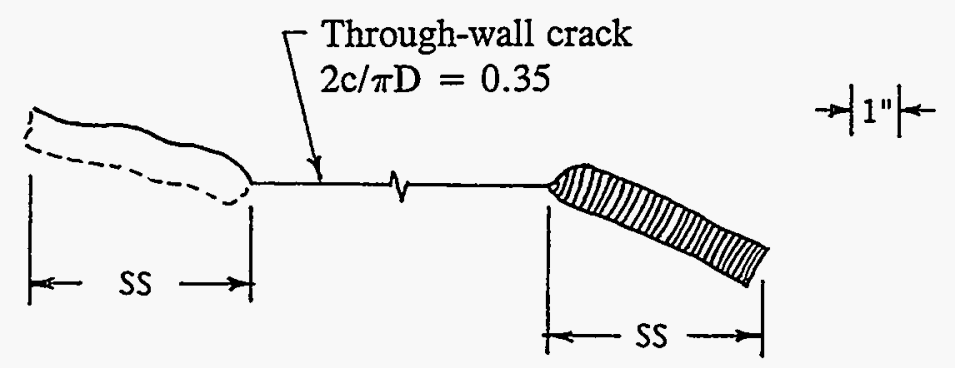

(m) Experiment No. 4131-7, four-point bending

Pipe DP2-F9, A333 Grade 6, 10-inch diameter, Schedule 100

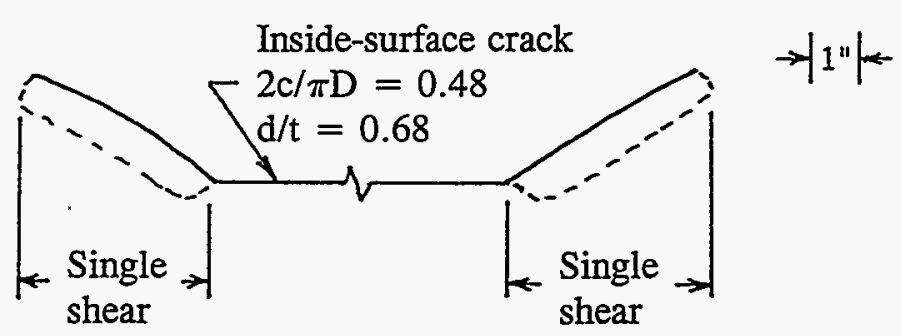

(n) Experiment No. 4131-8, four-point bending

Pipe DP2-F9, A333 Grade 6, 10-inch diameter, Schedule 100

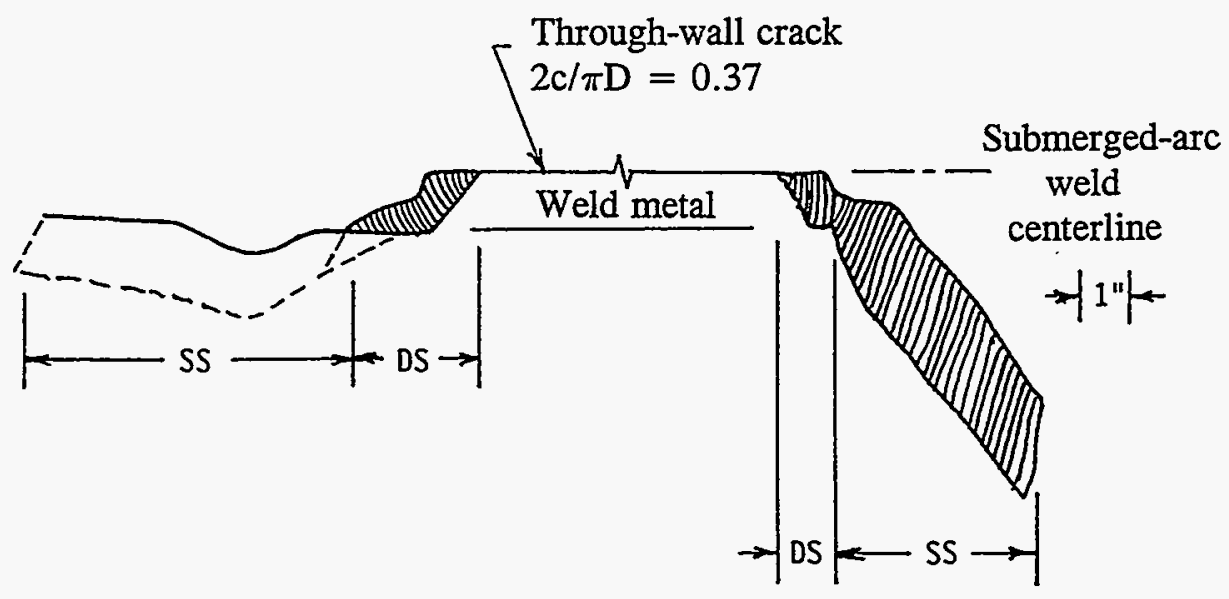

(o) Experiment No. 4141-9, four-point bending plus internal pressure Pipe DP2-F29W, SAW in A106 Grade B, 16-inch diameter, Schedule 100

Figure A-1. (Continued) 


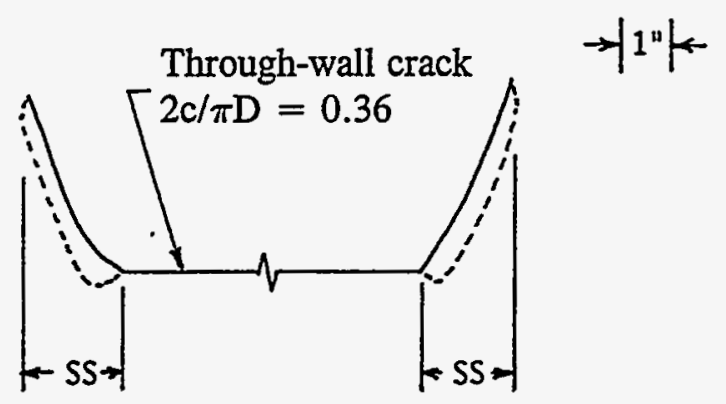

(p) Experiment No. IPIRG 1.2-2, four-point bending, quasi-static cyclic $(\mathrm{R}=0)$

Pipe DP2-F30, A106 Grade B, 6-inch diameter, Schedule 120

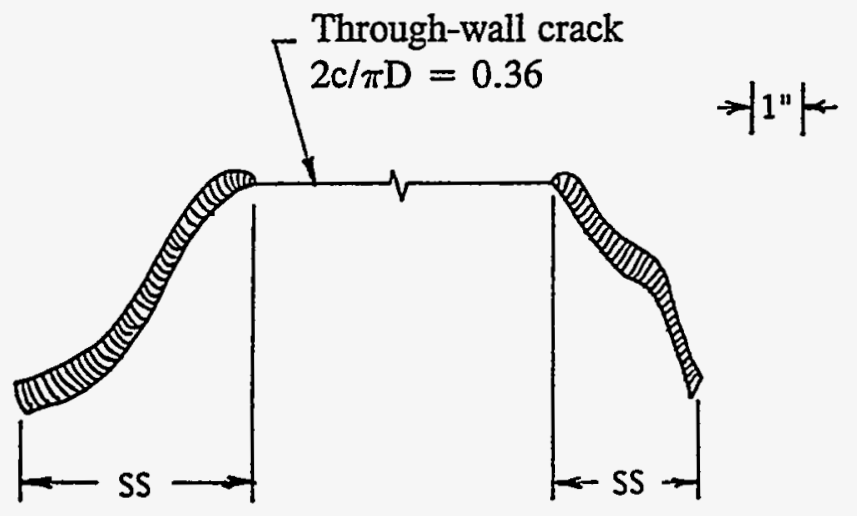

(q) Experiment No. IPIRG 1.2-4, four-point bending, quasi-static cyclic $(R=-1)$, Pipe DP2-F30, A106 Grade B, 6-inch diameter, Schedule 120

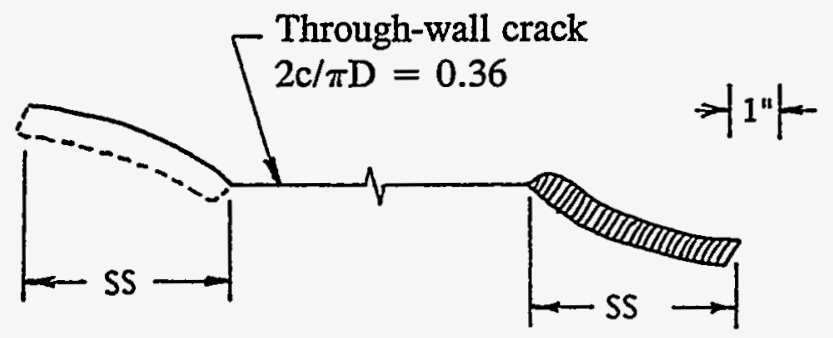

(r) Experiment No. IPIRG 1.2-6, four-point bending, quasi-static cyclic $(R=-1)$

Pipe DP2-F30, A106 Grade B, 6-inch diameter, Schedule 120

Figure A-1: (Continued) 


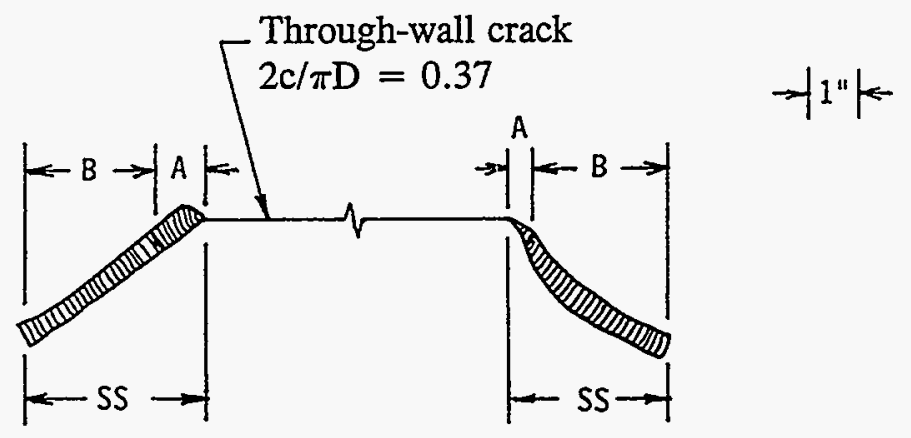

(s) Experiment No. IPIRG 1.2-6A, four-point bending, dynamic monotonic Pipe DP2-F30, A106 Grade B, 6-inch diameter, Schedule 120

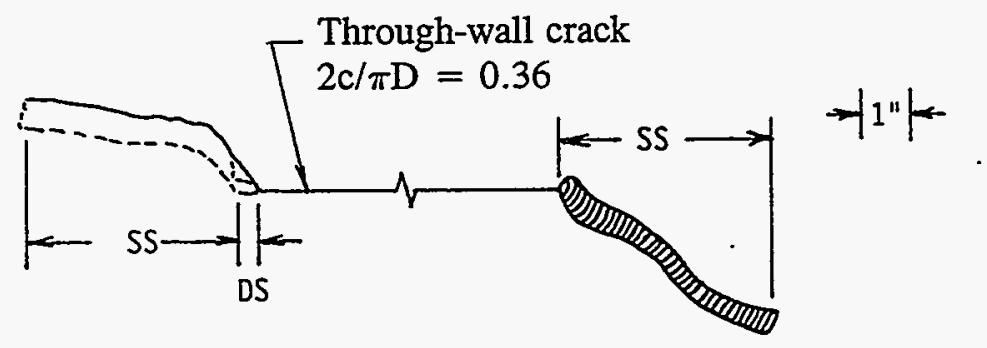

(t) Experiment No. IPIRG 1.2-7, four-point bending, quasi-static monotonic Pipe DP2-F30, A106 Grade B, 6-inch diameter, Schedule 120

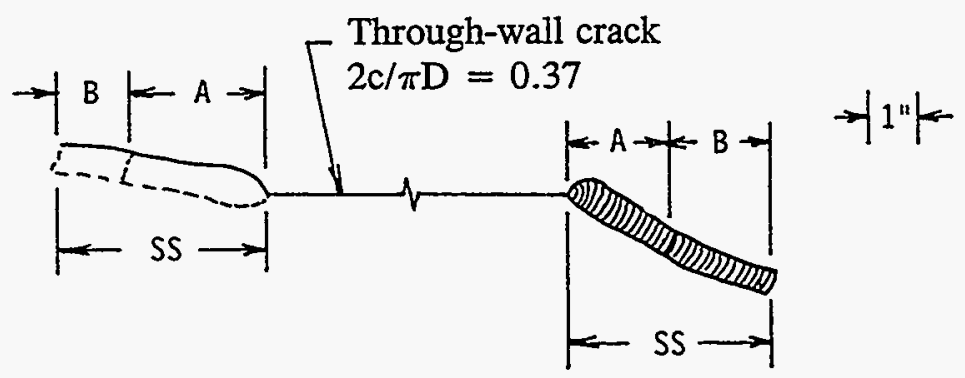

(u) Experiment No. IPIRG 1.2-8, four-point bending, dynamic monotonic Pipe DP2-F30, A106 Grade B, 6-inch diameter, Schedule 120

Figure A-1. (Continued) 


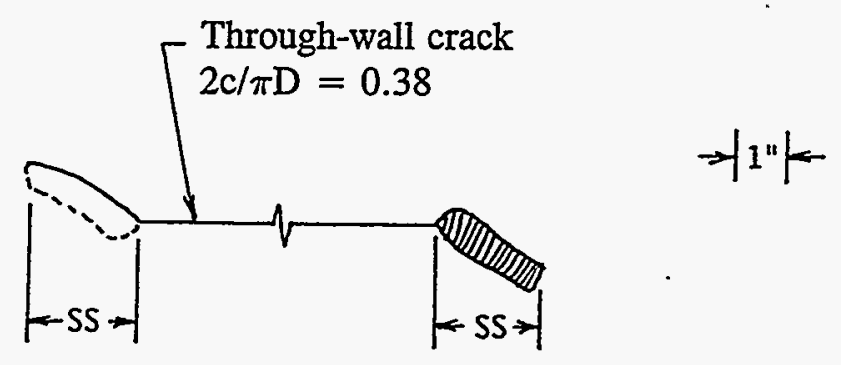

(v) Experiment No. IPIRG 1.2-10, four-point bending, dynamic cyclic $(\mathrm{R}=0)$

Pipe DP2-F30, A106 Grade B, 6-inch diameter, Schedule 120

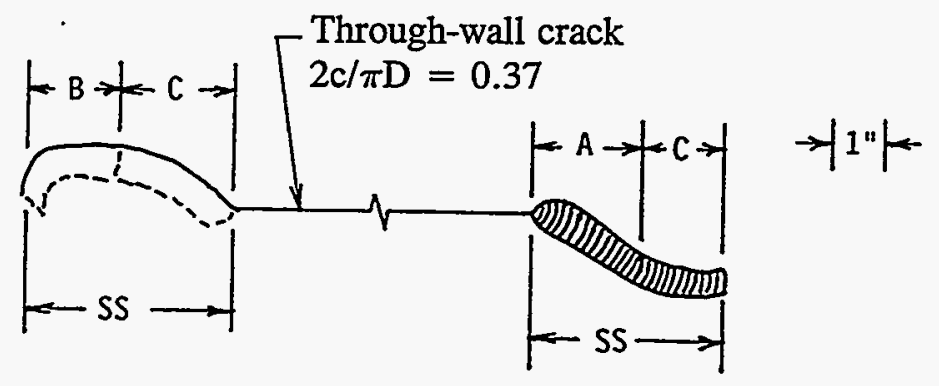

(w) Experiment No. IPIRG 1.2-11, four-point bending, dynamic monotonic Pipe DP2-F30, A106 Grade B, 6-inch diameter, Schedule 120

Figure A-1. (Concluded) 
(See instructions on the reverse)

\section{TITLE AND SUBTITLE}

Effects of Toughness Anisotropy and Combined Tension, Torsion, and Bending Loads on Fracture Behavior of Ferritic Nuclear Pipe

R. Mohan, C. Marscha11, P. Krishnaswamy, F. Brust,

N. Ghadiali, and G. Wilkowski

8. PERFORMING ORGANIZATION - NAME AND ADDRESS III NRC, provide Division, Office or Region, U.S. Nuclear Regulatory Commission, and mailting address; if contractor, provide name and mailling sddressi)

Battelle

505 King Avenue

Columbus, OH 43201-2693

9. SPONSORING ORGANIZATION - NAME AND ADDRESS IIf NRC, type "Same, as above"; if contractor, provide NRC Division, Office or Region, U.S. Nuclear Regulatory Commission, ond malling sodress.).

Division of Engineering Technology

Office of Nuclear Regulatory Research

U.S. Nuclear Regulatory Commission

Washington, D.C. 20555

10. SUPPLEMENTARY NOTES

11. ABSTRACT (200 words or less)

This topical report summarizes the work on angled crack growth and combined loading effects performed within the Nuclear Regulatory Commission's research program entitled "Short Cracks in Piping and Piping Welds". The major impetus for this work stemmed from the observation that initial circumferential cracks in carbon steel pipes exhibited angular crack growth. This failure mode was little understood, and the effect of angled crack growth from an initially circumferential crack raised questions of how pipes under combined loading with torsional stresses would behave. There were three major conclusions from this work. The first was that virtually all ferritic nuclear pipes will have toughness anisotropy. The second was that the ratio of the normalized crack driving force (as a function of angle) to the normalized toughness (also as a function of the angle of crack growth) showed that there was an equal likelihood of cracks growing at any angle between 25 and 65 degrees. This agreed with the scatter of crack growth angles observed in pipe tests. Third, for combined loads with torsional stresses, an effective moment allows pure bending analyses to be used up to crack initiation. Crack opening area under combined loads could also be determined in this manner.

Fracture, pipe, anisotropy, combined loads, torsion, toughness, $\mathrm{J}$-integral, ferritic steel, circumferential-crack, through-wall crack, leak before break
13. AVAILABILITY STATEMENT

Unlimited 14. SECUAITY CLASSIFICATION (This Page) $\frac{\text { Unclass ified }}{\text { (This Repord }}$

Unclassified 15. NUMBER OF PAGES 